Portland State University

PDXScholar

Spring 6-8-2018

\title{
Bilingual Teachers' Experiences: Being English Learners, Becoming Teachers, and Bilingual Education
}

Carrie Susan Larson

Portland State University

Follow this and additional works at: https://pdxscholar.library.pdx.edu/open_access_etds

Part of the Bilingual, Multilingual, and Multicultural Education Commons, and the Curriculum and Instruction Commons

Let us know how access to this document benefits you.

\section{Recommended Citation}

Larson, Carrie Susan, "Bilingual Teachers' Experiences: Being English Learners, Becoming Teachers, and Bilingual Education" (2018). Dissertations and Theses. Paper 4412.

https://doi.org/10.15760/etd.6309

This Dissertation is brought to you for free and open access. It has been accepted for inclusion in Dissertations and Theses by an authorized administrator of PDXScholar. Please contact us if we can make this document more accessible: pdxscholar@pdx.edu. 
Bilingual Teachers' Experiences: Being English Learners, Becoming Teachers, and Bilingual Education

by

Carrie Susan Larson

A dissertation submitted in partial fulfillment of the requirements for the degree of

\section{Doctor of Education}

in

Educational Leadership: Curriculum and Instruction

Dissertation Committee:

Esperanza De La Vega, Chair

Anita Bright

Yer Thao

Yves Labissiere

Portland State University

2018 
(C) 2018 Carrie Susan Larson 


\begin{abstract}
Bilingual students are the fastest growing demographic group in U.S. P-12 public schools and offer promise and hope to our increasingly global workforce. However, many bilingual students are lagging behind in school, too many do not complete high school, and their schooling experiences are overshadowed by racial and linguistic segregation, low-academic tracking, and subtractive educational experiences. There is a growing body of literature that recognizes the importance of bilingual and bicultural teachers and leaders who can include students' linguistic, cultural, and community assets in school. This qualitative research study explores the experiences of a specialized group of elementary bilingual and bicultural teachers that learned English in U.S. P-12 public schools and currently teach bilingual students in Oregon public schools. Through in-depth interviews and classroom observations, this study amplifies the voices of three bilingual teachers as they offer valuable insight into teaching and learning and contribute to how we can create excellent educational experiences for bilingual students. The findings point to how the interconnected nature of language, culture, and identity impacted these bilingual teachers' approach to teaching, the power of culturally responsive practices in the classroom, and the promise of building positive relationships and community with students and families.
\end{abstract}


Table of Contents

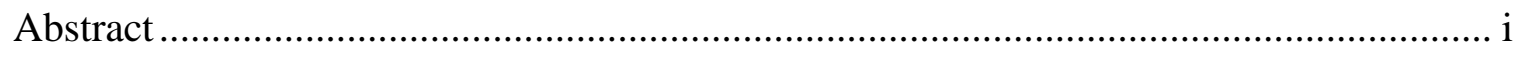

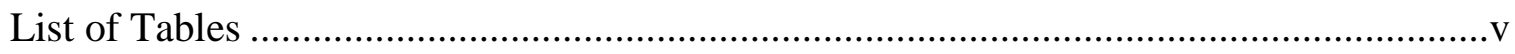

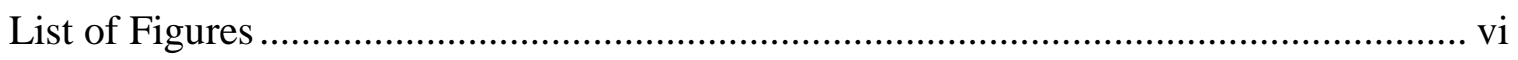

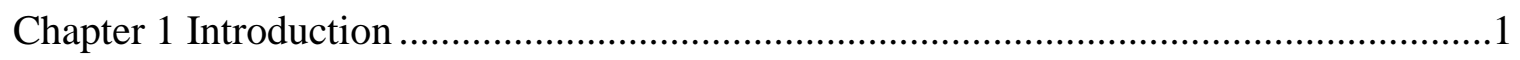

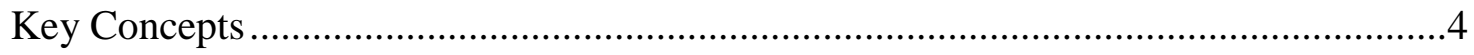

Bilingual and Multilingual Students and Teachers...........................................

Bilingual and Multilingual Demographics.....................................................

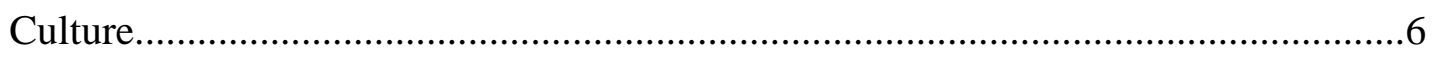

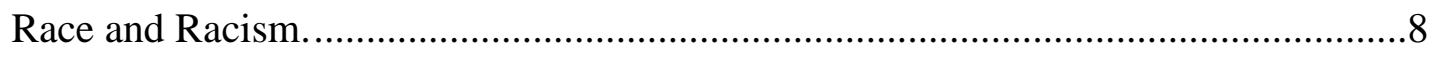

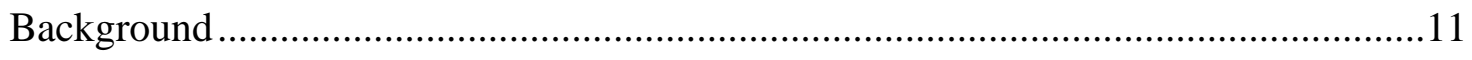

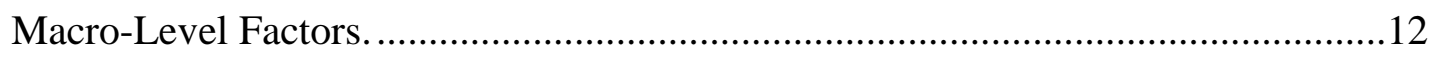

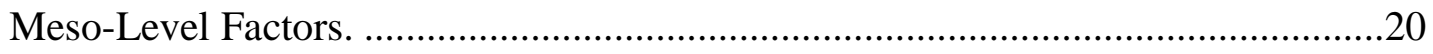

Micro-Level Factors.......................................................................................2

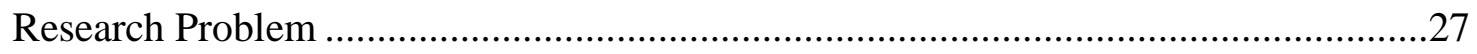

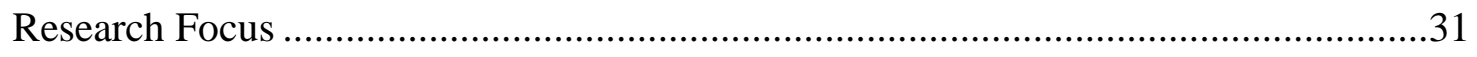

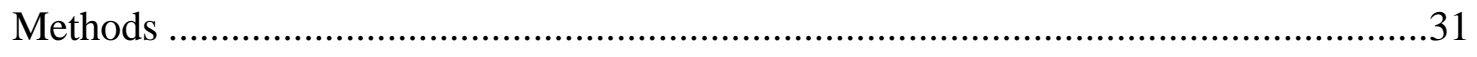

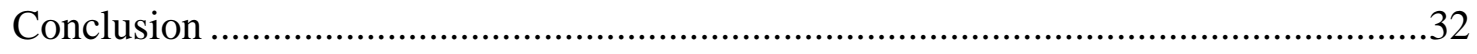

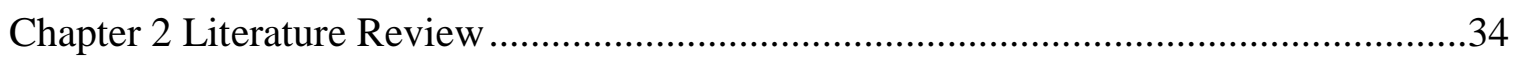

Sociocultural Perspectives on Educational Research. ...........................................35

Latinx Critical Race Theory Compliments Sociocultural Theory. ..........................42 
Educational Systems Impacting Bilingual Students.

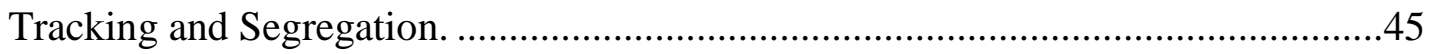

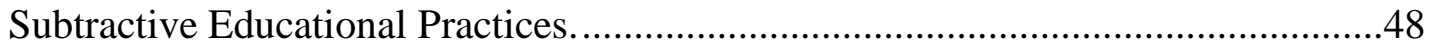

Cultural and Linguistic Representation. ......................................................50

Teachers of Bilingual Students Need Specific Experiences and Knowledge............51

Bilingual Education and Bilingual Teachers. .....................................................55

Qualitative Methods and the Power of Telling Stories..........................................61

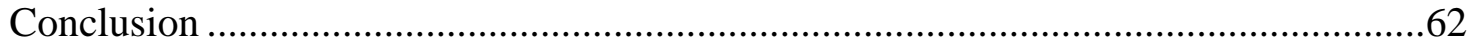

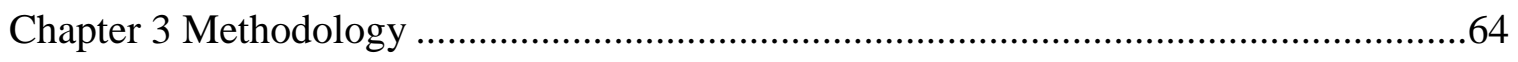

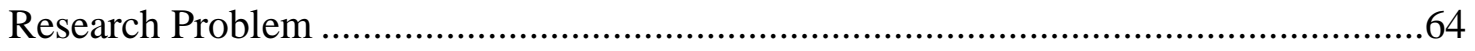

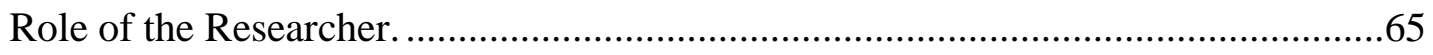

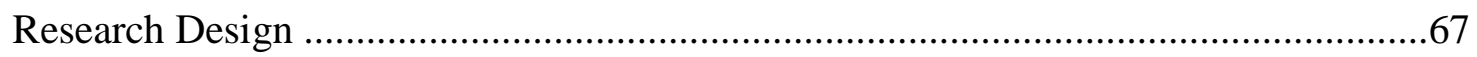

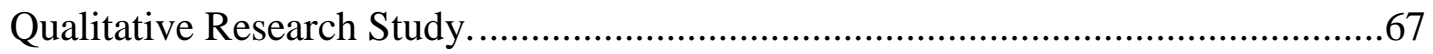

Recruitment Procedures. .....................................................................................6

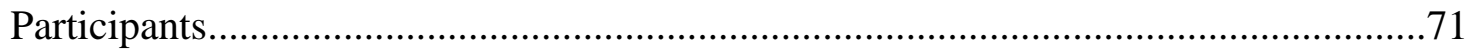

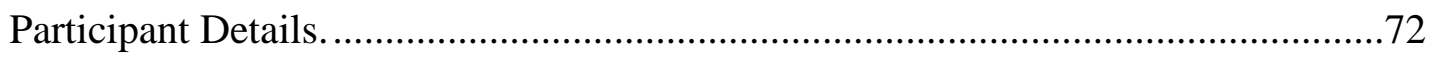

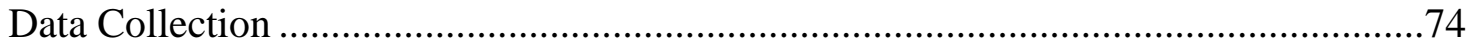

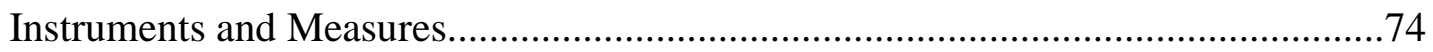

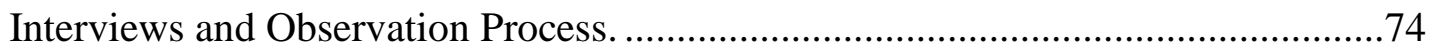

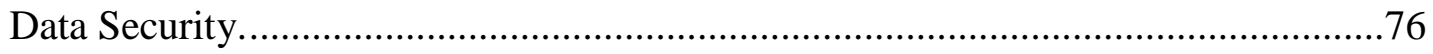

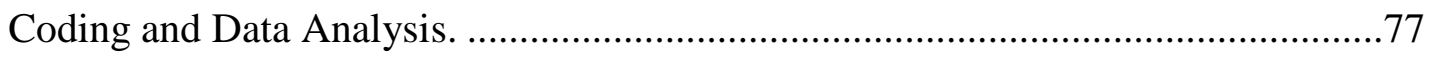

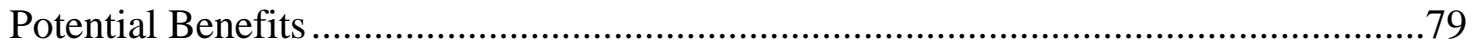


Conclusion

Chapter 4 Results

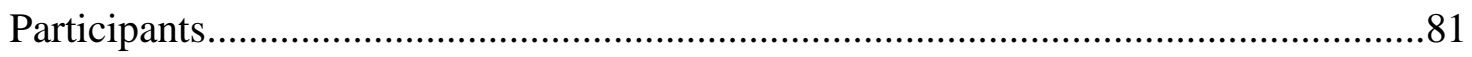

Presentation of Results.................................................................................. 82

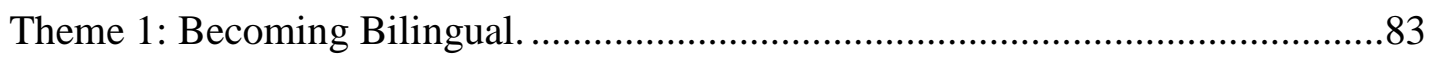

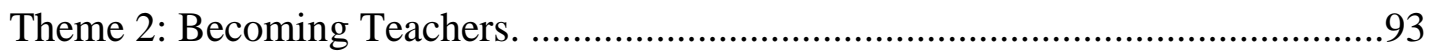

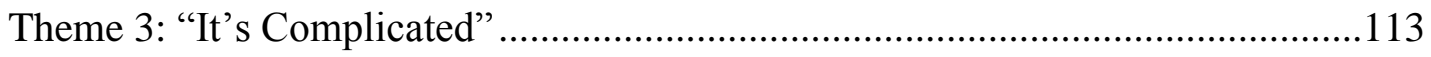

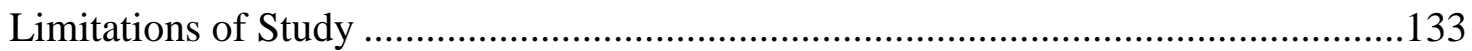

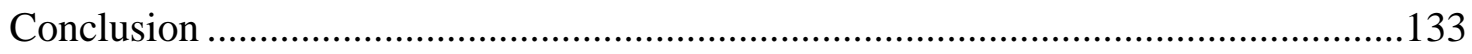

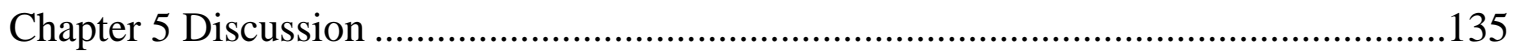

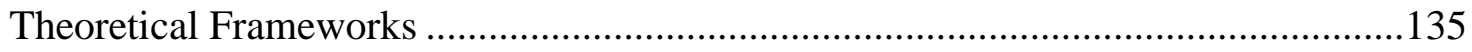

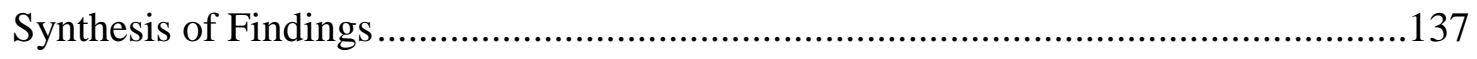

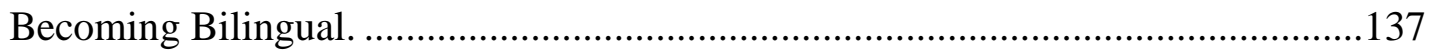

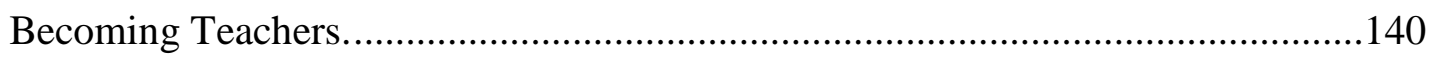

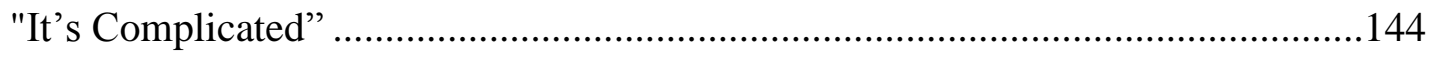

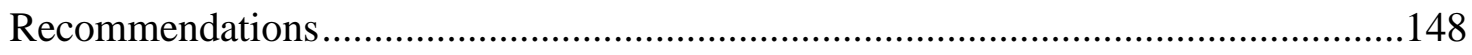

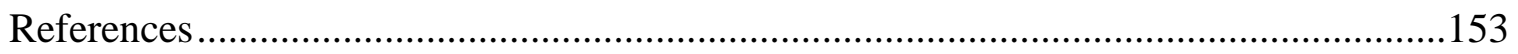

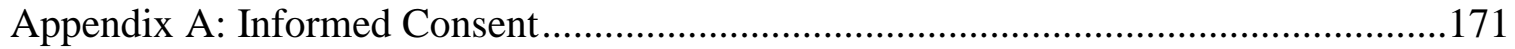

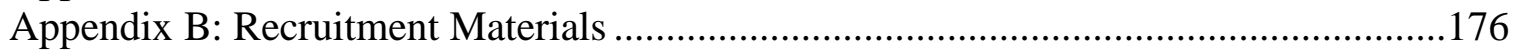

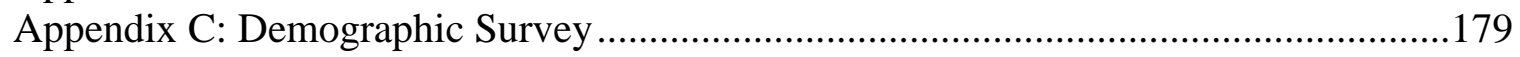

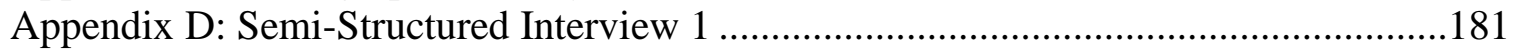

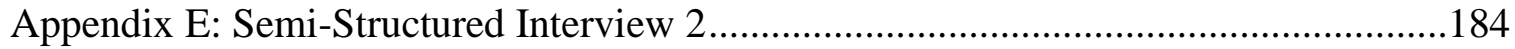

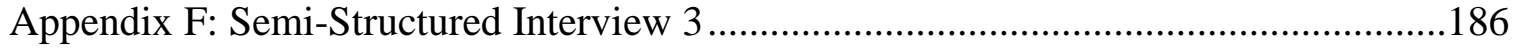


List of Tables

Table 3.1 Comparison of Participants' District Demographics .....................................72

Table 3.2 Timeline of Interviews and Classroom Observations by Participant ...............77

Table 3.3. Main Themes and Subthemes From the Analysis ........................................79

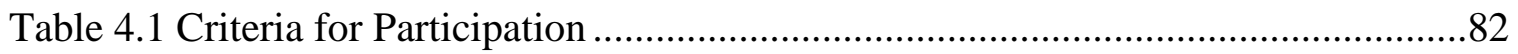

Table 4.2 Results of the Study: Main Themes and Subthemes.....................................83 
List of Figures

Figure 1.1 The Iceberg Concept of Culture ..............................................................

Figure 1.2 Macro-, Meso-, and Micro Levels of Factors Influencing Bilingual and Multilingual Student Achievement .........................................................................11

Figure 1.3 Timeline of Important Judicial and Legislative Events Affecting the Education of Bilingual and Multilingual Students......................................................14

Figure 1.4 National High School Graduation Rates, by Student Group: SY 2014-2014 ..16

Figure 1.5 Chicana/o Educational Pipeline.................................................................18

Figure 1.6 The Chicana/o Educational Pipeline Showing Graduation Outcomes for Chicana/o Elementary School Students ...................................................................19

Figure 1.7 National Math and Reading Scores by Language Status and Years Grades 4 and 8

Figure 1.8 Comparison of Bilingual Students and Teachers by Racial/Ethnic Categories.

Figure 1.9 Illustration of How Teachers Can Influence All Levels Educational Throughout Their Careers

Figure 2.1 Nieto's (2002) Five Intersecting Concepts of Sociocultural Theory in Education.

Figure 2.2 Socially Crafting Identities While Teaching and Learning .39

Figure 2.3 Competencies, Skills, and Knowledge Required of a Well-Prepared Teacher of Bilingual Students

Figure 5.1 The Components of Sociocultural Theory and LatCrit Work Together to Inform the Synethesis of the Findings 


\section{Chapter 1 Introduction}

As the United States and world become more interconnected and interdependent, the need for bilingual and multilingual individuals that can peacefully work within, between, and bridging cultures is even more important. There is opportunity and hope in the growing number of bilingual and multilingual students that will be the next generation's teachers, law enforcement, judges, and policy makers. The last three decades have seen a growing trend toward bilingualism and multilingualism. According to the United States Census Bureau (2016), the number of people speaking a language in addition to English in the United States increased 158\% from 1980 to 2010, the majority of whom speak English "very well” (Ryan, 2013, p. 5). Likewise, the percentage of bilingual and multilingual students has also grown dramatically. In 2014, nearly a quarter of all elementary and secondary public school children spoke a language in addition to English at home (United States Census Bureau, 2016).

Although the number of bilingual and multilingual students has steadily grown and continues to increase, these students still face significant barriers to an equitable education. Educational policies, institutional systems, and instructional practices have attempted to create a more equitable education for bilingual students and improve their educational outcomes, but according to standardized test scores and graduation rates, they have fallen short (Burciaga \& Erbstein, 2012; Ocasio, 2014; Orfield, Kucsera, \& SiegelHawley, 2012). This study aims to amplify the stories and experiences of three bilingual teachers, who despite these statistics, learned English in school and became teachers. As 
the data show, the voices of these three individuals who have experiences as former bilingual students and as bilingual teachers, have implications for future teachers of bilingual students and teacher preparation programs committed to transforming educational outcomes and opportunities for their bilingual and multilingual students.

I come to explore these questions from my own experience as a bilingual teacher and learner. I did not experience school as a bilingual learner, so my own understanding is limited. I grew up in a White, monolingual, English-speaking family. I was always interested in learning languages and finally, through immersion in Mexico and Guatemala, learned Spanish as a young adult. I enjoyed teaching and learning in bilingual environments in Mexico, Guatemala, and Chicago. When I moved back to Oregon, I taught in an English-only middle school, where $20 \%$ of my school's population was Latinx and from Spanish-speaking homes. Poco a poco, I began to see school from a very different lens. I saw my bilingual students segregated, misunderstood, stereotyped, and discussed from a deficit lens. Educators sighed and complained about how many English Language Learners they had, equating them with extra work and difficulties. The education of my bilingual students was stifled and their future opportunities were limited. I was heartbroken and angry. After teaching college Spanish to English speakers and K-8 English to Spanish speakers for many years, I had the opportunity to work with bilingual preservice teachers. They gave me hope. Examining bilingual education from multiple angles has allowed me to deepen my understanding of teaching and learning with bilingual students. The voices of my former K-8 bilingual students and families, as well as current bilingual preservice and in-service teachers join me in this work. 
Currently, bilingual and multilingual students in U.S. P-12 schools are not faring well. Words such as crisis and urgent are often used when talking about the standardized test scores and high school graduation rates of bilingual students. Those words are not exaggerating the educational outcomes. The standardized test scores that are published, usually organized by race, do not make sense to the public or educators. How can our students' scores be so different when grouped by home language or race? People will often say things like, "It must be the families. I'm sure not on purpose, but they just don't value education." Others blame language barriers as the main problem, stating, "They just need to learn English." These statements are reflective of majoritarian storytelling, which Yosso (2006) described as "a method of recounting the experiences and perspectives of those with racial and social privilege" (p. 9). Majoritarian stories tend to reflect entrenched stereotypes that maintain those in power. Explanations like these did not represent my experiences, as I taught bilingual students in middle school. My students fluidly translanguaged when it was allowed, meaning they could use their home language as an asset to explain, make connections, compare, and make sense of complex content and use English in class for academic purposes (O. García, Ibarra Johnson, \& Seltzer, 2017). In speaking with my students’ parents, I knew they cared deeply about their children's education, yet my students struggled academically.

Educational researchers in the fields of bilingual and multicultural education have been working on these questions too. They were able to uncover those majoritarian stories, blaming parents and/or language for students' academic struggles, as myths. First, many bilingual students' families actually have higher educational aspirations for their 
children than their monolingual counterparts (Gándara \& Contreras, 2009). Second, students can and should learn in all their languages (O. García \& Wei, 2014). More than half of the world is bilingual or multilingual, yet in the United States, coming to school knowing an additional language is often treated as a deficit. Many educational researchers also identify an urgent need to improve the education of bilingual students in U.S. P-12 schools (Darling-Hammond, 2010; E. García, Arias, Harris Murri, \& Serna, 2010; Valdés, 2001; Valenzuela, 1999). The educational barriers are much more complex than the majoritarian stories we often hear, with historical roots reaching back centuries. These barriers continue to be influenced by economics, immigration, policy and politics, gender and sexism, institutional racism, and more. These are not popular topics to discuss and they certainly are not easy to solve. However, if we agree that a well-educated society is better for everyone, we must make strides now to improve educational equity for bilingual and multilingual students.

\section{Key Concepts}

Bilingual and multilingual students and teachers. The language regarding bilingual and multilingual students is constantly evolving, as is the language regarding the potential causes of the educational inequity they experience. There are many different terms used to describe bilingual and multilingual students (Palmer \& Martínez, 2013), often depend on the organization and geography. For example, in a 2013 report by the Oregon Education Investment Board, English Learners in Oregon's Education System, there are eight different terms: English Learners, English Language Learners, Limited English Proficient, Dual Language Learners, English as an Other Language, English as a 
Second Language (ESL), Long-Term English Learners, and Emergent Bilinguals. Unfortunately, these terms discuss children in terms of what they are lacking, ignoring the language and ways of knowing they bring with them to school. For the purpose of this study, I use the terms bilingual and multilingual students, to refer to students who speak another language at home and are developing English as an additional language (Valdés, Menken, \& Castro, 2015). Using the terms bilingual and multilingual intentionally forefronts the additional linguistic and cultural ways of knowing students bring with them to school.

Bilingual and multilingual demographics. According to the National Center for Education Statistics (2016a), about 10\% of P-12 students in U.S. public schools were enrolled in English language programs. However, the exact number varies, in part, because districts and states have different criteria for determining who is enrolled in such programs and there is some autonomy on when bilingual and multilingual students are no longer considered English learners (ELs), and are exited from these programs.

We know that bilingual and multilingual students are the fastest growing segment of the student population in U.S. public schools (Calderón, Slavin, \& Sánchez, 2011), but who are they? Linguistically, over 75\% of bilingual students speak Spanish at home (National Center for Education Statistics, 2016b). When referring to these students in general, this paper uses the term Latinx, which is a gender inclusive form of Latina/o, describing people from Latin America or of Latin American origin. The next two most frequent languages are Arabic and Chinese, each of which represents about 2\% of bilingual students. The remaining languages reported to be spoken at home by bilingual 
and multilingual students are English, Vietnamese, Hmong, Haitian, Somali, Russian, and Korean.

Students also vary in terms of other factors such as race, socioeconomic status, number of years in the United States, immigration and citizenship status, home language literacy, former formal schooling, and parents' education. Together, they make up an incredibly diverse and complex group of students. Although my study is focused on bilingual and multilingual education and teachers, concepts and terms such as culture and race are intertwined with multilingual students and teachers.

Culture. Culture is the logic behind our thinking and often the organization behind our stories. It is dynamic and sometimes imperceptible to people unless they have the opportunity to engage in a community outside their own culture. Culture and language go together, influenced by each other. In classrooms, the language and culture of students and teachers is central to teaching and learning. Multicultural educators, Nieto and Bode (2012), defined culture as, "The values, traditions, worldview, and social and political relationships created, shared and transformed by a group of people bound together by a common history, geographic location, language, social class, religion, or other shared identity" (p. 158). Culture is expressed in many ways, as Figure 1.1 from Sensoy and DiAngelo (2017) illustrates. What is easily seen, like food, clothing, and language constitutes the tip of the iceberg. The majority of the other aspects of culture exist beneath the surface. 


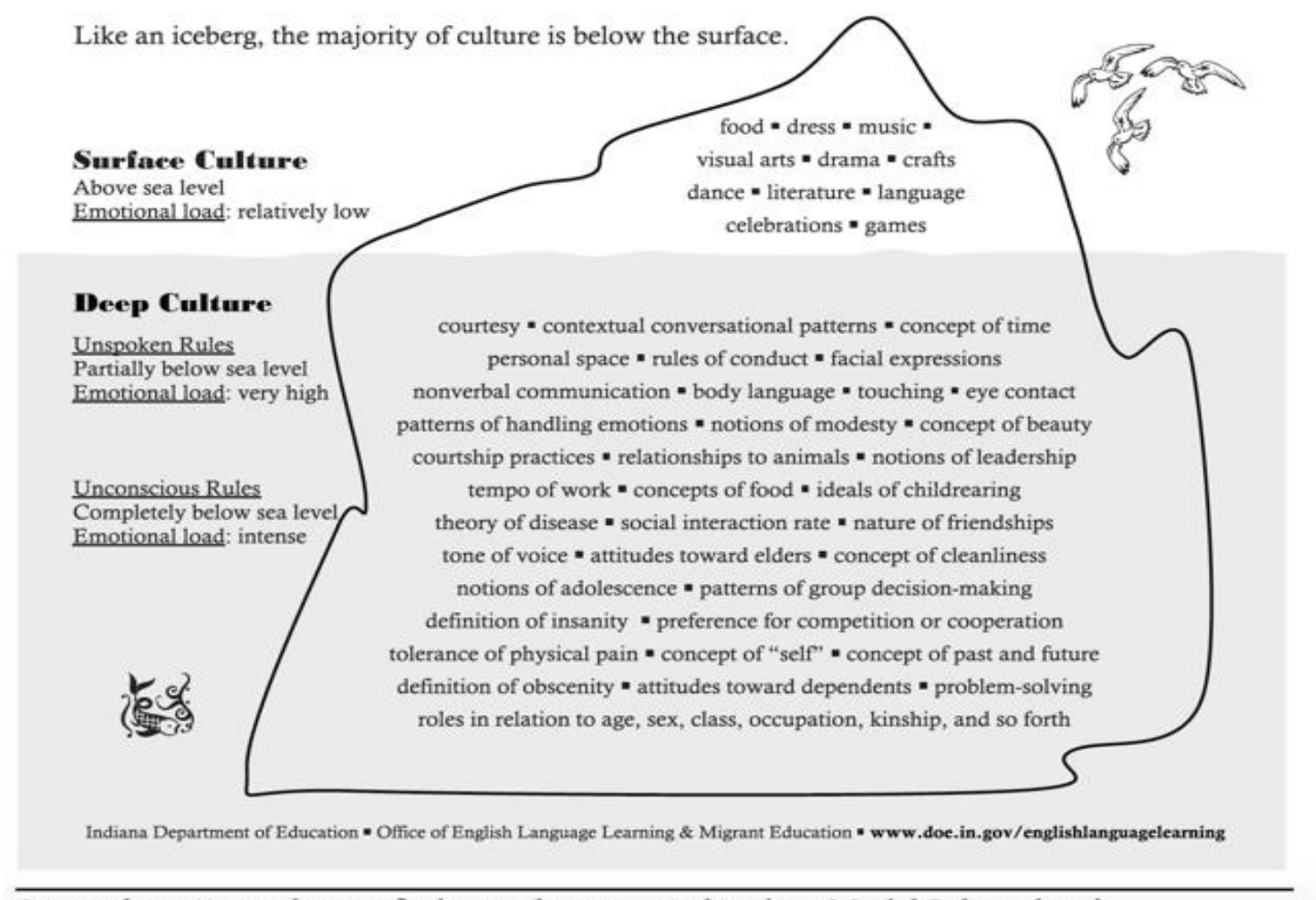

Source: http://www.homeofbob.com/literature/esl/icebergModelCulture.html

Figure 1.1. The iceberg concept of culture. As illustrated by Sensoy and DiAngelo (2017), shows many aspects of culture, demonstrating that the majority of cultural lies below the surface, just like the bulk of an iceberg also is hidden beneath the surface.

The cultural aspects that influence educational practices are subtler, for example: how power is demonstrated, how to give and receive respect, who has authority, time and the value of community, independent vs. interdependent learning, and communication styles (Gay, 2010). McLaren (2015) asserted that teachers are more likely to interact with and praise students that replicate the behavior, speech, and styles of the dominant culture, which in the United States is White, middle to upper class, and English speaking. Bilingual students are affected by dominant culture every time they walk into the school. From the language that is privileged, to the "correct" structure of writing a story, politely 
addressing a teacher or appropriately speaking to a classmate, bilingual students are negotiating cultural norms every day.

Nieto (2010) would agree, she explained that culture is dynamic, multifaceted, embedded in context, influenced by social, economic, and political factors, created and socially constructed, learned, and dialectical. Although members can be from the same cultural group, they can have different behaviors and communication styles. It is not generalizable to everyone from a particular culture. Culture also encompasses students' ways of knowing and the understandings they bring to school. González, Moll, and Amanti (2005) referred to this as students' funds of knowledge, which include cultural, linguistic, and historical knowledge and skills. They highlight the need for educators to investigate and utilize their students' funds of knowledge, in order to connect students learning to and with the classroom. It is important to understand the influence of all these aspects of culture when talking about bilingual and multilingual education. Although race is a socially constructed term, it is often cited in association with culture. Therefore, the next section demonstrates how race and racial identity have influenced the educational experiences of bilingual and multilingual students.

Race and racism. In education, race is prevalently used in disaggregate data, to compare successes or failures. Race is at the forefront of discussions of high-stakes test scores, graduation/dropouts, and college admissions. Sometimes it seems useful, as Aud, Fox, and KewalRamani (2010) demonstrated in this explanation of demographic trends:

Between 1988 and 2008, the percentage of public school students who were White decreased from 68 to 55 percent. During this period, the percentage of Hispanic students doubled from 11 to 22 percent, and in 2008, Hispanic enrollment exceeded 10 million students. In general, from 1988 to 2008 White 
enrollment decreased in each region and Hispanic enrollment increased, while Black enrollment remained stable. (p. iv)

This gives educational researchers information on the shifting demographics in U.S. public schools. However, what do we mean by race? In Oregon schools, the categories used for reporting data are American Indian/Alaska Native, Asian, Black/African American, Hispanic/Latino, Multi-Racial, Native Hawaiian/Pacific Islander, and White. These categories have obvious problems. For example, in Portland there is a growing population of recent immigrants from Somalia, who would presumably choose “Black/African American.” However, grouping recent Somali immigrant students” academic scores in the same category with "African Americans," whose roots in the United States go back hundreds of years, seems inaccurate. Is the purpose to quantify high stakes test scores by skin color? On the surface, race seems to be guided by historical and geographic reasons but looking at the Hispanic/Latino category presents similar complications and inaccuracies. The word Hispanic includes all Spanish speaking people from Spain and countries colonized by Spain, which excludes a large portion of South America (Brazil, Guyana, Surinam) and one country in Central America (Belize). On the other hand, Hispanic does not include colonized and Spanish-speaking Equatorial Guinea, in West Africa. Racial categories seem to be connected to historical and geographical roots, but then racial categories do not take into account such things as: Spain is part of Europe and Europeans are considered White. Racial categories do not consider the global movement of people over the last several centuries. There are "White" Africans (of European descent), "Black" Latinxs, and "Asian" Peruvians. The racial categories used in educational data come from false, racist, and outdated scientific 
ideas, used to segregate and oppress people of color while proving White supremacy (Goodman, 2008). It might be confusing why I am addressing this in a study focused on bilingual and multilingual students, but their schooling in the U.S. has historically and consistently been affected by the socially constructed idea of race and institutionalized racism in the United States. For example, the landmark case Mendez vs. Westminster (1947), was brought about because of school policies that separated what school officials believed to be White and Mexican students from the same family to vastly different schools with very different resources. The school administrators proclaimed that the children were separated for their own good because of their English language ability, however all the children spoke English fluently. The school officials used language and culture as their rationale, but the courts eventually found that they were segregating students based on skin color, derogatory stereotypes, and last names (Ballón, 2015). Racism continues to exist in schools today. Ayón and Philbin (2017) found that Latinx students regularly experienced institutional and interpersonal discrimination, from microaggressions and microinvalidations, to physical attacks. Furthermore, Latinx students attend the most racially segregated public schools in the U.S. and/or are segregated within their schools (Gándara \& Aldana, 2014). N. Flores and Rosa (2015) found that even as students learn English and/or demonstrate bilingualism they are still perceived to use non-Standard English if they are not viewed as White. In one example, there is a dialogue between a researcher and student, where the student described speaking with someone in English, Spanish, and a mixture of the two. Although the student displayed complex linguistic abilities, both oral and written, according to the 
school, she was considered a Long-Term English Learner. N. Flores and Rosa (2015) asserted that if she were considered White, she would not be seen or heard this way, “.. . even when long-term English learners, heritage language learners, and Standard English learners adopt idealized linguistic practices, they are still heard as deficient language users" (p. 167). They imagine that a White student describing the same linguistic abilities, smoothly transitioning between languages based on audience, would potentially be seen as linguistically gifted.

\section{Background}

Language rights and the education of bilingual and multilingual students have always been a part of U.S. public schooling, and society has responded in several ways. One way to look at the many factors producing inequities in education is to use a framework proposed by Ochoa (2013) that looks at macro-, meso-, and micro-level influences. These levels of factors are illustrated in Figure 1.2.

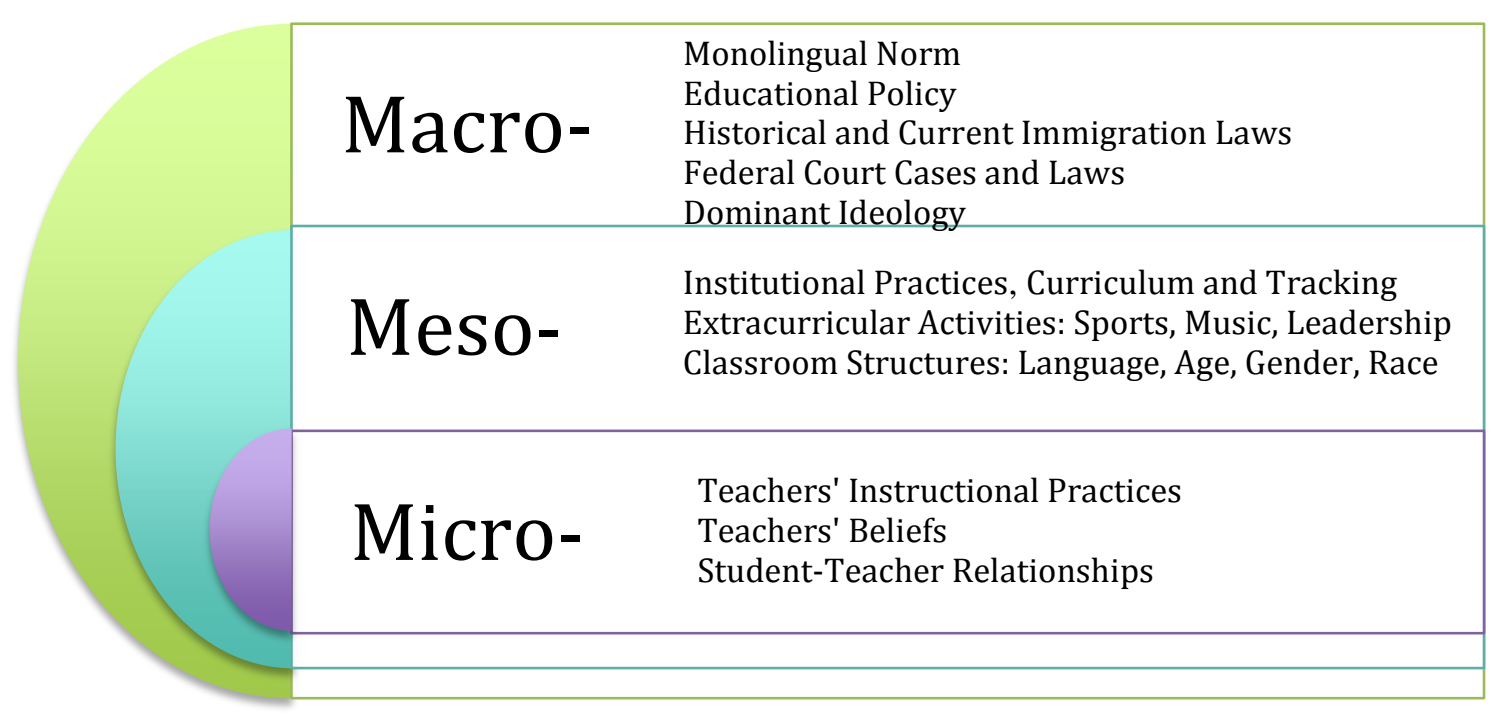

Figure 1.2. Macro-, meso-, and micro-levels of factors influencing bilingual and multilingual student achievement. 
Ochoa (2013) explained that this, “. . . involves understanding the specific and intersectional aspects of macroscopic structural factors and dominant ideologies, mesolevel school policies and practices, and microscopic everyday exchanges on educational outcomes and school relationships" (p. 11).

Macro-level factors. The macroscopic structural factors are often unnoticed and related to historical events. For example, multilingual and bilingual are educated under a monolingual norm which influences all other aspects of schooling. At the macro-level, one must understand that language dominance and forced assimilation have long been part of the United States history. In the early $19^{\text {th }}$ century, a few years after the Louisiana Purchase, legislatures attempted to eliminate French and imposed English as the official language. The same happened a half-century later when the United States claimed the southwest after the Mexican-American War and suddenly had 75,000 new Spanishspeaking citizens. By the end of the $19^{\text {th }}$ century English-only legislation for educational purposes and in some cases, all governmental purposes, was enacted in the United States for Native Americans, the French-speaking southeast, the Spanish-speaking southwest, Hawaii, Wisconsin, and Illinois, as well as Puerto Rico and the Philippines. The newest way the monolingual norm is being exercised is subtler, not by federally legislating English-only language laws, but through educational policy that mandates English-only standardized testing for students and future teachers (Lucas, 2011; Motha, 2014).

Educational policy. Looking back over the last half-century, educational historians point to the publication of A Nation at Risk as the start of the English Only standardized testing era (Cross \& Manna, 2014). A Nation at Risk, published in 1983 by 
the National Commission on Excellence in Education during the Reagan administration stated that, "the educational foundations of our society are presently being eroded by a rising tide of mediocrity that threatens our very future as a Nation and a people" (Gardner, Larsen, Baker, Campbell, \& Crosby, 1983, p. 1). Although the report was criticized for many reasons, the media gained the public's attention and the message that the United States needed to urgently reform its schools and be run like a business was unleashed. The reforms that followed were constructed under a monolingual norm.

The No Child Left Behind Act passed in 2002, almost 20 years later, increasing standardized testing, English, and more standardization based on dominant ideology and a monolingual norm. Schools were suddenly held accountable for the standardized test results for their subgroups and disaggregated data were reported to the state and the federal government. The subgroups were reported by students' race, disability, and Limited English Proficient (LEP). Schools' test scores were tied to funding, status, and firing of administration and teachers. With this new data, standardized test scores were analyzed and compared. This illuminated what many already knew, the racial and linguistic educational inequities in U.S. public schools were startling, our bilingual students were significantly below any other group of students identified.

Judicial and legislative events impacting bilingual and multilingual education. In addition to federal educational policy, another macroscopic level influencing bilingual and multilingual students' education were major judicial decisions and legislative actions. Figure 1.3 illustrates the major judicial decisions which have led to the legal responsibility schools have today to equitably educate bilingual students. 


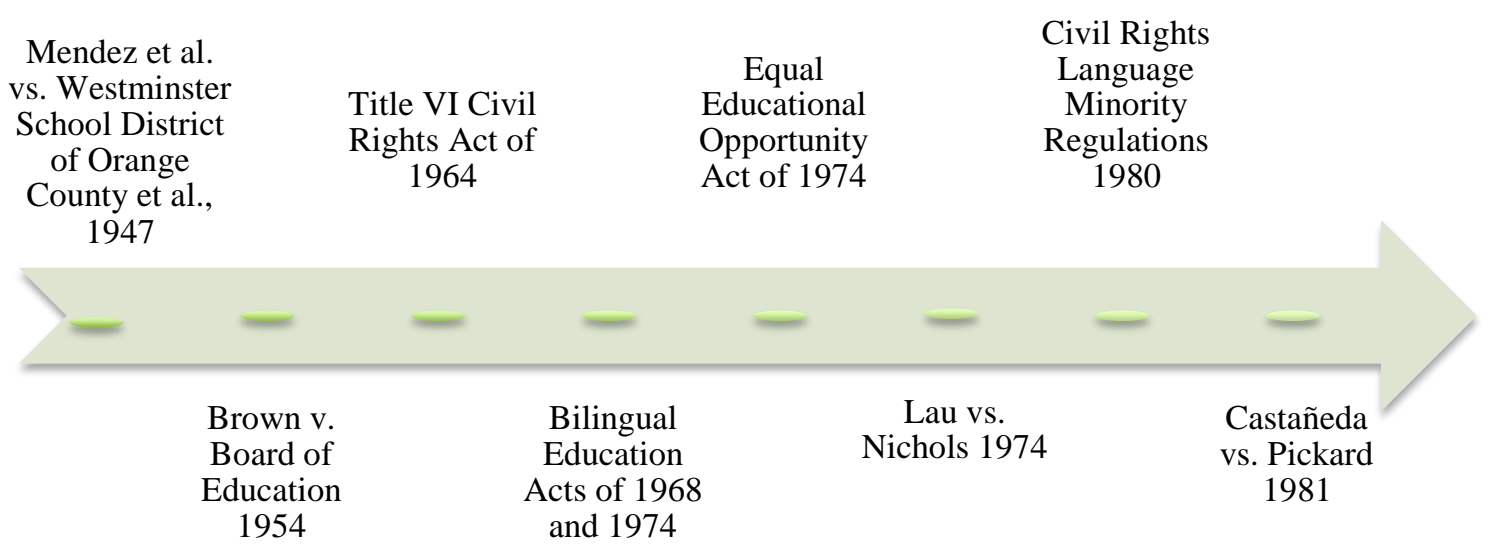

Figure 1.3. Timeline of important judicial and legislative events affecting the education of bilingual and multilingual students.

Mendez vs. Westminster School District of Orange County (1947), as previously discussed, made the regular practice of segregating Mexican, Mexican-American, and White students illegal in California. This meant schools could no longer send Mexican and Mexican-American students to Americanization schools or Mexican schools, which trained girls to clean houses and prepared boys for low paying labor jobs and were characterized by overcrowding and poor resources (Ballón, 2015). The next year a similar case outlawed the segregation of Mexican children in Delgado v. Bastrop Independent School District (1948). Then in 1951, a federal court ruled in favor of Latinx students once again in Gonzales v. Sheely (D.C. Ariz. 1951) and declared the practice of segregating students based on language ability was unconstitutional. Finally, in 1954, the more well-known U.S. Supreme court decided in favor of Brown in Brown vs. the Board 
of Education, which found "separate but equal" to be unjust and ordered all public schools nationwide to desegregate with "all deliberate speed."

Although schools still struggled with segregation, there were strides toward improving education for bilingual and multilingual students. Title VI Civil Rights Act of 1964 prohibited schools from, "discriminating on the basis of race, color, or national origin" (Overview, para. 1). The Bilingual Education Acts of 1968 and 1974 designated funding and compelled 'school districts to take 'affirmative steps' to address language barriers so that EL students may participate meaningfully in schools' educational programs" (Lhamon \& Gupta, 2015, p. 5).

In 1974, in Lau vs. Nichols the U.S. Supreme Court decided in favor of bilingual and multilingual students. The court found that it was the students' civil right to be able to meaningfully participate in school, regardless of English language proficiency. Because of this decision, every school district has a Lau Plan which details their plans to ensure the meaningful participation of students that are learning English as an additional language.

That same year, Congress passed the Equal Educational Opportunities Act, which stated, "public schools and State educational agencies must act to overcome language barriers that impede equal participation by students in their instructional programs" (Lhamon \& Gupta, 2015, p. 1). Casteñeda vs. Pickard (1984) aimed to fine tune exactly how school districts were to evaluate the effectiveness of their Lau plans. However, according to the U.S. Department of Education's National Center for Education Statistics (2017), bilingual students still experience significant barriers to equitable education. 
Language policy and legislation were enacted to address the inequalities and barriers to education that bilingual students faced through desegregation and policies. However, these decisions and policies have not ended segregation or increased academic achievement, as measured by graduation rates and standardized tests.

As previously discussed, bilingual and multilingual students represent many languages, ethnicities, families with different amounts of formal education, economic resources, and many other factors that can affect how students do in school. One way to look at bilingual students' academic success is by graduation rates of high school, college, and graduate school. Figure 1.4 shows the national graduation rates of ELs as $62.6 \%$, nearly 20 percentage points behind the national average.

\section{National High School Graduation Rates, by Student Group: SY 2013-14}

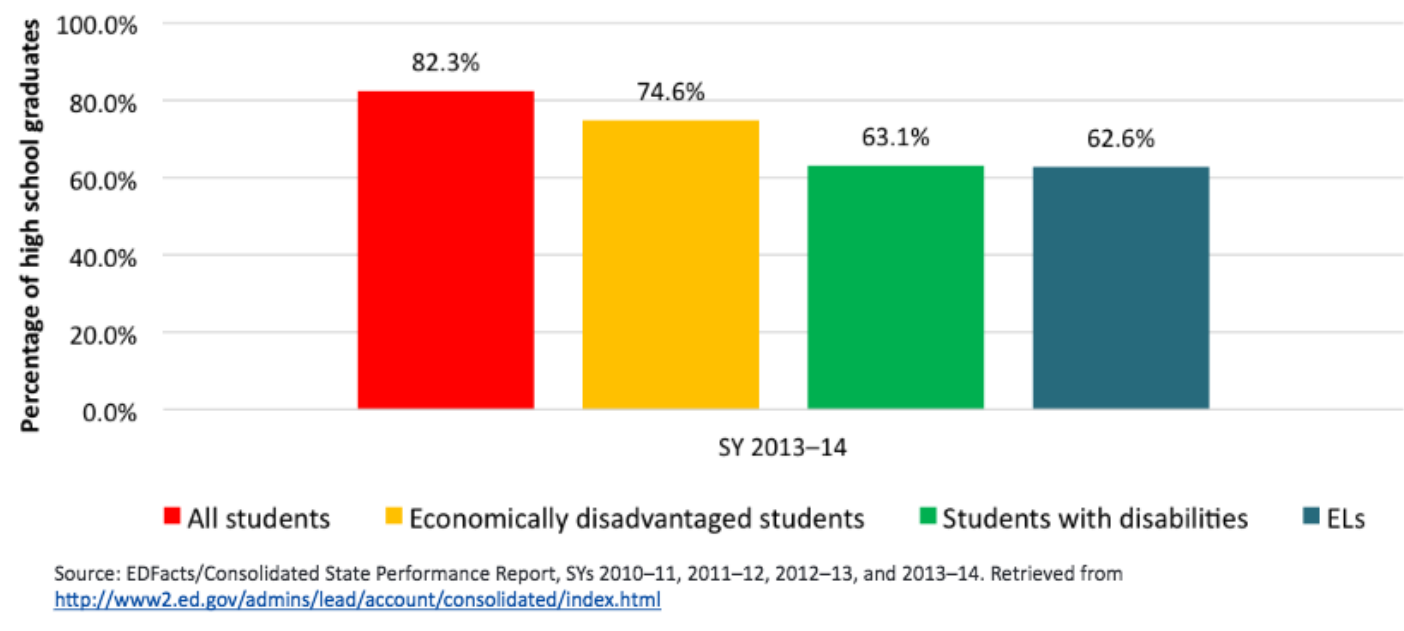

Figure 1.4. National high school graduation rates, by student group: SY 2013-2014. Retrieved from U.S. Department of Education (2016).

The inequities impact future schooling and job choices for bilingual and multilingual students. Furthermore, the repercussions extend throughout their lives and 
future generations, to the communities in which they live, and the sociocultural dynamics of the broader society. For example, high school dropout rates for bilingual students are higher than any other federally identified subgroup; almost half of the states had less than $60 \%$ of their ELs graduate in 2010-2011 (Romo, 2013). Without a high school diploma, it is difficult to find employment and earn a livable wage. "In today's workplace, only $40 \%$ of adults who dropped out of high school are employed, compared to $60 \%$ of adults who completed high school and $80 \%$ for those with a bachelor's degree" (National Dropout Prevention Center, 2018, para. 2). Sometimes it is useful to look at broader categories that are reported such as race or ethnicity in order to see the long-term outcomes of students that learn English as an additional language at school because of the variance in determining who is an English language learner (ELL). Yosso and Solórzano (2006) looked specifically at Chicana and Chicano students, defined as "people of Mexican descent" (p. 2), because they are the fastest growing and youngest subgroup, representing the majority of Latinx students. Their education impacts communities across the nation and will continue to do so. Using data from the 2000 national census, Yosso and Solórzano created a graphic to show the educational attainment of Chicana/o students. They begin with a hypothetical group of 100 elementary Chicana/o students, and using the census data, show how many would graduate high school and go on to college. According to their study, 44 students would graduate from high school, 26 students would enroll in college, 7 students would graduate with a baccalaureate degree and only 2 students would earn a graduate degree. When they displayed this information visually, the results were startling (see Figure 1.5). 


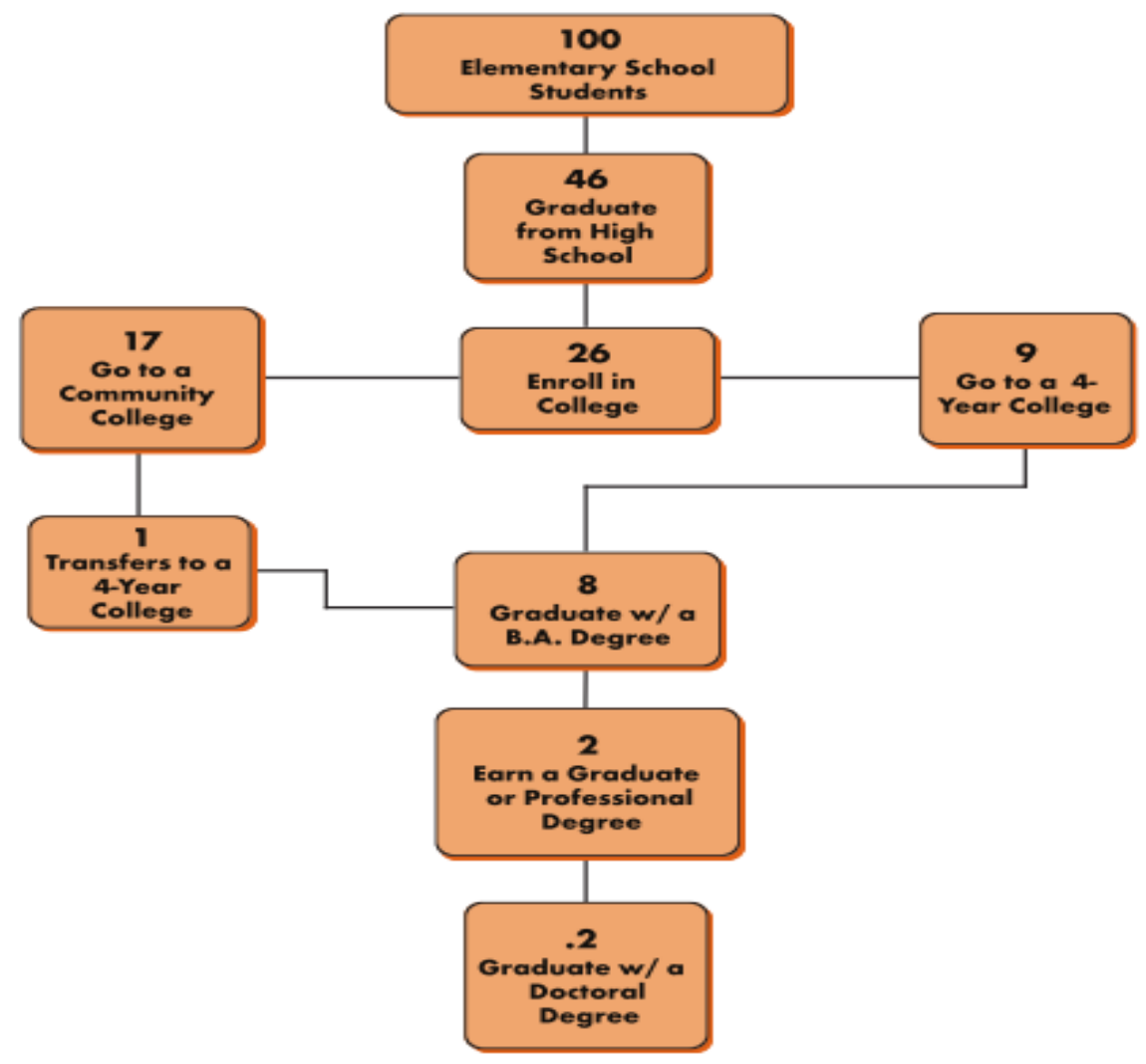

Figure 1.5. Chicana/o educational pipeline. Source: Yosso and Solórzano (2006).

Building off of Yosso and Solórzano's (2006) work, which came from the national census from 2000, Covarrubias (2011) updated this work with the new census data from 2010. While there was some improvement, particularly for high school graduation (increased from 44\% to 56\%), Covarrubias emphasized that "people of Mexican origin continue to be failed by American educational institutions at all levels ... [see Figure 1.6] demonstrates that $44 \%$ of students entering the educational pipeline are eventually pushed out before completing a high school diploma" (p. 92). 


\section{Chicana/o Educational Pipeline}

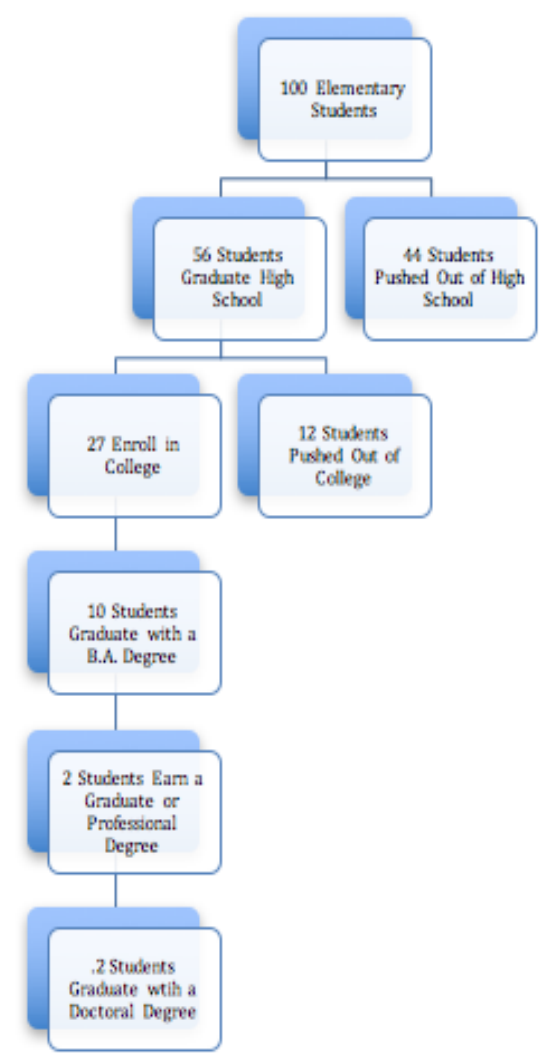

White Educational Pipeline

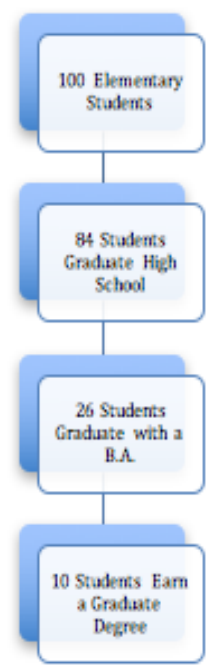

Figure 1.6. The Chicana/o educational pipeline showing graduation outcomes for Chicana/o elementary school students. Source: Covarrubias (2011, p. 93). On the right is a similar pipeline for White students (Huber, L. P., Huidor, O., Malagon, M. C., Sanchez, G., \& Solórzano, 2006).

Although their study does not specify the languages spoken by either the

Chicana/o or White students, Yosso and Solórzano (2006) defined Chicana/o as people of Mexican descent and the U.S. Department of Education (2015) defined White as people of European, Middle Eastern, and North African origins. In the United States, over 75\% of the bilingual students speak Spanish, the majority of whom are of Mexican descent. For that reason, it is reasonable to conceive that the students represented in these studies 
are, or were, from families of bilingual students who learned English as an additional language (Valenzuela, 1999).

The connection between education and economic prosperity is clear, and the inequality in education between monolingual English speakers and bilingual and multilingual students is evident. For this reason, it is critical teachers and teacher education programs examine their structures and practices to identify and eliminate ways in which groups of students, like bilingual students, are marginalized. Our educational programs need to be transformed into places where bilingualism and biculturalism are nurtured and esteemed (O. García \& Wei, 2014; Hakuta, 2011; Valenzuela, 1999).

Meso-level factors. The last section discussed the macro-level ways that state and federal policies, as well as national judicial decisions have impacted bilingual and multilingual learners educational experience. This historical context culminates in statistical profiles of how Chicano/a students are being pushed out, dropped out, and disappear from the educational pipeline to higher education, which in turn, would enable them to develop economic stability. This section focuses on how bilingual and multilingual learners' education is impacted by meso-level factors that are structural. These factors are such things as institutional practices, curriculum and tracking, extracurricular activities, and classroom structures.

The impact of segregation on English learners has been particularly harmful in terms of academic outcomes ... In other words, segregation had a broader impact on EL student achievement when compared with other school factors such as school resources, practices, and structure. Therefore, in order to improve the achievement outcomes for Latinx English learners, policy makers would need to include measures to desegregate schools. (Gándara \& Aldana, 2014, p. 742)

Segregated schools and segregation in schools are some of these meso-level factors. 
According to educational research, there are many variables contributing to educational inequities, both inside and outside of school. For bilingual and multilingual students, teachers' beliefs, attitudes, interactions, and decisions can be the most influential factors for increasing or decreasing educational opportunities (Lucas, Villegas, \& Martin, 2015). Educators, administrators, policy makers, and researchers have investigated and attempted to remedy the achievement gap between students categorized as ELs and non-ELs. Although the achievement gap is a common term in education, it is important to note it has also been referred to as the "opportunity gap" (Milner, 2010; Téllez \& Mosqueda, 2015) and the "education debt" (Ladson-Billings, 2006), which call into focus the incredible economic disparities and the disparity in opportunities between the groups of students compared in the achievement gap. Unfortunately, as seen in Figure 1.7, the academic disparities are real and growing, and the number of students that speak a language other than English at home are increasing (Hopkins, Thompson, Linquanti, Hakuta, \& August, 2013; Polat, Zarecky-Hodge, \& Schreiber, 2016).

There are many factors that are understood to be linked to students' likelihood of academic success in U.S. public school even before they enter school. Some of these factors have been identified as: household income and housing (Darling-Hammond, 2010), parents' formal educational level, and family involvement with the school (Aud et al., 2010). In particular, Latinx bilinguals are also more likely to come from families from lower socioeconomic status and limited formal education, with the corresponding limitations such as less opportunities for after school activities and sports, tutoring, SAT prep classes, transportation, etc. According to Tatum (2017), 
Education and family income remain below the U.S. average. Only 9 percent of Mexican Americans age twenty-five and older have earned at least a bachelor's degree) compared to 13 percent of all Latinx adults and more than 30 percent of all US adults over twenty-five). In 2014 the median household income in the US was roughly $\$ 51,400$, but it was only $\$ 38,000$ for Mexican families. (p. 239)
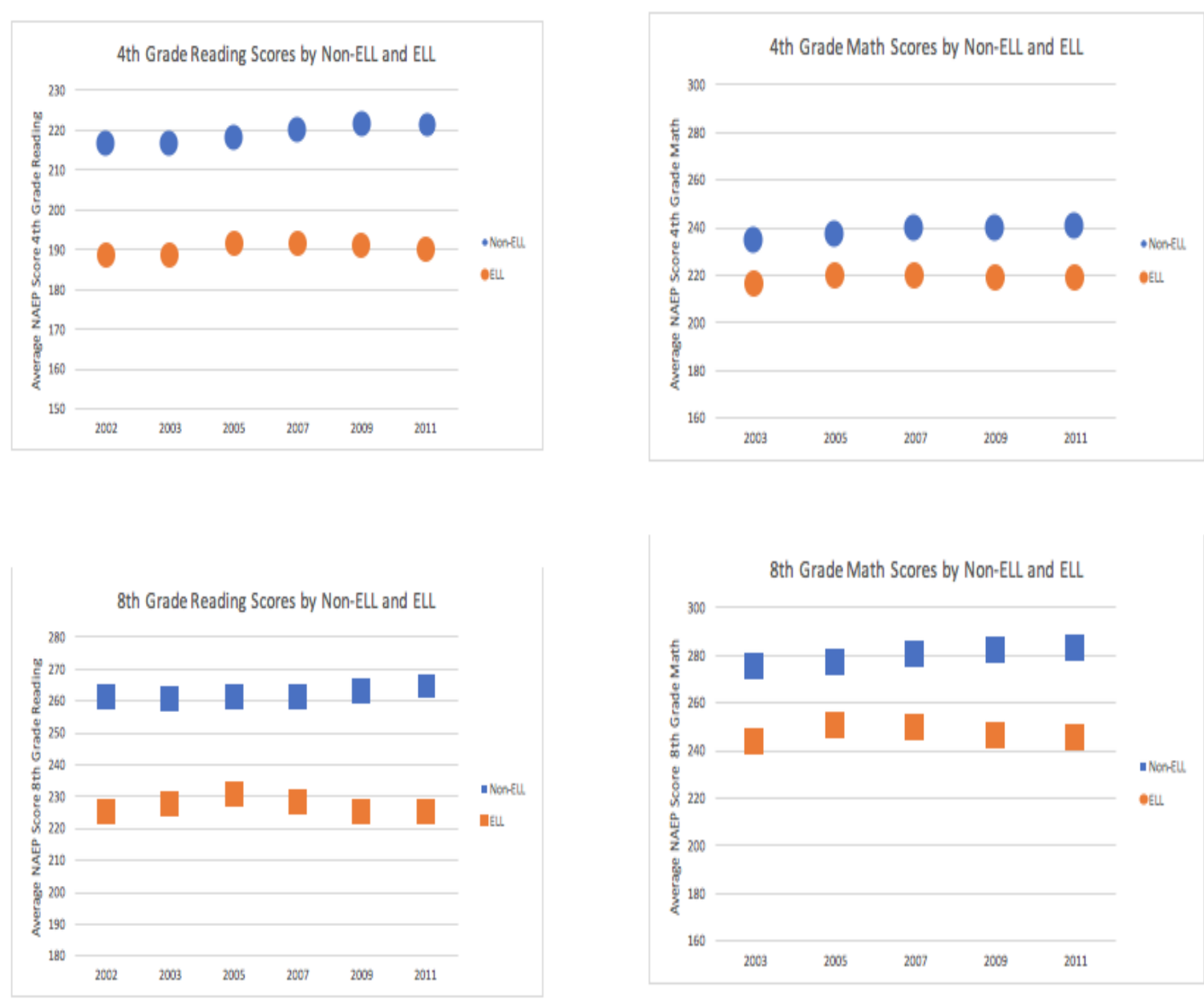

Figure 1.7. National math and reading scores by language status and years grades 4 and 8. Source: Polat et al. (2016). These figures show the wide gap between ELL and NonELL students' National Association of Educational of Educational Progress math and reading scores.

Once students enter school there are institutional factors, such as academic tracking, that can have an enormous impact on academic achievement. Bilingual students are more likely to be placed into lower tracked classes than their non-bilingual peers; 
these classes are "less interesting, less demanding (even relative to their starting points), and ultimately less productive of learning compare to those in higher tracks" (Gamoran, 2010, p. 3), leaving these students to fall further and further behind. Limited English language proficiency can be confused with low academic ability, resulting in placement in "low math" and "basic science" courses for the rest of their academic careers (Gamoran, 2017). Bilingual students are over represented at schools with less resources and opportunities for advanced courses, and when those courses are available, they are underrepresented, compared to English-speaking students with equivalent standardized test scores (Umansky, Valentino, \& Reardon, 2016). Bilingual students may also encounter an English-only curriculum, linguistic segregation, and a range of school climates from linguistically and culturally inclusive to exclusive (Ochoa, 2013). In addition to these institutional factors there are also state and federal educational policies influencing everything from teacher preparation to textbook adoption (Lucas, Villegas, \& Freedson-Gonzalez, 2008). All of these macro and meso-level factors matter and influence a student's education. However, teachers' day to day interactions and decisions are one of the most influential forces in a student's academic life (Hattie, 2009).

Micro-level factors. Teachers' beliefs, interactions, and decisions have a cascading effect on bilingual students' academics (Gay, 2015; Lucas et al., 2015). Teachers decide which students go into advanced, regular, or remedial math and language arts classes. They refer students to Special Education, recommend students for leadership and robotics classes. These everyday decisions direct bilingual and multilingual students into more or less opportunities and to gain or lose social capital, which may grant 
students the freedom to walk around the school, interview the principal, learn how to raise funds for nonprofits and partner with businesses, or plan a dance (Ochoa, 2013). Many times, the decisions to be included or excluded from these opportunities are informed by test scores or class participation, but ultimately teachers use their understanding of students to make their final decisions.

How do teachers understand the inside and outside factors influencing their bilingual students and the ways these factors play out in the classroom? Do teachers know what it is like to learn academics in a language and culture different from their home? Palmer and Martinez (2013) emphasized the need for teachers to have this deep comprehension of language and culture. They explained:

Indeed, these more robust understandings of language and interaction are necessary if teachers are to capitalize on the flexibility and intelligence displayed by bilingual students as they engage in hybrid language practices in order to guide them in the development of bilingual/bicultural academic identities that would support their continuing success in school. In fact, we believe that teachers are the professionals best positioned to capitalize on such understandings. (pp. 269-270)

It is hard to say exactly how many teachers are bilingual and bicultural and have an understanding of language and culture. What we do know is that $84 \%$ teachers are White (Feistritzer, 2011) and 95\% of bilingual students are either Latinx (79\%), Asian (11\%), Black (3\%), American Indian/Alaskan Native (.7\%), Pacific Islander (.5\%), or 2 or more races (.6\%) (National Center for Education Statistics, 2016b). This disproportionality, between the percentage of teachers who are racially/ethnically similar to their bilingual students, may indicate that there is a disproportionate number of teachers who are not able to truly engage the assets of bilingual learners in order to guide them in developing positive academic identities, a crucial component fostering success in school. For 
example, Figure 1.8 shows the percentages of students and teachers by race/ethnic categories as reported by the U.S. Department of Education.

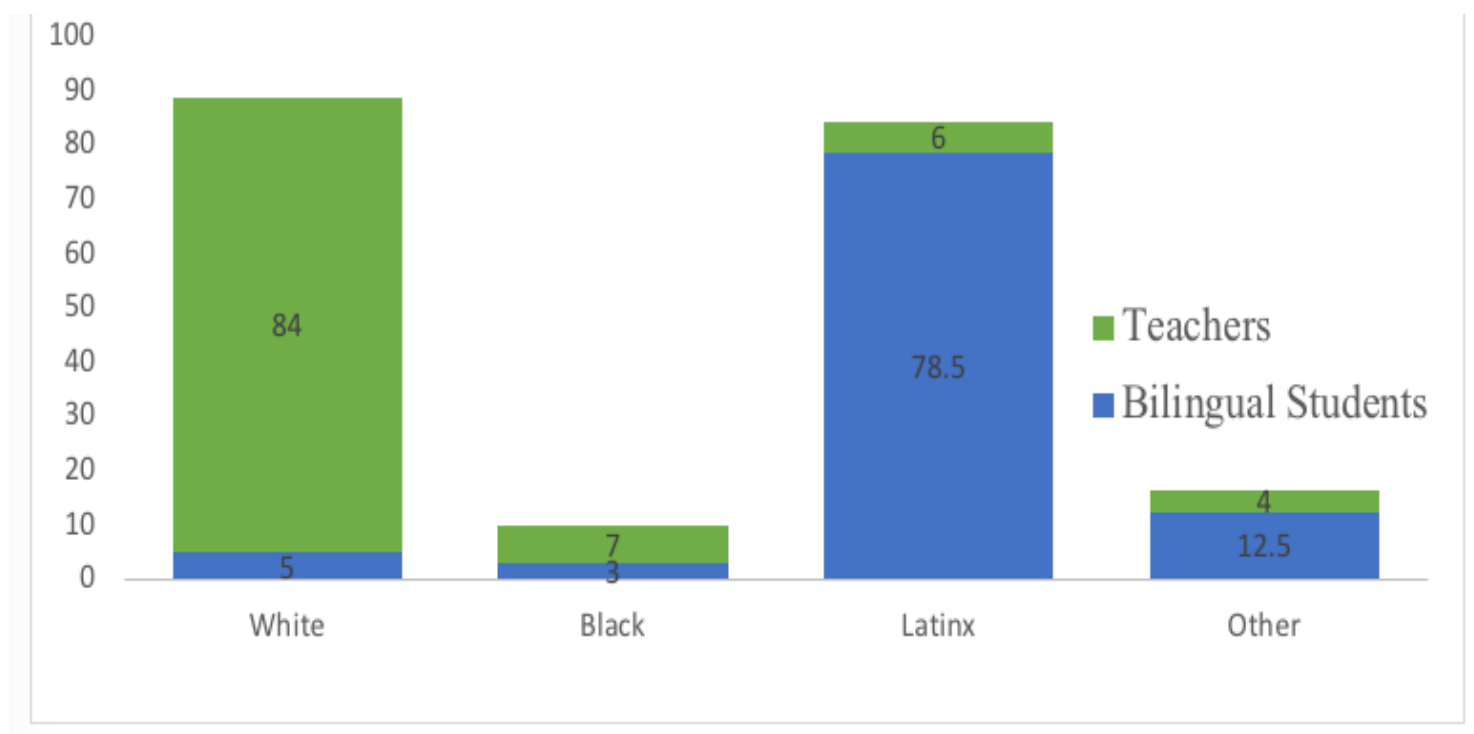

Figure 1.8. Comparison of bilingual students and teachers by racial/ethnic categories. Sources: Feistritzer (2011) and National Center for Education Statistics (2016). The racial/ethnic categories for teachers were not disaggregated beyond White, Black, Latinx, and Other.

Chapter 2 continues the discussion on the research about students and teachers racial (in)congruence. While language, culture, and race/ethnicity are different, they will continue to be connected in this paper because of their interrelatedness. (For example, all Latinxs/Hispanics do not speak Spanish. All Whites are not monolingual Englishspeakers.)

If teachers do not understand what it is like to be a bilingual learner, there are constant decisions, small and large, that can go unseen, imperceptible to many monolingual White educators that can affect the educational outcomes for bilingual learners. Teachers are incredibly influential in students' day-to-day academic life. As 
they progress in their careers, teachers' influence goes from microscopic, to the mesoand macroscopic levels. At the microscopic level, there are day to day interactions and decisions made in teachers' classrooms. Additionally, classroom teachers' influence extends beyond this, for example, as members of building level teams that determine if and when, which students are retained, suspended, expelled, included or excluded from bilingual programs, and more determinations that have lifelong effects. At the mesolevel, teachers can become Special Education, English to Speakers of Other Languages (ESOL), and behavior specialists, assistant principals, principals, curriculum directors, special education directors, and human resource directors and are able to sway aspects such as tracking, curriculum choices, and extracurricular choices as they. Teachers can even be a part of, or work against, academically influential ideologies at the macroscopic level such as meritocracy, racialization, and stereotypes. Classroom teachers are the heart of education, in every role. They have the potential to open and close doors for bilingual students every day. For that reason, this study focuses on classroom teachers. The participants in this study are bilingual teachers who were former ELs in U.S. P-12 schools. The teacher's role is primarily in the micro-level, but they can move into the meso- and macro-levels in their different roles or during their career, as demonstrated in Figure 1.9, making it even more important for all teachers to be equipped to teach bilingual and multilingual students. 


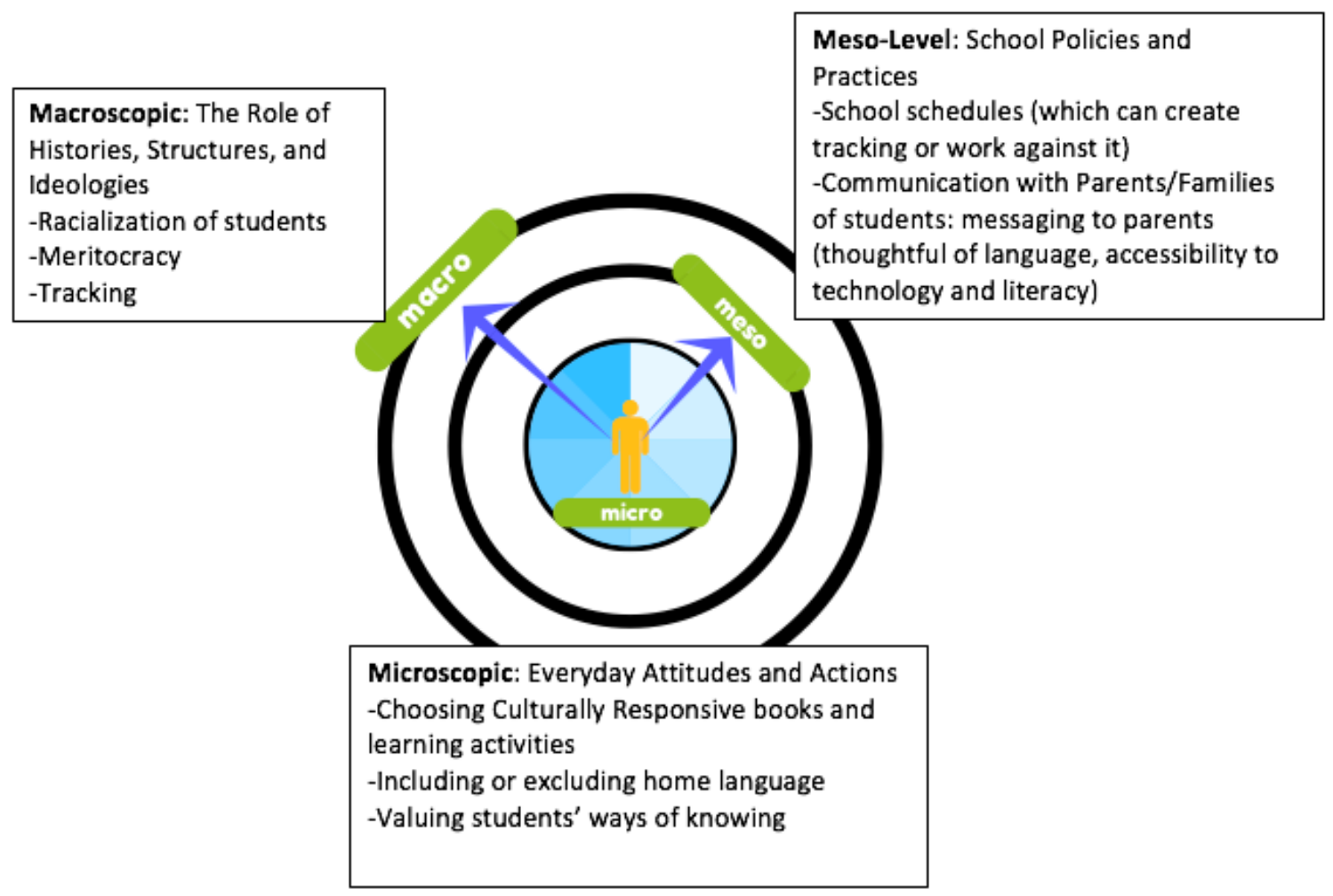

Figure 1.9. Illustration of how teachers can influence all levels educational throughout their careers.

This research aims to unpack the complexity of equitably educating bilingual learners in a narrow scope — by looking at one group of individuals (former bilingual learners) who have experienced these macro-, meso-, and micro- factors, both inside and outside of school, and have arrived to become bilingual and multilingual teachers.

\section{Research Problem}

As the number of bilingual students is on the rise, it is especially important for teachers and teacher educators to understand how to improve educational outcomes for bilingual students. This study seeks to explore the experiences of students formerly 
classified as ELLs as they become bilingual teachers. The purpose is to explore how these bilingual teachers, describe their past educational experience as ELLs while they are beginning to teach bilingual students (B. B. Flores, Sheets, \& Clark, 2011). This study seeks to contribute to the literature in the fields of multicultural and multilingual education, as well as inform teacher educators in order to create opportunities to recognize and recruit bilingual teachers into the profession.

Bilingual teachers are in the unique position of having lived experiences as ELs in U.S. P-12 public schools, as well as knowledge and experiences as educators in these same schools. There exists the possibility, through their stories, experiences, conflicts and connections to find ways to transform the education of bilingual and multilingual students. Bilingual teachers have funds of knowledge, which they can draw from on their journey to becoming culturally responsive teachers. This is especially critical for creating an equitable education for multilingual learners. Being multilingual and multicultural in the United States includes understanding the intricacies of language, culture, and racism that are often imperceptible to teachers from the dominant culture.

Bilingual teachers operate translinguistically every day, moving fluidly between and with their languages, they can make connections for students' learning unseen by many monolingual teachers. In general, bilingual educators understand the connections between languages and literacy practices, knowing that oral fluency in one language does not exclude a person from being able to read or write in that language. Students learning English do not have to be orally fluent before they are ready to begin learning how to read or write in English, rather speaking, reading, writing, and listening skills can 
develop at different rates for each learner. Fostering this multiliterate identity is essential to engaging multilingual learners and in turn, creating the possibility of a future generation of bilingual teachers.

Some bilingual teachers have experienced and/or seen language loss and understand the devastating generational effects for families and society (Gándara \& Hopkins, 2010; Wong-Fillmore, 1991). Many bilingual individuals have experienced being students under common linguistic and cultural myths that have long misguided teachers, administrators, and policy makers. These detrimental myths, like "math is a universal language," are transparent to multilinguals. Bilingual educators are able to see the linguistic and culturally laden barriers in math, especially on high stakes tests which do not account for students' distinct funds of knowledge and linguistic and cultural ways of knowing. Similarly, multilingual adults compare and contrast idiomatic phrases and experience how language influences thought. They know English proficiency does not equal the ability to think, a common stereotype experienced by multilingual individuals in the United States (Motha, 2014).

Culture and community are integral to learning and accessing multilingual students' funds of knowledge. Culture can simultaneously be invisible and a blockade, guiding our logic, interaction styles, likes and dislikes. Gay (2010) explained, “Culture provides the tools to pursue the search for meaning and to convey our understanding to others and thereby has strong shaping influences on the communication styles prominent among different ethnic groups and their children" (p. 76). Bilingual teachers may understand that cultural perspectives guide not only our communication style, but also 
our understandings of fundamental concepts such as time, health, attitudes, respect, and values. They shape how we think about architecture and plan for holidays. Even between bilingual teachers from different cultures and languages, they can connect and value varying families’ funds of knowledge (González et al., 2005).

Many bilingual teachers also understand that racism is systemic, pervasive, and must be countered in order to achieve an equitable education for bilingual students (Ladson-Billings, 2009; C. M. Steele, 2010). Unfortunately, many understand and have experienced discrimination, color blind racism, and the effects of White privilege (Ayón \& Philbin, 2017; Leonardo, 2015). They can also pick up on deficit views held by other educators and institutions, which can lead to low academic tracking, low expectations (Milner, 2010), and to students feeling like they are being pushed out of school. Even the use of commonly used terms like ELL and LEP, view bilingual students as innately lessthan and as a deficit (Gándara \& Contreras, 2009). Bilingual teachers may also have experienced racial identity negotiation and may be able to identify youth struggling through those developmental stages as well (Chávz \& Guido-DiBrito, 1999; Pizarro, 2005; Tatum, 2017; Zirkel, 2002). Additionally, bilingual teachers may have the funds of knowledge to identify and work against linguicism and discrimination based on accent in order to improve the educational opportunities for multilingual students (Motha, 2014).

In sum, I believe bilingual teachers and bilingual learners have experienced how language, culture, racism, and educational opportunity intersect in bilingual education, and their expertise has provided an area from which we can learn. 


\section{Research Focus}

This study is interested in the experiences of students formerly classified as EL in U.S. K-12 public schools, who are now bilingual teachers. There is a lack of research that amplifies the voices of former students labeled and tracked as ELLs who have completed college and are now bilingual teachers. This research centers on these questions:

1. How do the bilingual teachers in this case study describe their schooling experiences (up to and including their teacher education program)?

2. How do these bilingual teachers describe their current daily teaching and learning experiences with bilingual learners?

3. How do these bilingual teachers make sense of their experiences as ELs and as bilingual teachers?

These questions focus on the experiences of the participants and the ways in which the participants describe the impact of those experiences.

\section{Methods}

The research questions in this qualitative study focus on participants' experiences and ideas in order to gain a more complex understanding of how students formally classified as ELs experienced schooling and how that may or may not influence them as educators. Glesne (2016) described a qualitative researcher's role as “accessing others' interpretations of some social phenomenon and of interpreting, themselves, others' actions and intentions [so that one can] share the goal of understanding human ideas, actions, and interactions in specific contexts or in terms of the wider culture" (p. 9). She went on to describe that this kind of research operates from the ontology, or worldview, that comes from the idea that "reality is socially constructed, complex, and ever changing” (p. 9). In order to understand the lived realities of the participants and the ways 
that may influence them in the future, this research study utilized research interviews, non-evaluative classroom observations, and artifacts such as reflections, lesson plans, assignments, and field notes. This study used purposive sampling to select participants who were both: bilingual or multilingual teachers and were formerly classified as ELs in U.S. public schools.

The participants in this study are part of a larger cohort of multilingual teacher candidates at a large, public institution in the Pacific Northwest. All the students in the cohort are also involved in a larger research project on developing socially just teachers of bilingual and multilingual students (Institutional Review Board \#163973). However, the multilingual teacher candidates asked to participate in this study were chosen because they were formally classified as ELs in K-12 public schools in the United States. There is a large body of research that shows that students classified as ELs are often tracked into low, non-college preparatory classes, face significant racism, linguicism, institutional oppression, have less contact with high school counselors to ensure high school graduation and college readiness, in addition to attending the most racially segregated and poorly funded schools in the United States (Darling-Hammond, 2010; Gándara \& Contreras, 2009; Motha, 2014; Noguera, 2008; Singleton, 2013; Yosso \& Solórzano, 2006). Therefore, this study explores the participants' educational trajectory and gleans insights into how to improve schools for our growing population of bilingual students.

\section{Conclusion}

Bilingual teachers represent hope for the transformation of education for bilingual and multilingual students. These bilingual teachers are former ELLs who are 
academically successful, invested members of their communities, passionate about creating socially just, multilingual, multicultural classrooms, curriculum, and schools. They are the future principals, superintendents, and policy makers. Educational transformation for bilingual students begins with bilingual teachers.

The next chapter reviews the literature surrounding this research study. I begin with a brief overview of the problem and how a Sociocultural perspective with LatCrit helps pull apart the intersecting factors in bilingual education. Then I review the educational systems impacting bilingual students, the experiences and knowledge teachers of bilingual students need, a basic overview of the benefits of bilingual education and bilingual teachers, and finish with a review of the qualitative methods relevant for this study. 


\section{Chapter 2 Literature Review}

Bilingual and multilingual students are the fastest growing student population in U.S. public schools, and yet bilingual students still experience many barriers that can prevent them from completing high school and college (Morillo-Campbell \& Arias, 2008). Researchers have illuminated many of the barriers facing bilingual students. Bilingual and multilingual students are more likely to attend poorly funded, racially segregated schools (or are segregated within schools), be tracked into low level and noncollege track classes, be subjected to deficit thinking and subtractive bilingualism (Darling-Hammond, 2010; Kozol, 2005; Noguera, 2003; Valenzuela, 1999). While the population of bilingual and multilingual students continues to rise in U.S. public schools, our schools are not ready.

This study focuses on one slice of this multilayered educational dilemma, the teachers. Specifically, I aim to explore the experiences of these bilingual and bicultural teachers who were formerly classified as ELs in U.S. public schools. The goal is to amplify the voices of former ELs who are now bilingual and bicultural teachers in order to identify barriers and supports and in order to illuminate ways to make educational improvements that could transform education for bilingual P-12 students and create a pathway to graduate bilingual students who can become the future teachers, administrators, teacher educators, and policy makers for future generations.

The previous chapter discussed the macro-, meso-, and micro-levels influencing bilingual students. This chapter reviews the current literature, beginning by situating 
teaching and learning with bilingual and multilingual learners with a Sociocultural theoretical frame, complimented with LatCrit. After a discussion of Sociocultural and LatCrit, a review of the research literature follows. The literature review begins with identifying common and detrimental current practices for bilingual learners in U.S. public schools. The next part describes the knowledge and experiences teachers of bilingual students need, the unique role of bilingual and bicultural teachers, and finally, a brief preview of the qualitative research approach to this study. This chapter concludes with a summary of the literature and transitions to the next chapter on methodology.

\section{Sociocultural Perspectives on Educational Research}

The literature on Sociocultural theory is generally attributed to the work of $19^{\text {th }}$ century Russian psychologist Lev Vygotsky. Vygotsky focused on developmental psychology and theorized about how teaching and learning worked in tandem with cognition, and influences on learning (Daniels, 2001). Sociocultural theory interprets teaching and learning as socially constructed, context and culturally dependent, and influenced by historical and political events (Daniels, 2001). Vygotsky is known for developing educational concepts such as the Zone of Proximal Development, and scaffolding in the process of learning and development (Scott \& Palincsar, 2013). His theories have been widely used to better understand teaching and learning in U.S. schools, as described by Scott and Palincsar (2013):

Vygotsky was not only interested in what more knowledgeable others brought to the interaction, but also in what the child himself or herself brought to the interaction, as well as how the broader cultural and historical setting shaped the interaction ... Sociocultural theory has also been called upon to advance instructional practice that might redress disparities in the current educational system. (p. 5) 
Sociocultural theory looks at what is happening in the classroom between the teacher and learner, and also the social, cultural, and historical influences that affect learning. "The goal of a sociocultural approach is to explicate the relationships between the human action, on the one hand, and the cultural, institutional, and historical situations in which this action occurs on the other" (Wertsch, Del Río, \& Alvarez, 1995, p. 11). A key aspect of Wertsch's work on Sociocultural theory is the notion of mediated action and cultural tools. In classrooms, this means paying attention to a task, how it is received by students, and any social, cultural, and political influences on that action.

Culture, language, social and historical influences are intricately woven into teaching and learning with bilingual and multilingual students. Sociocultural theory is a lens with which to see students, teachers, classrooms, and schools situated within broader social, political, and cultural contexts. Nieto (2002), a renowned multicultural educator and researcher, described how she uses Sociocultural theory to view teaching and learning, especially with bilingual and multilingual students:

Traditional theories explain my experience, and those of others who do not fit the conventional pattern, as springing primarily if not solely from our personal psychological processes. Sociocultural theory, on the other hand, gives us different lenses with which to view learning, and different metaphors for describing it. This is significant because how one views learning leads to dramatically different curricular decisions, pedagogical approaches, expectations of learning, relationships among students, teachers and families, and indeed, educational outcomes. (p. 5)

These lenses of Sociocultural theory guide this review of research on teaching and learning with multilingual students. Nieto used five intersecting concepts of Sociocultural theory in education to explore teaching and learning: agency, experience, identity, context, and community, as shown in Figure 2.1. 


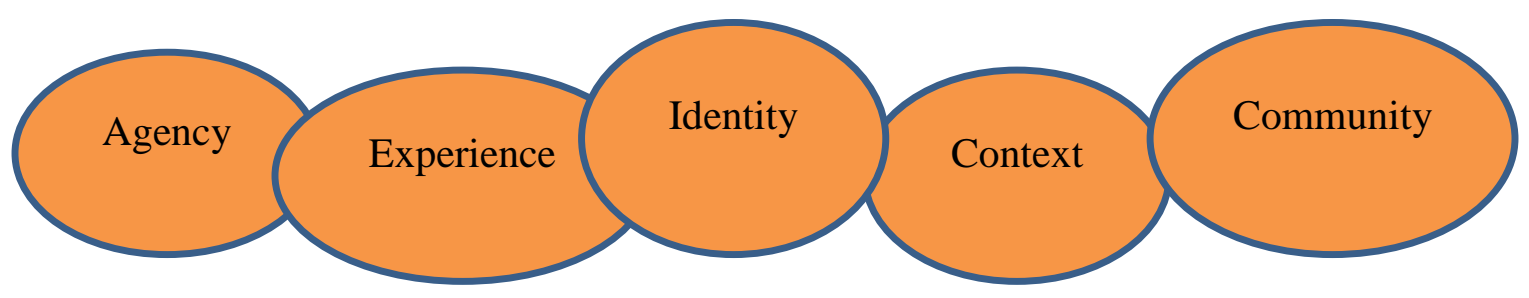

Figure 2.1. Nieto's (2002) five intersecting concepts of Sociocultural theory in education.

The five related concepts begin with agency, which, according to Nieto (2002), refers to classrooms in which knowledge is co-constructed. Students are seen as both part of a cultural, social, historical people and as having individual agency.

Learning is not simply a question of transmitting knowledge, but rather of working with students so that they can reflect, theorize, and create knowledge ... focus on reflective questions invites students to consider different options, to question taken-for-granted truths, and to delve more deeply into problems. (pp. 7-8)

Bilingual and multilingual teachers and students work together to create the learning environment, recognizing that they are both individuals and part of a community. Agency is linked to the second concept, experience. Teachers and students come to school with experiences, which informs the basis for teaching and learning. Bilingual learners come to school with experiences that can be used to anchor early learning. Teachers can promote reading, writing, and math by connecting with students' home experiences and valuing their home language. In a study on using Culturally Responsive Teaching instruction to improve reading comprehension for Latinx bilingual students, the Special Education teacher stated, "I always try to make an effort to draw upon students' cultural and linguistic capital during instruction, as background knowledge is fundamental to developing reading comprehension" (Orosco \& O'Connor, 2014, p. 523). Her instruction 
included reading books that her students could relate to, in English and Spanish, depending on the students. She went on to explain, "These children come from competent and knowledgeable households. Their parents, communities, and life experiences have given them so much knowledge. I can use these cognitive resources to make me a better teacher, and my students better readers" (Orosco \& O'Connor, 2014, p. 524). Her students' reading comprehension soared, and their families made strong connections with the school too. She integrated their knowledge and skills into their classroom too, emphasizing the assets and values the students and families bring. Unfortunately, many teachers do not value the kinds of experiences students come to school with, "for instance, speaking languages other than English, especially those languages with low status, is often thought of by teachers as a potential detriment rather than a benefit to learning" (Nieto, 2002, p. 9). Sociocultural theory includes how the experiences of bilingual teachers and students are part of the teaching and learning process.

In addition to agency and experience, individuals' identities are also part of the teaching and learning process. Individuals' identities are layered with a cultural, linguistic, historical, social, and political past, present, and future. These changing forces also influence a person's identity and how they see themselves being a part of, or not, the school's curriculum and community. Lave (1996) described how identities are also socially constructed and influenced by the interconnected development of learning, community, and ways of knowing:

Who you are becoming shapes crucially and fundamentally what you "know." "What you know" may be better thought of as doing rather than having something - "knowing" rather than acquiring or accumulating knowledge or information. "Knowing" is a relation among communities of practice, 
participation in practice, and the generation of identities as part of becoming part of ongoing practice. (p. 157)

Lave agreed with Nieto (2002), identity is a central aspect of teaching and learning, as identities influence participation and communities of practice. My interpretation of how knowledge, identity, and communities constantly influence each other is represented in Figure 2.2.

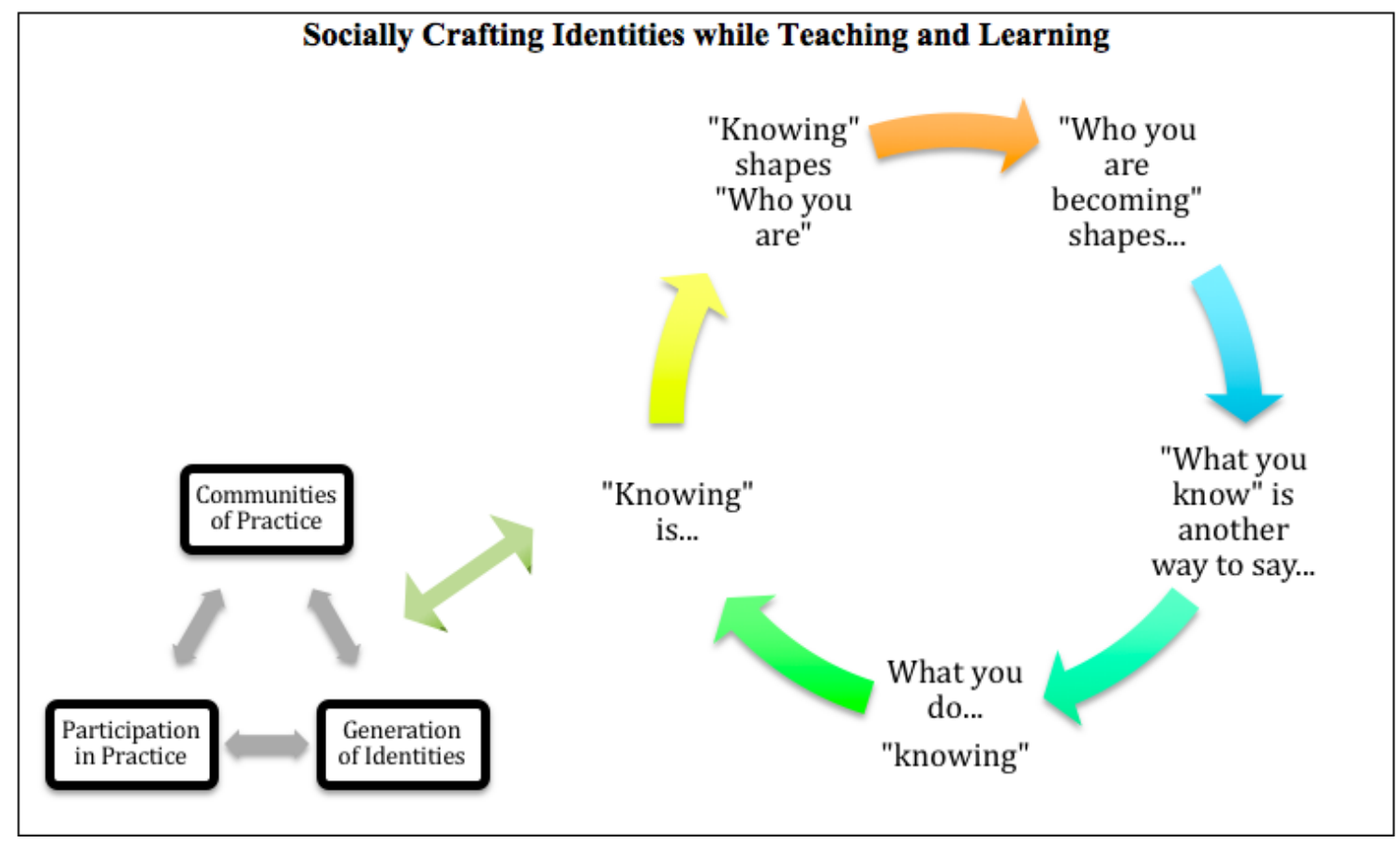

Figure 2.2. Socially crafting identities while teaching and learning. This figure shows how I imagine the cyclical nature of identity formation with community and ways of knowing as explained by Lave (1996).

How one's identity is affirmed or marginalized can be seen as a mediating tool in Sociocultural theory. Of course, all of these concepts are also wholly connected to the context. By context, Nieto (2002) emphasized that culture is contextual as it is everything that happens in the classroom. When the context is not included, we run the risk of 
looking at education as neutral and apolitical. By considering the context, we continually admire the dynamic nature of culture, language, teaching, and learning. The context can bolster teachers and students to learn or hold them back. Nieto explained it this way:

How do students learn to use language in a way that both acknowledges the context in which they find themselves, and challenges the rules of that context? How do young people learn to negotiate the chasm that exists between their home languages and cultures and those of school? (p. 14)

Teachers need to be aware of this chasm and be aware of the power they have to determine whose voice is heard. Dyson and Genishi (1994) explained that the very stories we tell, how we tell them, and what we include, are "evidence of cultural membership" (p. 4). Teaching and learning with bilingual students is dependent on being aware of the context - and whose cultural membership matters. This means being conscious of the context for learning of students, teachers, schools, families, and communities, including their cultures and languages.

The final concept Nieto (2002) used to explain Sociocultural theory is community. Bilingual students and teachers teach and learn in community. The community that affects academic success can be the school, the classroom, or even peer groups. For example, when bilingual students are tracked into remedial classes, they can be isolated from a community of peers who are on track to go to college and may not have teachers, counselors, or mentors that make sure they get the right credits, take entrance exams, fill out applications, and apply for financial scholarship opportunities. Valenzuela's (1999) work with high school students demonstrated that the communities they were a part of gave them the strength and resilience to keep going in school. One student recounted how his schedule was done incorrectly and he had taken two classes he 
did not need. He would have to take classes in the summer to be able to graduate on time, and he had just found out on accident by going to see his school counselor, "Pisses me off! How can I even think about going to college when getting out of high school is such a pain in the ass! What if I wouldn't have gone to see my counselor?" His group of friends helps each other out in these circumstances and their interdependence "strengthens the bonds between the friends and reinforces their individual and group commitment to academic achievement" (Valenzuela, 1999, p. 158). They have extended their community to bolster their success. When Valenzuela asked them to describe the "best" kind teacher or counselor, they explained,

... one who "helps you to be a better person book-wise and social-wise," "looks for ways to help and praise you, even if you think you don't deserve it," "connects with you rather than talking down to you," and "loves Mexicans and the Spanish language that we speak." (p. 157)

Their desire for being connected and cared for was at the core of what they needed from teachers, and from each other, which is at the heart of community.

Instead of viewing education in a traditional sense, of individual learners, a sociocultural perspective views teaching and learning in context and with community. It is essential to take into consideration the sociocultural and sociopolitical perspectives because they create the community of learners. Nieto (2002) explained how using a sociocultural frame to look at teaching and learning with bilingual students makes a difference:

Sociocultural and sociopolitical perspectives have been especially consequential because they have shattered the perception that teaching and learning are neutral processes uncontaminated by the idiosyncrasies of particular context. Whether to what extent teachers realize the influence social and political context have on learning can alter how they perceive their students and, consequently, what and how they teach them. (p. 15) 
How teachers perceive their students can affect their community of learners, their context, their identity development, and subsequent agency and experiences in school. A sociocultural perspective on teaching and learning with bilingual teachers and students looks back at the sociopolitical and sociohistorical context, to create a more complex understanding of what is happening in schools today.

\section{Latinx Critical Race Theory compliments Sociocultural theory. A}

sociocultural perspective on teaching and learning with bilingual and multilingual teachers and students goes more in depth than traditional views, which often focus solely on strategies or curriculum, without cultural, social, and linguistic considerations. However, some say sociocultural contexts make studies too context specific, "limiting the ways in which we can meaningfully speak across contexts" (Perry, 2012, p. 65). While others say sociocultural perspectives in education are too broad and have the potential to water-down educational research, as it leaves out issues of power, identity, and agency (Lewis, Enciso, \& Moje, 2007). Although Nieto's sociocultural perspective on education includes identity and agency, it does not specifically address issues of race and power that impact most bilingual teachers and students in U.S. public schools. This research is concerned with the experiences of bilingual teachers and students, which is inextricably linked to the socially constructed concept of race in the United States. In 2009, over 11 million students spoke another language at home and $94.3 \%$ were racial minorities (did not identify as White). Of those who reported to "speak English with difficulty" $99 \%$ were racial minorities (Motha, 2014, p. 36). Therefore, even though the construct of race as biological has been disproven (Goodman, 2008), many bilingual students in U.S. 
public schools have a racialized school experience school (Pimentel, 2011). Latinx

Critical Race Theory (LatCrit) is used to compliment Sociocultural theory to expose the ways racism, linguicism, and classism intersect to impact teaching and learning with bilingual and multilingual students.

LatCrit comes from Critical Race Theory, which in education counters the dominant ideology, or Whitestream education (Urrieta, 2006), that educational structures and practices are neutral, color blind, and meritocratic. Instead, Critical Race Theory (CRT) asserts that the socially constructed categories of race, racism, and their consequences are real, pervasive, and detrimental. CRT also legitimizes the experiential knowledge of people of color and values their stories (Ladson-Billings, 2009; C. M. Steele, 2009). LatCrit extends the scope of CRT by including, in addition to racism, sexism, and classism, the "other layers of subordination based on immigration status, sexuality, culture, language, phenotype, accent and surname" (Yosso, 2005, p. 72). Sociocultural theory and LatCrit together can equip educators to more accurately and authentically investigate teaching and learning with bilingual students by opening up the educational space to value students and communities of color funds of knowledge (González et al., 2005), acknowledging the systematic ways society and institutions have oppressed and marginalized them. These two theories provide a hope for the future of bilingual bicultural individuals and educational experiences available to them.

\section{Educational Systems Impacting Bilingual Students}

There is a historical and widening achievement gap between bilingual students, classified as ELs, and students who are not considered ELs (generally students who speak 
English at home). Ochoa (2013) described the educational systems impacting bilingual students as "macro- meso- micro- processes that work insidiously to differentially impact students' school-sanctioned human, cultural, and social capital" (p. 25). One way to see the difference in academic achievement is to look at standardized test scores, like those collected by the National Association of Educational Progress at fourth and eighth grades, for math and reading as discussed in Chapter 1 (Figure 1.7). In a year-long ethnography of a high school in California, Ochoa found these standardized test scores were prominently displayed during beginning of the year staff meetings in racial categories. There was not a discussion of why the racial disparities might exist, whether the scores were a valid measure of students' learning, or the implications of using the panethnic categories to describe students' learning. The consequences of continually viewing students' scores by panethnic categories that show Latinx, Black, and Native American students consistently much lower than White students may lead to reifying stereotypes and teachers and staff internalizing unconscious beliefs.

In particular, several studies show that school staff and faculty believe bilingual students have lower academic abilities than language majority students, and disproportionately place them into lower ability groups and academic classes (Christian, 2006; Gándara, Rumberger, Maxwell-Jolly, \& Callahan, 2003). In many cases, the label LEP equated "Limited Intelligence" in schools (Callahan, 2005). Noguera (2008) found that across the nation, Black, Latinx, and Native Americans were negatively and disproportionately affected by low academic tracking, unusually high numbers placed in Special Education, harsh school discipline policies, focus on direct instruction directly 
tied to high-stakes standardized testing, less access to school counselors, and low expectations from teachers and administrators. Darling-Hammond (2010) would agree, calling attention to the dire conditions and segregation many bilingual students were found in, calling it the ELL Ghetto. The following sections review recent research on some of these factors; tracking, segregation, subtractive schooling, and cultural and linguistic representation. After a discussion of these topics, a review of what is currently understood to be what teachers need to know to successfully teach emerging bilingual and bilingual students, and how bilingual teachers may be part of the transformation that needs to happen in education today.

Tracking and segregation. In the United States, the ability to speak what is considered Standard English is often misunderstood as the ability to think, learn, and be successful academically (Motha, 2014). According to the American Heritage Dictionary (2015), Standard English is,

The variety of English that is generally acknowledged as the model for the speech and writing of educated speakers, especially when contrasted with speech varieties that are limited to or characteristic of a certain region or social group.

As the language "of educated speakers," it is also the written and oral English that is acceptable in schools (Wiley \& Lukes, 2014). However, the legitimacy of Standard English is contested by many as racist and classist, because it often serves as a gatekeeper to exclude students that are not from White, middle to upper-class, educated families (N. Flores \& Rosa, 2015). Consequently, many teachers unconsciously hold lower academic expectations of bilingual and multilingual students. Unable to see their strengths, teachers instead focus on what they perceive their bilingual students cannot do (Escamilla, 2006). In this way, ESOL classes and lower tracked classes can have the effect of racial and 
linguistic segregation. In an ethnographic study in a middle school, Haneda (2008) found that teachers' perceptions of students influenced the opportunities for bilingual learners.

Adolescent ELLs, who are routinely placed in low-track mainstream classes, are fed a steady diet of undemanding tasks, which severely compromises their opportunities to learn English as well as the grade-appropriate subject matter. (p. 59)

This study's findings echo a long history of segregation and tracking in public schools in the United States.

Historically, tracking and segregation by intelligence tests were a commonplace. In the documentary, As American as Public School (Mondale, 2001), Latinx brothers Julian and Henry Nava remarked on this process as students in Los Angeles Unified School District during the 1940s when it was common for Mexican American boys to be put into classes for manual labor and Mexican American girls were taught to domestic jobs like cooking and cleaning (Ballón, 2015). The older brother, Henry, remembered taking the IQ tests that placed him into a vocational track and away from college.

We were held back. Not because someone hated us, but because the teachers accepted who we were on the basis of our family and heritage and kind of assumed that we would repeat the pattern of our parents. And so, they were helping us get ready for the future.

Their teachers were helping maintaining status quo. After high school, Henry joined the Navy during World War II. After realizing the severe casualties coming back from the Pacific were soldiers that had less education, he took leave to go home and make sure his brother, Julian, had a different chance. Henry took Julian to his school counselor and in his Navy uniform, demanded Julian be put in college preparatory classes, forever changing the course of his life. Instead of becoming a mechanic or joining the Navy, as his schooling was preparing him for, Julian Nava earned a doctoral degree from Harvard. 
He returned to California and was elected to the Los Angeles school board where he helped end IQ testing and racial tracking. He was later appointed to U.S. Ambassador to Mexico. By coming home and changing Julian's track in school, his life trajectory changed, and he in turn changed the community around him. This legacy of racial and linguistic tracking has had a lasting effect on the education of bilingual students.

Gándara and Orfield's (2010) research demonstrates how Black and Brown students are more segregated now than they were 50 years ago before the Brown vs. Board of education decision. Gándara's (2010) research on Latinx students finds they are currently triply segregated, through race/ethnicity, poverty, and language, all three negatively impacting students' academic success. In another article, Gándara and Orfield characterized it as a "return to the Mexican Room" (p. 9), a reference to the sanctioned racial and linguistic segregation and denial of an equitable education before Mendez v. Westchester in 1947. In fact, the U.S. Department of Education found linguistic segregation to be so detrimental that it listed ending it as one of their top recommendations for all school in order to improve outcomes for Emergent Bilinguals (Lhamon \& Gupta, 2015). In a study on segregation in schools, Orfield and Frankenberg (2014) found that in the United States,

Mexican Americans account for about two thirds of the Latino enrollment in the United States, and they have experienced the most dramatic increases in segregation. More than $43 \%$ of all Latinos in the United States are in $90 \%$ to $100 \%$ minority schools in 2011, a 20 percentage point increase since 1968. (p. 730)

This is particularly concerning because students that attended these highly segregated schools are more likely to dropout, do not do as well in college, and are more likely to 
stay in racially segregated work and living environments as adults, as reported by

Gándara and Orfield. They found,

The schools that serve linguistically isolated Latino students also tend to be much weaker in their ability to deliver a quality education than other schools. They are more likely to be in urban centers, with larger enrollments, larger class sizes, have higher incidences of student poverty and health problems, tardiness, and difficulty filling teacher vacancies. They are also more likely to rely on unqualified teachers and have lower levels of parent involvement. As the concentration of ELL students increases in schools, the percentage of fully credentialed teachers, qualified to serve them, decreases. (p. 8)

When educators can take a step back and look at the larger picture, it becomes clear that bilingual students are at a clear disadvantage at schools in the United States in comparison to White, monolingual English-speaking students. Racial, linguistic, and economic segregation has come back with a vengeance for bilingual students, limiting their educational opportunities (Anderson, 2015; Gándara, 2010; Kozol, Tatum, Eaton, \& Gándara, 2010; Noguera, 2008; Roda \& Wells, 2013; Urrieta, 2006).

Subtractive educational practices. In addition to the negative aspects of ability tracking and racial and linguistic segregation, many emerging bilingual and multilingual students also experience what Valenzuela (1999) termed subtractive schooling. In her three-year ethnographic research following emerging bilingual students, she found that, "Students' cultural identities are derogated and diminished" (p. 173). A few ways this happens is through viewing students' language as a deficit, changing students' names, and the absence and misrepresentation of Mexican and Mexican-Americans in the curriculum. Valenzuela observed students referred to as LEP, a category that she asserted automatically posits them as humans that are less than. Macedo and Bartolomé (2014) put it this way, 
The reason that even committed educators have failed to understand the linguistic drama that helps shape the cultural identities of most linguistic minority students is they naively treat language as if it were disarticulated from those cultural signposts which are integral for identity formation. (p. 32)

D. M. Steele and Vargas (2013) agreed, their research on identity safe classrooms show that students who feel their identity is affirmed and connected to their learning are more academically successful.

Valenzuela (1999) poignantly related how the students in her research viewed as having a deficit, instead of as students coming with a language, and adding English to what they already knew. She also described how students' names were changed to sound like English, one of the many ways they learned their families' language culture, and ways of knowing were unimportant, invalid, meaningless at school. In fact, when Valenzuela looked at the curriculum, she found only master script versions of Mexicans or Mexican-Americans. There were no examples of models to whom these emerging bilinguals could look up to; models that looked like them or had similar heritage and experience. This absence of Mexican/ Mexican American figures is an example of what is referred to as the hidden curriculum. Some argue that this absence of positive examples of Latinx historical figures, authors, and voices is detrimental to students' identity development, and especially developing a positive school identity.

Subtractive educational policies occur throughout the K-12 system and these have impacted the experiences and identity development of bilingual students beyond the school settings. Lucas (2011) described how policy changes have slowly created an educational system in which English has become the only language that matters in school. One effect of the monolingual English ideology that contributes to a subtractive 
education is that the home language is often not passed on from parents to children, which can have devastating effects on families and identity development (Sánchez \& Machado-Casas, 2016; Wong-Fillmore, 1991).

Cultural and linguistic representation. Many bi/multilingual students do not see themselves represented in schools, which is vital in forming a positive personal and school identity (D. M. Steele \& Cohn-Vargas, 2013). There is a critical shortage of people of color in school curriculum, picture books, teachers, administrators, etc. According to the Cooperative Children's Book Center (2015), the annual publication of books by and about people of color and First Nations has remained about the same for the last 20 years, in 2015 only $5.27 \%$ of books featured people of color as main characters. The diversity gap in literature, including textbooks and other curriculum, is especially problematic for bilingual students. Not being able to see oneself represented in books or curriculum, as characters, authors, or people in history, alienates students from belonging in school (O. García et al., 2017).

Delpit (1988) explained that who students see and read about in school teaches them the "culture of power," that is, who wields the power in the classroom and in society. Further, Delpit stated "Those with power are frequently least aware of — or least willing to acknowledge - its existence. Those with less power are often most aware of its existence" (p. 296). This contributes to an educational cycle that re-oppresses those who are disadvantaged and marginalized. Hornberger (2007) agreed, "These multilingual learners deserve our continual reimagining and opening up of educational spaces that foster their ongoing development and creative transformation of their transnational—and 
biliterate-lives and literacies" (p. 333). Students' languages and cultures need to be represented, not only in the curriculum, including texts, pictures, historical figures, and currents role models, but also by the teachers.

Unfortunately, instead of schools being a place where bilingual and multilingual students' identities are affirmed as they are educated as whole humans, Cummins et al. (2005) argued that schools are operating under these instructional assumptions:

- Students' home language (L1) is at best irrelevant, and at worst an impediment, to literacy development and academic success;

- The cultural knowledge and L1 linguistic abilities that ELL students bring to school have little instructional relevance;

- Instruction to develop English literacy should focus only on English literacy;

- Students can learn only what has been explicitly taught;

- Culturally and linguistically diverse parents, whose English may be quite limited, do not have the language skills to contribute to their children's literacy development. (p. 4)

When bilingual students are learning in environments that are operating under these principles, it is no wonder why the achievement gap exists. Instead, Cummins et al. asserted that connecting with bilingual students' cultural knowledge and linguistic abilities is essential and bilingual students will "engage academically to the extent that instruction affirms their identities and enables them to invest their identities in learning" (p. 3). The next section addresses different ways these principles are enacted, and the experience and knowledge teachers need to effectively teach bilingual and multilingual students.

\section{Teachers of bilingual students need specific experiences and knowledge.}

There is evidence to support that teachers are more effective when they have in-service or 
preservice education about, and experience with, teaching and learning with bilingual students (Bunch, 2013; Master, Loeb, Whitney, \& Wyckoff, 2016; Musanti, 2014). This makes sense; that with experience and knowledge teachers would be more effective with bilingual learners. However, most teachers are not bilingual and their teacher preparation programs historically have not included how to provide high-level content instruction, while scaffolding for language acquisition (Lucas et al., 2008). Waxman, Téllez, and Walberg $(2004$, p. 1) found that more than half of public school teachers in the United States have emerging bilingual students in their classes, but less than $20 \%$ are certified to teach ESOL. The majority of teachers and administrators are not prepared to teach bilingual and multilingual students or to work with culturally and linguistically diverse communities. Also, teachers that are not prepared or do not have much experiences with bilingual learners, are more likely to hold deficit views about the academic abilities and potential of bilingual students according to Lucas et al. (2015). This includes teachers and administrators that do not have much experience learning a second language, ESOL education, or specific experiences with bilingual students.

Additionally, schools with high percentages of bilingual students are also more likely to have new teachers and high numbers of teachers without licenses, as they "face more difficulties filling teaching vacancies and are more likely to rely on unqualified and substitute teachers than schools with few or no LEP children" (Cosentino de Cohen \& Clewell, 2007, p. 4). So, what does the research say about what they should know? There is considerable agreement in theory and research about what all teachers of emerging bilingual students should know. 
As Calderón et al. (2011) asserted, the quality of instruction is what matters most in educating ELs, although "effective instruction is nested in effective school structures" (p. 118). Teaching and learning with bilingual students takes a complex set of competencies. In a current review of research, Faltis (2013) found that the literature on teacher preparation of bilingual students to be nested under three main categories: language, teaching, and advocacy, shown in Figure 2.3..
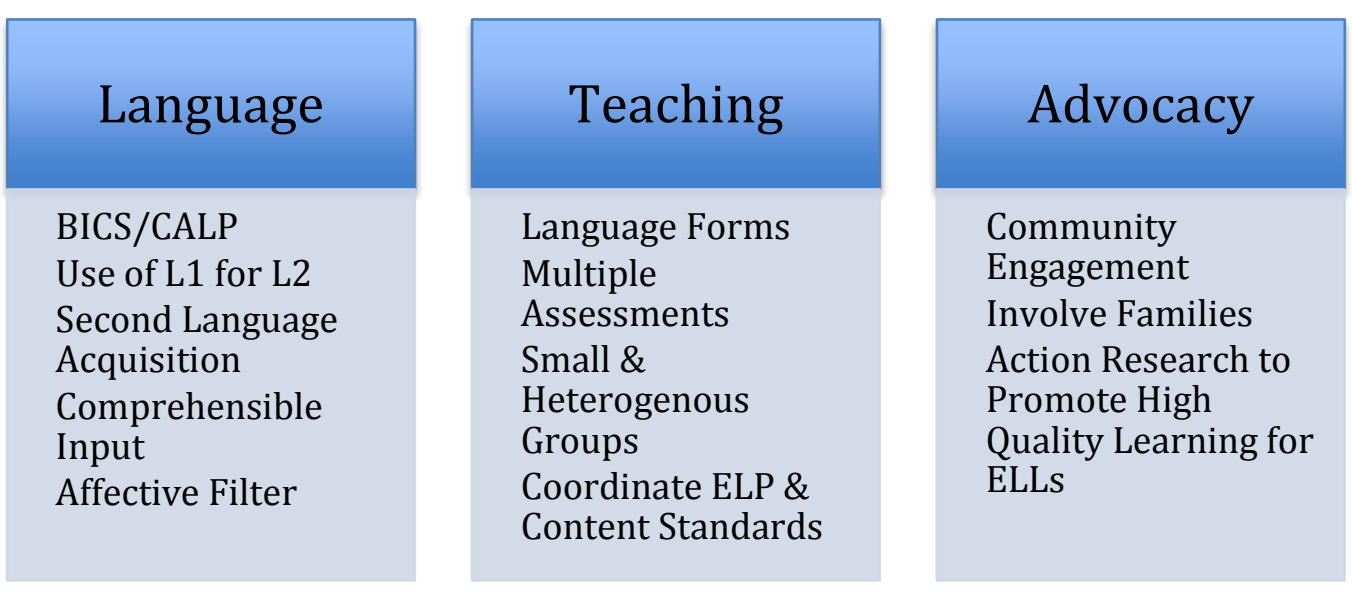

Figure 2.3. Competencies, skills, and knowledge required of a well-prepared teacher of bilingual students.

Linguistically, teachers need a general understanding of second language acquisition, including the difference between interpersonal communication and academic communication, how a student's home language (or first language, L1) can support learning their second language (L2), the affective filter, and comprehensible input (Cummins, 2008; Krashen, 1982; Krashen \& McField, 2005; Orosco \& O’Connor, 2014; Wong-Fillmore \& Snow, 2000). For teaching to be effective, teachers need to know how to combine learning English with content, including explicitly teaching language forms in context, how to foster language use in the classroom through small and heterogeneous 
groups, and how to assess students in multiple ways (Echevarria, Vogt, \& Short, 2002;

Pappamihiel, 2007; Téllez \& Mosqueda, 2015). Last, in an educational system that uses a deficit lens, teachers need to know how to advocate for high-quality professional development and learning through group study and teacher study, as well as engaging with the community and students' families (Faltis, Arias, \& Ramírez-Marín, 2010; Ochoa, 2007).

The teacher competencies, skills, and knowledge outlined in Figure 2.3 are the principal goals of most educational programs to prepare teachers to teach ESOL. However, some warn that this can lead to overly focusing on strategies. When schools focus on strategies and curriculum without these considerations, bilingual and multilingual students and their families can often be re-marginalized and blamed for their low achievement on standardized tests (Gándara \& Contreras, 2009). Molle (2013) found this happened during a teachers' professional development class aimed at increasing teachers' competencies with ELs. While they discussed a learning situation with ELs, the teachers' conversation digressed into blaming the students while they reinforced the work they had done. Molle's analysis showed that the,

... dominant deficit views of language minority students are perpetuated not through any malicious intent on the part of the educators but through reinforced discursive norms that privilege technical approaches to professional learning and preclude political, ideological, and ethical discussions of the ways in which we think about students. (p. 118)

Teaching ESOL strategies is a good start, but many argue that it is not enough. Cummins et al. (2005) made a case for identity texts to draw bilingual and multilingual students into teaching and learning, so they can see themselves, their language, and culture in school. Nieto (2000) contended teachers must be critically reflective of themselves and 
their reality and get to know that of their students, while they form authentic relationships. Lucas and Grinberg (2008) made the case that all teachers of bilingual learners need to be multilingual, at least learning other languages can help them understand what their students are going through. De Jong (2014) contended that all teachers need to understand and facilitate multilingual classrooms. Together, effective teachers of bilingual and multilingual students should have the combination of skills to know how to use strategies to scaffold instruction for bilingual and multilingual learners, the linguistic understanding that comes from becoming bilingual or multilingual and be able to practice critical caring and reflection.

\section{Bilingual Education and Bilingual Teachers}

Despite the evidence to the contrary, many schools and districts are still under the impression that the sooner students learn English, the sooner they will meet benchmarks on standardized tests. However, as López, Harvey, and Chesnut (2013) concluded after a recent review of the research on Latino ELs, "not only are these beliefs misplaced, but they reinforce a subtle, but powerful, form of benevolent racism: where 'good intentions' and compassionate altruism reproduce and reify a highly racialized discourse surrounding language, culture, and broader notions of citizenship" (p. 278). In fact, the English-only policies in states like Arizona, California, and Massachusetts, have been shown to limit the academic achievement of bilingual students (E. García, Lawton, \& Diniz de Figueiredo, 2011; McField, 2014). On the other hand, the benefits of quality bilingual education are now understood to be not only academic, but are also seen in health, social, 
and economic areas of bilingual students' lives (Moore, Fee, Ee, Wiley, \& Arias, 2014; Umansky et al., 2016).

While English-only policies fail, bilingual education has been shown to be one of the most successful ways to achieve long-term academic achievement on standardized tests in English (Thomas \& Collier, 2002). In addition, Genesee, Lindholm-Leary, Saunders, and Christian (2006) supported this point in the following:

There is strong convergent evidence that the educational success of ELLs is positively related to sustained instruction through the student's first language ... most long-term studies report that the longer the students stayed in the program, the more positive were the outcomes. (p. 201)

Bilingual education naturally dismantles many of the barriers to an equal education for bilingual students and families by elevating the status of bilingual students' home language, providing bilingual teachers and leaders as role models and advocates, creating access to and involvement of students' families and communities, and in many places, it reduces or eliminates harmful racial and linguistic segregation as monolingual parents and families have to apply for the limited spots available to be a part of a dual-language or bilingual program. Admittedly, not all bilingual programs accomplish these outcomes. N. Flores (2016) warned against what he calls "hegemonic Whiteness" in bilingual education, in which bilingual education becomes a way to further privilege and norm “standard English" and White middle-class ways of knowing and being. O. García et al. (2017) would agree, while bi/multilingual education is a must; it should also challenge traditional power structures and embed the goal of social transformation. There is an urgent need for more bilingual and bicultural teachers, in order to start, continue, and 
expand the bilingual programs that are essential to serve bilingual students, which also benefit all students.

Several studies show bilingual teachers that speak the same language as their bilingual students, and teachers with bilingual certificates, are more effective in narrowing the achievement gap for bilingual students (Boyd, Grossman, Lankford, Loeb, \& Wyckoff, 2009; Loeb, Soland, \& Fox, 2014; Master et al., 2016). Bilingual teachers provide cultural and linguistic role models for bilingual students (Ocasio, 2014; Wiemelt \& Welton, 2015). Salinas and Castro (2010) found that their participants, Latinx preservice teachers, "had personal experiences with discrimination or economic oppression that allowed them to recognize stereotypical and deficit thinking, as well as structural inequities that reproduce the marginalization of particular groups" (p. 448). These life experiences also translate to empathy and ways to connect with bilingual students. A research study exploring the perspectives of native and non-native English speaking teachers identified that what they called Non-Native English Speaking Teachers as being able to "strengthen the school curriculum by bringing to the classroom their 'cultural awareness,' involving, but not limited to, an understanding of two or more cultures, multicultural experiences, and a broad worldview" (Kamhi-Stein, Aagard, Ching, Paik, \& Sasser, 2004, p. 92).

In addition to being empathetic, according to Valencia (2002), teachers with similar cultural and linguistic backgrounds may identify with bilingual students of the same heritage, serve as positive role models, and be less likely to hold deficit mindsets about the academic abilities of bilingual students. Valencia, suggested Chicana/o, and 
more broadly Latina/o, teachers offer the prospect of improving the education of all students through multicultural and Culturally Responsive Teaching. Bilingual and bicultural teachers have been shown to be able to engage the families of their students and advocate for the inclusion of their funds of knowledge in curriculum, instruction, and programs (González et al., 2005; Morillo-Campbell \& Arias, 2008). Similarly, other studies suggest when students have at least one racially matched teacher, they are more academically successful (Dee, 2004; Zirkel, 2002). Wiemelt and Welton (2015) added to the conversation a need for bilingual and bicultural educators in leadership as well:

In order to move away from subtractive forms of schooling and to foster more culturally and linguistically responsive school opportunities for EBLS (Emergent Bilingual Latin@ Students), leadership at the school level is essential ..... we argue that social justice leadership should be contextualized in bilingual settings for EBLS and highlight the culturally and linguistically empowering approaches of bilingual principals of color. (p. 83).

Their research identified three ways that bilingual leaders created a positive environment for bilingual students; they fostered dual language programs, enacted transcaring practices, and demonstrated instructional bilingual leadership for their staff (Wiemelt \& Welton, 2015). This concept of transcaring, builds from Noddings' (2012) concept of the ethics of care, which places caring and relationships at the center of teaching and learning. O. García, Woodley, Flores, and Chu (2012) also identified transcaring practices in a study of high schools in New York, where Latino Emergent Bilingual youth were academically successful. Four main strategies for transcaring are described below:

These schools helped emergent bilingual youth negotiate rigid borders of languages, cultures, and ways of learning and performing, in order to expand their abilities and gain greater understandings. The four transcaring strategies that we have identified are:

1. Translanguaging and bilingualism in education; 
2. Transculturación in culturally transforming pedagogy;

3. Transcollaboration and compadrazgo among all communities of learning;

4. Transactions through dynamic assessments.

Rather than moving these students toward English only or working to maintain the Spanish of their home countries, these schools used practices that allowed Latino students to "language" fluidly, using their entire emergent bilingual repertoire to learn. (p. 808)

As the number of bilingual and bicultural students continue to rise, U.S. public schools are in need of transcaring practices that come alongside students and their families, to foster success in schools. Bilingual and bicultural classroom teachers, specialists, administrators, policymakers, and educational leaders are uniquely positioned to create culturally and linguistically empowering educational environments.

The need for bilingual and bicultural teachers continues to grow, yet, there is a nationwide shortage (Mitchell, 2018). In one case study, Amos (2013) worked with Latina preservice teachers to identify issues that made it difficult to complete. Some of the issues they identified were that: their teacher education program replicated racialized low expectations experienced in their K-12 experiences, they were led by White faculty, surrounded by white students, and use unexamined dominant discourse and curriculum. Irizarry (2011) found similar results with Latina/o preservice teachers; they faced many of the same barriers as K-12 education: stringent policies that did not reflect an understanding of the lives and experiences of Latina/o students, absence of linguistic and cultural diversity in the curriculum and faculty, silencing in classrooms by students and by faculty, and an emphasis on standardized tests. Although these barriers persist, bilingual teachers desire to be the role models that bilingual students need. Fitts and 
Weisman (2010) found that the "contributions of role models, personal relationships, and caring" (p. 380) was central to bilingual teacher candidates' school success, as well as to their growth as educators and advocates for immigrant children and families. They went on to explain, "Part of the sense of urgency preservice teachers felt with regards to the need to work with immigrant children came from instances of discrimination, oppression, and aversive racism that they themselves had experienced or witnessed in public school classrooms" (p. 385). Determined to work against marginalization, oppression, and racism in schools, many bilingual teachers have turned their experience and knowledge into action, and a desire to prevent future students from negative schooling experiences.

Bilingual teachers in schools with large numbers of bilingual students are likely to teach in school that are large, urban, hard-to-staff, and also have significantly higher "incidence of poverty and health problems" (Cosentino de Cohen \& Clewell, 2007, p. 2) compared to schools with a few or no bilingual students. Yet, even as bilingual teachers serve in the schools with the least amount of resources and lower salaries, they need to be exceptionally skilled. They need to know and understand language policy, as their day to day decisions regarding bilingual students can enact or counter macro-level language policies (Varghese \& Stritikus, 2005). Yturriago and Gil-Garcia (2010) found bilingual teachers also needed to:

. . be knowledgeable of the obstacles they face in schools and school districts: A lack of knowledge on the part of staff regarding educating ELLs, possible racism, misunderstandings about the appropriate use of native language instruction, and an understanding of how belief systems are developed and changed. (p. 13)

Bilingual teachers must be highly qualified with specialized skills, knowledge, and experiences and persist through the many known and still unknown K-12 and university 
barriers. How can schools do a better job graduating highly educated bilingual students to become transformational bilingual teachers for social justice?

Listening to the experiences of bilingual teachers is a valuable way to inform other teacher education programs in order to identify ways in which they can improve their programs to be more culturally responsive and be a supportive environment for future bilingual teachers. Irizarry (2011), working with Latina/o preservice teachers, explained it this way:

The everyday challenges that preservice teachers of color at PWIs [Predominantly White Institutions] encounter are unfamiliar to many, in part because the voices of students of color are often rendered mute, especially in regard to issues of racialized discrimination ... Conversely, amplifying the voices of students of color affirms their experiential knowledge and provides important perspectives that need to be considered. (p. 2816)

While this quote refers to preservice teachers of color, this also applies to bilingual teachers, especially those who, at one time, were classified as ELs themselves. There is a strong rationale for listening to the voices we have not heard. The experiences of bilingual teachers, their schooling as ELs, and also as students in an education program are all valuable perspectives that can inform educational programs to identify ways to become be more culturally responsive. Thus, there is a strong rationale for listening to the voices we have not heard. One way to do this is through qualitative research.

\section{Qualitative Methods and the Power of Telling Stories}

Humans have been telling stories to relate information since the beginning of history. Qualitative research methods are consistent with research from sociocultural and critical perspectives because they lend themselves to gathering information from many perspectives, situations, and artifacts. Participants share their narratives, experiences, and 
ways of understanding with the researchers and together they may develop a deeper understanding of a concept (Glesne, 2016). Stories are what tie us together. They are the intersection of culture and language, with the powerful ability to connect people from all different backgrounds (Coles, 1989).

Interviews are a common form of gathering rich information when the aim of a study is to better understand a phenomena (Vogt, Gardner, \& Haeffele, 2012). These structured conversations are organized around a research question and allow the researchers to be responsive and respectful of the participants (Rubin \& Rubin, 2012). They are ideal for going in-depth into personal histories and experiences as this study does.

\section{Conclusion}

This literature review shows that:

1. Schools need to improve the educational experiences of ELs (work to eliminate tracking, racial/linguistic segregation, subtractive language policies and to increase cultural/linguistic representation in staff and curriculum), additionally;

2. Teachers of ELs needs specific experiences and knowledge, in particular;

3. Bilingual teachers and teachers from bilingual students' communities can be more effective at reducing the achievement gap between ELs and non-ELs;

4. Qualitative research is an effective way to gather insights about the educational experiences of former ELs and how those experiences may inform them as beginning bilingual teachers.

Although there is a lot of research on strategies and policies having to do with bilingual learners, the perspectives of those bilingual students and teachers are largely absent. Gay (2015) reported, "very few prospective teachers of color are being studied" (p. 437).

Therefore, is it important to see how bilingual and bicultural teachers teach bilingual 
learners, and to explore how their experiences as ELs in school may have influenced them. This study aims to amplify the voices of these bilingual teachers. Schools, administrators, and policy makers must understand the experiences of bilingual students to make the necessary changes to improve the educational outcomes of bilingual students. As former ELs, these bilingual teachers are uniquely positioned to inform the educational community. Their experiences were collected through a variety of qualitative methods, which are further explained in the next chapter. 


\section{Chapter 3 Methodology}

This chapter reviews the research problem and presents the purpose of this qualitative research study. The research questions and methods for data collection are explained along with the researcher's role. This chapter also explains how the participants were selected, how they were interviewed, and the other ways data were collected and analyzed. This chapter closes with a summary.

\section{Research Problem}

There is a historic, persistent, and widening achievement gap between bilingual students and the majority English-speaking population in U.S. K-12 public schools (Calderón et al., 2011; Gándara, 2010; Master et al., 2016; Polat et al., 2016). Current research shows one effective way to close this gap is through different forms of bilingual education (Cosentino de Cohen \& Clewell, 2007; Faltis et al., 2010; Macedo \& Bartolomé, 2014; Orosco \& O’Connor, 2014; Thomas \& Collier, 2002; Varghese \& Stritikus, 2005; Yosso, 2005). Even though bilingual education has been shown to benefit all students (Hakuta, 2011), it is limited by policy (Gándara et al., 2003; Villegas \& Lucas, 2011), knowledgeable leaders (Menken \& Solorza, 2015; Scanlan \& Lopez, 2012; Wiemelt \& Welton, 2015), and most important, qualified bilingual and bicultural teachers knowledgeable about their community of learners (Gándara et al., 2003; Irizarry, 2011). This research study focuses on the experiences of these uniquely qualified bilingual and bicultural teachers, who were also formerly classified as ELs in U.S. public schools. 
The purpose of this research study was to explore the experiences of these current bilingual and learner bicultural teachers who were formerly classified as ELs, in order better understand the way they teach and learn with bilingual learners. The following research questions guided this study's inquiry.

1. How do the bilingual teachers in this case study describe their schooling experiences (up to and including their teacher education program)?

2. How do these bilingual teachers describe their current daily teaching and learning experiences with bilingual learners?

3. How do these bilingual teachers make sense of their experiences as ELs and as bilingual teachers?

These questions were explored through interviews and observations. As Krathwohl (2009) explained, "qualitative researchers often gather data by interview; interviews and observations interact—observations provide meanings to the interviews, and interviews suggest things to look at or attach new meanings to the observations" (p. 296). The next section explains my positionality as a researcher.

Role of the researcher. According to Glesne (2016), researchers must look within as they look out. As a bilingual learner, I hold a great deal of empathy with language learners. As a bilingual teacher, I recognize the difficulties in finding quality and culturally responsive curriculum and the myriad of ways language learning intersects with all other aspects of planning, teaching, and assessing learning in the classroom. As a teacher educator, I spend a lot of time with individuals who are just beginning to learn about teaching, as well as my role in observing student teachers putting into practice what they have learned. Understanding these multiple views, I find myself viewing these bilingual teachers with even more admiration. 
As a beginning researcher, I understand that my experiences influence my approach, but that research needs to be conducted in a systematic and logical format. I found the work of coding and organizing the data to be invigorating and at times overwhelming. Seidman (2013) reminded us that, "The researcher must come to the transcripts with an open attitude, seeking what emerges as important and of interest from the text" (p. 119). However, as humans with personal experiences, we are not blank slates. As I conducted the interviews, several times I became aware that I was listening to my participants' stories and categorizing them with concepts from the research on teaching and learning with bilingual students. When this happened during the interviews, I told the participants in an effort to be as honest and forthcoming as possible. It was important to me that I be as transparent during the interviews with the participants as I would be later, while analyzing the transcripts, trying to "come to the transcript prepared to let the interview breathe and speak for itself" (Seidman, 2013, p. 120).

Seidman (2013) explained how his experiences and ways of looking at the world influence how one may hear the stories of their interviewees. Like Seidman, there are particular details and experiences that speak to me as I engaged in conversations about education with my participants. I am alert to social structures that tend to privilege based on language, accent, perceived race, gender, and class. I am also aware that I pay attention to: how we talk about students and teachers in school, linguistic choices regarding students' assets and deficits, experiences of inclusion and exclusion, successes and failures, language and culture, and ways people indicate valuing or devaluing English and Spanish. I did not enter the interviews or transcripts looking for these things. 
However, when they came up or I noticed myself paying attention to them, I noted them and disclosed this to the participant.

\section{Research Design}

This qualitative research study explores the experiences of bilingual teachers, who were formerly classified as ELs in U.S. K-12 public schools, through in-depth interviews, classroom observations, and artifacts from their educational experiences. Glesne (2016) described qualitative research as descriptive, "with the research goal of interpreting the social world from the perspectives of those who are actors in that world" (p. 9). Creswell (2009) explained qualitative research as "a means for exploring and understanding the meaning individuals or groups ascribe to a social or human problem” (p. 4). Both definitions describe the nuances of this research study, to amplify the voices of bilingual students and bilingual teachers, a group seldom heard by educational leaders and policy makers. As Quiroz (2001) explained in her study, “. . . voice is not synonymous with empowerment nor is language synonymous with voice. Rather, language is merely the tool through which voice is expressed. For voice to be empowering, it must be heard, not simply spoken" (p. 328). This study aims to make the voices of the participants heard.

Qualitative research study. This qualitative research study was designed to gain an in-depth understanding of three Bilingual Teachers who experienced learning English during school in the United States. According to Merriam (1998), a qualitative research study is descriptive, particularistic, and heuristic. In other words, it aims to create a thick description of a phenomenon, focused on a particular situation or group, and seeks to gain insights about how a situation evolved. Merriam and Tisdell (2016) called this 
methodology a basic qualitative research study, which is characterized by the intent to understand, "(1) how people interpret their experiences, (2) how they construct their worlds, and (3) what meaning they attribute to their experiences" (p. 24). A qualitative research study may have aspects of other types of qualitative research, such as narrative inquiry or case study, but is not defined by or limited to those methodologies. It does include these characteristics of qualitative research, as identified by Creswell (2007): conducted in a natural setting, uses multiple sources of data, including the researcher, data analysis is done inductively, focuses on participants' meanings, has an emergent design that can change, uses a theoretical lens, is interpretive, and intends to create a holistic account (pp. 37-39). This qualitative research study is bound by participants' characteristics (current bilingual teachers, ESOL endorsed, former EL students, graduates of the same university), location (urban area, Pacific Northwest), and time (teaching in spring 2017). I used a variety of data collection methods, such as in-depth interviews, classroom observations, and artifacts from their teacher education program.

The primary source of data however, was in-depth interviews. The research questions are process focused, as opposed to variance-oriented questions which compare two groups. These process questions aim to explore the experiences of the participants in order to better understand the phenomena of being educated as ELLs in U.S. public schools, becoming bilingual teachers, and how participants make meaning of that. Process-oriented questions call for qualitative research studies (Maxwell, 2013). In particular, interviews are essential when seeking knowledge that requires:

- in-depth answers;

- learning in detail about a smaller group; 
- participants to have time to reflect and seek clarification before answering; and,

- probes difficult or sensitive matters of meaning and belief (Vogt et al., 2012).

The benefit of this in-depth interview approach is the ability to spend time with participants to be able to develop a thick description of their experiences (Glesne, 2016). This research study follows Seidman's (2013, p. 16) protocol of three, 90-minute interviews, each about a week apart. Each interview had a distinct focus, in order to get a deeper understanding of these bilingual teachers' schooling experiences, past and present. The three focused interviews were: (a) focused life history, (b) details of experience, and (c) reflection on the meaning. The focused life history interview explored the schooling and life experiences of the participants from childhood until becoming teachers. The second interview concentrated on participants' current experiences in school as bilingual teachers. During the third interview, participants were asked to think about the significance of their experiences and their current views on being bilingual educators from their positions. The three interviews build on each other and progressed into more detail with a specific focus.

Recruitment procedures. The research questions for this study explored the past and current experiences of these bilingual teachers who were formerly classified as ELLs in K-12 public schools. Because of the narrow aim of the study, participants must be both bilingual teachers and former ELLs. A random sampling would not yield participants with these qualifications; therefore, non-probability purposive sampling was employed (Krathwohl, 2009). By using purposive sampling, I was able to investigate the specific experiences of bilingual teachers. The benefit of purposive sampling is the ability to 
study a sampling of specific characteristics in-depth. However, the downside as some contend, is that there is not strong external generalizability (Krathwohl, 2009). This study employs both a very small sample and very specialized population.

In order to find qualified participants, I contacted graduates from 2012 to 2016, from a bilingual teacher education program at a large, public university in the Pacific Northwest. This university has the only education program specifically designed for bilingual individuals to obtain their teaching license and become ESOL endorsed within a 2-year program. The reason for the limitation on graduates from 2012-2016 is because the emphasis of the program changed after 2010 to include a focused approach to culturally responsive practices in curriculum and pedagogy. This study focuses on bilingual teachers that experienced the program with a focus on culturally responsive practices.

The research study began with an email to potential participants introducing myself and explaining the goals and methods of the study. The email explained that the research study was voluntary and there were no consequences for choosing not to participate. The email asked for volunteer participants who were:

- currently teaching in K-12 public schools;

- former ELLs in U.S. K-12 public schools;

- have bilingual students (ELs) in their current classes;

- hold a state-issued current license and an ESOL endorsement.

The email also included the informed consent form. The email asked interested recipients to read the informed consent and reply to the email if they were interested in 
participating. As I received emails, I evaluated the responses for the qualifications previously described. I received three responses that met the requirements above.

\section{Participants}

This study invited three graduates of a bilingual teacher preparation program from a large public university in the northwest United States to participate. I emailed the bilingual teachers that volunteered to be a part of the research and scheduled the first interview. During that email I also sent the Informed Consent (Appendix A) and the Demographic Survey (Appendix C), which were reviewed and collected at the first interview. After the first interview, we scheduled the second interview and an observation at their convenience. The third interview continued in the same way, at their convenience.

The participants teach in elementary schools in three districts in Oregon. All three participants teach in bilingual classrooms and the majority of their students speak Spanish at home and qualify as ELs. The districts are different in size and geography: large urban, small rural, and medium suburban. The urban and suburban districts are demographically similar, with approximately 30\% Ever ELs (term now used in Oregon to describe all students who have ever qualified as ELs), 90\% White teachers, 6\% Latinx teachers, and 37\% Latinx students. The small rural district is geographically in between these larger population areas, in a rural, smaller district. There are over $80 \%$ Latinx students and $20 \%$ Latinx teachers. However, in all three participants' classes, their students are almost 100\% Latinx and Ever ELs (representing all the students that have ever been in a program to support their English learning). Table 3.1 shows the district demographics of each district. 
Table 3.1

Comparison of Participants' District Demographics

\begin{tabular}{|l|c|c|c|}
\hline & Cristina & Cynthia & Hugo \\
\hline & Large Urban & Small Rural & $\begin{array}{c}\text { Medium } \\
\text { Suburban }\end{array}$ \\
\hline District Population & 40,000 & 6,000 & 20,000 \\
\hline Languages & 57 & 12 & 87 \\
\hline Ever ELs & $35 \%$ & $70 \%$ & $30 \%$ \\
\hline Students With Disabilities & $18 \%$ & $12 \%$ & $15 \%$ \\
\hline Economically Disadvantaged & $70 \%$ & $>95 \%$ & $58 \%$ \\
\hline White Teachers & $90 \%$ & $75 \%$ & $87 \%$ \\
\hline White Students & $50 \%$ & $17 \%$ & $45 \%$ \\
\hline Latinx Teachers & $6 \%$ & $20 \%$ & $7 \%$ \\
\hline Latinx Students & $40 \%$ & $82 \%$ & $35 \%$ \\
\hline $\begin{array}{l}\text { Ever ELs } \\
\text { Graduation Rate }\end{array}$ & $66 \%$ & $81 \%$ & $70 \%$ \\
\hline
\end{tabular}

Participant details. Cristina grew up in Oregon and Mexico. She has two older sisters. When she was a child, they spoke Spanish at home. She attended school in Mexico for Kindergarten through second grade and learned English when they moved to Oregon. She is now a bilingual second-year teacher in a K-5 elementary school with a school population of approximately 450 students. According to the state report card for her school, 54\% of students are Ever ELs, eight different languages are spoken, and the whole school receives free breakfast and lunch. This school is situated in a large urban district where approximately $40 \%$ students are identified as Latinx and $6 \%$ of teachers are identified as Latinx. Cristina has a teaching license with an ESOL, Bilingual, and Multiple Subjects Elementary endorsements. 
Cynthia grew up in California, Oregon, and Mexico with two older sisters and multiple cousins. Right before kindergarten, she moved from Mexico to California. She is a bilingual third-year teacher in a K-5 elementary school with a population of approximately 900 students. According to the state report card, $70 \%$ of students are Ever ELs, 8 different languages are spoken, and the whole school receives free breakfast and lunch. This school is situated in a small rural district where approximately $80 \%$ students are identified as Latinx and 20\% of teachers are identified as Latinx. Cynthia has a transitional teaching license and has completed requirements for the ESOL endorsement. Hugo is also the youngest sibling in his family and has five older sisters. He moved back and forth between Guatemala and California various times while attending school. He started elementary school in Guatemala City, Guatemala and moved to Los Angeles, California in second grade to learn English and attend school with his cousins. Later, he moved to Sacramento, California to live with his sister, where he completed fourth grade through high school. He is now a bilingual third-year teacher in a K-6 elementary school with a population of approximately 230 students. According to the state report card, 79\% of the school's students are Ever ELs, eight different languages are spoken, and the whole school receives free breakfast and lunch. This school is situated in a medium suburban district where approximately $35 \%$ students are identified as Latinx and $7 \%$ of teachers are identified as Latinx. Hugo has a teaching license with an ESOL and Multiple Subjects Elementary endorsements. 


\section{Data Collection}

Instruments and measures. The instruments to collect data were three interview transcripts from each participant, field notes, classroom observation recordings, pictures, and notes. These data sources were intentionally identified when collected. Then when the data were analyzed and stored it was coded-confidential, meaning names were redacted and replaced with initials. It was stored in a locked office. The coded transcripts were kept on a restricted computer with password protection. Ultimately, the results are reported with first names. A more in-depth description of the analysis which resulted in the theme and subtheme findings is presented in the following chapter.

Interviews and observation process. Once informed consent was discussed and collected, I conducted the first interview. The individual interviews were planned to be approximately 60-90 minutes, at one to two week intervals throughout the spring, and include one classroom observation. This schedule was followed for Hugo and Cristina; however, Cynthia's interviews were more spread out because of unavoidable schedule changes at her school. Her first and second interviews were a little over five weeks apart. Because there was an observation in between Cynthia's first and second interviews, the continuity of conversations was maintained. Her interviews also ran longer, at 80, 150, and 100 minutes, respectively. The third interview followed two weeks later, in her home. All other interviews were conducted in the participants classrooms.

According to Seidman (2013), the 90-minute interview structure allows for enough time to go in depth into the experiences of the participants, while also setting a reasonable limit so that it does not feel overwhelming or endless for participants. At the 
first interview, I collected the informed consent and demographic survey. During this interview, we discussed the demographic survey and went in-depth into the participants' K-16 schooling experiences following the semi-structured interview protocol: Focused Life History (Appendix D).

The second interview and classroom observation were scheduled about a week later, to give the participants time to reflect and consider the experiences they have shared. The interview followed the second semi-structured interview protocol: Focus on Concrete Participant Experience (Appendix E). The first classroom observation took place before the second interview, so we spent the beginning of the interview talking about their day, their students, and getting their perspective on what I had seen. I spent about half a day in each classroom, giving me insight into how participants approached teaching different subject matters, transitions, and different parts of the day. The observation was planned before the second interview, so they could use the observation as a point of reference as they described their current practice teaching and learning with bilingual students. During that interview, the participants were asked in-depth questions about their daily life as a bilingual teacher. The observations resulted in giving a deeper context to our conversations, so when possible, I returned to observe in the classrooms before the final interviews. One to two weeks later, I returned to Hugo and Cristina's classrooms to observe and conduct the third interview, which followed the protocol: Reflection on the Meaning (Appendix F). The third interview asked participants to make sense of their experiences, making connections from their experiences as bilingual students and as bilingual teachers. While I was in all three classrooms, with the 
participants' permission, I took pictures of anchor charts, student work, books, curriculum, and planning documents as artifacts to refer back to in my analysis.

At this point, I thanked the participants for their participation, their time, their willingness to share their stories, and for me to be able to come and be a part of their classroom. All three participants invited me back to their classrooms. The next fall, I returned to visit Hugo and Cristina's classrooms. I was able to see them with new students, beginning a new year, and starting again. Cynthia was on leave for the fall, so I was unable to visit her class again.

All the interviews were recorded and transcribed and sent to each participant for member checking. I also used an electronic notebook to audio record and take field notes during the observations and interviews. I emailed each participant individually to make sure their experiences were represented and understood as they intended. The goal of this data collection process was to capture a range of experiences, development, and learning from the participants' perspectives as students and teachers. This adds to a more holistic profile of participants and provides triangulation in order to better understand their experiences as students, bilingual teachers, and how they make meaning from that. Table 3.2 demonstrates the timeline of interviews and observations for all three participants.

Data security. Participants' privacy is protected through the use of first names only, for all data collection, analysis, and findings, as the participants requested. They were given the opportunity to choose a pseudonym but declined. Because they graduated from a large institution, and the years they graduated are not mentioned, their identity is reasonably protected. Any artifacts that could be traced back to participants or 
participants' specific schools were redacted. All interviews were conducted at participants' choice of time and location. They also had the opportunity to withdraw at any time.

Table 3.2

Timeline of Interviews and Classroom Observations by Participant

\begin{tabular}{|c|c|c|c|c|c|}
\hline \multicolumn{2}{|l|}{ Hugo } & \multicolumn{2}{|l|}{ Cristina } & \multicolumn{2}{|l|}{ Cynthia } \\
\hline $5 / 15 / 17$ & $\begin{array}{l}\text { Interview \#1 } \\
\text { (80 min.) }\end{array}$ & $5 / 17 / 17$ & $\begin{array}{l}\text { Interview \#1 } \\
\text { (85 min.) }\end{array}$ & $5 / 19 / 17$ & $\begin{array}{l}\text { Interview \#1 } \\
\text { (80 min.) }\end{array}$ \\
\hline $5 / 22 / 17$ & Observation \#1 & $5 / 24 / 17$ & Observation \#1 & $5 / 26 / 17$ & Observation \#1 \\
\hline $5 / 22 / 17$ & $\begin{array}{l}\text { Interview \#2 } \\
\text { (80 min.) }\end{array}$ & $5 / 24 / 17$ & $\begin{array}{l}\text { Interview \#2 } \\
\text { (90 min.) }\end{array}$ & $6 / 27 / 17$ & $\begin{array}{l}\text { Interview \#2 } \\
\text { (150 min.) }\end{array}$ \\
\hline $6 / 5 / 17$ & Observation \#2 & $5 / 31 / 17$ & Observation \#2 & $7 / 11 / 17$ & $\begin{array}{l}\text { Interview \#3 } \\
\text { (100 min.) }\end{array}$ \\
\hline $6 / 5 / 17$ & $\begin{array}{l}\text { Interview \#3 } \\
\text { (105 min.) }\end{array}$ & $5 / 31 / 17$ & $\begin{array}{l}\text { Interview \#3 (97 } \\
\text { min.) }\end{array}$ & & \\
\hline $9 / 27 / 17$ & Observation \#3 & $9 / 22 / 17$ & Observation \#3 & & \\
\hline
\end{tabular}

Coding and data analysis. The nine interviews resulted in over 500 pages of transcripts, 100 pages of electronic field notes, photos, and classroom recordings. After listening to each interview while reading the transcripts to verify and edit them line by line, I imported them into the electronic qualitative research tool, NVivo, to help organize the data and facilitate the coding process. I followed Saldaña's (2013) suggestions to assign attribute codes to the interviews and observations according to the participant and the specific data set, such as the first, second, and third interviews, observations, and artifacts (p. 69). Then, I coded all nine interviews in NVivo using a combination of coding styles recommended by Saldaña for the first cycle: Initial, Descriptive, In Vivo, 
and Values Coding. As I listened and read through the transcripts the first time, I tried to come to it with an open mind, creating descriptive categories for each response of the participants. Seidman encouraged the researcher to "err on the side of inclusion" (p. 121). The first cycle resulted in approximately 90 codes.

For the second cycle of coding, I returned to the research questions and looked at the data through the lens of those three questions. I considered what stood out in regards to their schooling, teaching, and how they put it together. Seidman (2013) suggested reducing the transcripts down to a very concentrated form, by eliminating all the parts that do not contribute to that narrative (p. 120). I began doing this, but found that process unsettling, unsure that I was keeping or eliminating "the right" parts. I went back to the transcripts and interview recordings and began open coding again, using many of the original nodes and the three research questions as my guide. Then I used Focus Coding, to categorize and find themes from the coded data (Saldaña, 2013).

Under the overarching themes of schooling, teaching, and putting it together, I coded the transcripts again, starting with the codes from the first cycle of coding. The data from the theme of schooling resulted in approximately 20 codes. The data from the second theme of teaching resulted in 40 codes. The third theme, putting it together, resulted in about 20 codes. Some codes from the first cycle were combined and others were eliminated. I analyzed the codes, looking for instances of thick data from all three participants, or codes that could be collapsed so that all participants were represented. Table 3.3 shows the thematic topics with subthemes. 
Table 3.3

Main Themes and Subthemes From the Analysis

\begin{tabular}{|c|c|c|}
\hline $\begin{array}{c}\text { Theme } 1 \\
\text { Becoming Bilingual }\end{array}$ & $\begin{array}{c}\text { Theme } 2 \\
\text { Becoming Teachers }\end{array}$ & $\begin{array}{c}\text { Theme } 3 \\
\text { "It's complicated" }\end{array}$ \\
\hline $\begin{array}{l}\text { Keeping Spanish and } \\
\text { Learning English }\end{array}$ & $\begin{array}{l}\text { Developing Into } \\
\text { Teachers }\end{array}$ & $\begin{array}{l}>\text { "Te desinfla, te saca el } \\
\text { aire" }\end{array}$ \\
\hline $\begin{array}{l}\text { Tracking and Escaping } \\
\text { the ESL Ghetto }\end{array}$ & $\begin{array}{l}\text { Culturally Responsive } \\
\text { Teaching }\end{array}$ & $\begin{array}{l}>\text { Pass it on! } \\
>\quad \text { "I love being a } \\
\text { bilingual!" }\end{array}$ \\
\hline
\end{tabular}

\section{Potential Benefits}

The teaching community is striving to improve the education for linguistically and culturally diverse P-12 students. The participants' stories offer important insights into the sociocultural experiences of bilingual students in U.S. schools, their path through higher education, and their development as bilingual teachers. These insights can be applied to teacher education programs and P-12 education. The benefits have the potential to be applied in multiple teacher preparation programs and P-12 public schools, by offering insight and support for future bilingual/ESOL teachers and administrators. Therefore, the benefits outweigh the minimal risks of possible discomfort among participants.

\section{Conclusion}

The research questions in my study were designed to explore, in-depth, the lived experiences of bilingual teachers, as students and as teachers. This qualitative research study has the potential to inform educational practices and teacher education programs. The need for more bilingual teachers is clear, but how do have more bilingual teachers if 
our educational pipeline continues to "leak" bilingual students? The stories and insights from the participants in this study echo the research covered in the literature review in Chapter 2 in many ways. Their circumstances growing up and their approach to teaching and learning with bilingual students also have surprising nuances, similarities, and differences, which are discussed in the next chapter. 


\section{Chapter 4 Results}

The purpose of this research study is to explore the experiences of current bilingual and bicultural teachers, who learned English in school, in order better understand the way they teach and learn with emerging bilingual learners. This qualitative study explores the experiences of three bilingual teachers through interviews and classroom observations. The research questions are:

1. How do the bilingual teachers in this case study describe their schooling experiences (up to and including their teacher education program)?

2. How do these bilingual teachers describe their current daily teaching and learning experiences with bilingual learners?

3. How do these bilingual teachers make sense of their experiences as ELs and as bilingual teachers?

This chapter begins with a review of the participants and data collected in order to answer the research questions. Then I discuss the themes and subthemes that emerged from the study. Finally, this chapter concludes with a brief discussion of the interpretation of the findings.

\section{Participants}

This qualitative study sought participants with specific characteristics: The participants are currently licensed, bilingual, public elementary school teachers in the Pacific Northwest and have been teaching less than five years. They attended the same bilingual teacher preparation program, which has a social justice focus and includes an ESOL endorsement. When the participants began elementary school in the United States, 
they were ELs. They spoke Spanish at home and learned English in school. The criteria are displayed in Table 4.1 .

Table 4.1

Criteria for Participation

\begin{tabular}{|c|c|}
\hline Criteria for Participation \\
\hline$>$ Learned English in U.S. PK-12 schools \\
$>$ Currently an Elementary Bilingual Teacher \\
$>$ Currently teaching students who are Emerging Bilinguals \\
$>$ Has been teaching 0-5 years \\
$>$ Attended Bilingual Teacher Preparation program \\
$>$ ESOL endorsed, licensed teacher
\end{tabular}

\section{Presentation of Results}

Three main themes emerged from the data, corresponding to the research questions. The first theme is Becoming Bilingual, which has two subthemes: 1.1 Keeping Spanish and Learning English, and 1.2 Tracking and Escaping the ESL Ghetto. The second broad theme that emerged was Becoming a Teacher. This theme has two subthemes: 2.1 Developing Into Teachers, and 2.2 Culturally Responsive Teaching. The third theme is an In Vivo code, “It's complicated." That theme has three subthemes, 3.1 “Te desinfla, te saca el aire," 3.2 Pass it on!, and 3.3 "I love being a bilingual!" (In Vivo codes are in quotations.) The themes and subthemes are presented in Table 4.2. 
Table 4.2

Results of the Study: Main Themes and Subthemes

\begin{tabular}{|c|}
\hline Becoming Bilingual \\
\hline$>$ Keeping Spanish and Learning English \\
\hline$>$ Tracking and Escaping the ESL Ghetto \\
\hline Becoming a Teacher \\
\hline$>$ Culturally Responsive Teaching \\
\hline$>$ Developing Into Teachers \\
\hline "It's complicated" \\
\hline$>$ "Te desinfla, te saca el aire" \\
\hline$>$ Pass It On! \\
\hline$>$ "I love being a bilingual!" \\
\hline
\end{tabular}

Theme 1: Becoming Bilingual. Becoming bilingual in school in the United States is a complicated cultural and linguistic process. A common myth in second language acquisition is it is easier for children to learn languages (Brown, 2007). In fact, children contend with social, emotional, and cognitive demands like adults, but without the benefit understanding how grammar works in their first language. Additionally, they are learning math, science, social studies, and language arts with monolingual Englishspeaking peers. When children are submerged in English all day for school or day care, they can lose their family language before it is mastered, this is called subtractive bilingualism (Lightbown \& Spada, 2000). This process can devastate familial relationships and diminish resources for navigating educational and life decisions (Valenzuela, 1999; Wong-Fillmore \& Snow, 2000). Many of these students miss out on key content while they are learning English and struggle to catch up to their monolingual 
English-speaking peers. All this occurs while students are also developing an academic identity — one that may impact their future learning and career choices for a lifetime (Zirkel, 2002). However, there are success stories. It is not common or easy, but these participants offer hope and insight into this process. The participants in this study reflect on becoming bilingual: learning English, keeping Spanish, and their development as learners.

Keeping Spanish and Learning English. The participants in this study all had transnational experiences as they learned English and Spanish. Cristina and Cynthia were born in the United States and moved to Mexico with their parents and sisters when they were just a few years old. They both moved back to the United States in early elementary school. They remember speaking Spanish at home and not understanding English at school. They also both had older sisters. Hugo was born in Guatemala and moved by himself to Los Angeles in second grade, to join his aunt, uncle, and cousins. He remembers speaking Spanish at home with family and learning English at school. His cousins also helped him learn English. Cristina went to school in Mexico; Hugo went to school in Guatemala. They both describe schooling in Mexico and Guatemala as rigorous. They believe what they learned in Mexico and Guatemala helped them academically once they came to the United States, because the subject matter was more advanced than what students in the same grade were doing in United States. These early experiences with schooling and language seem to contribute to the participants' positive feelings on becoming bilingual and their identity development as learners. 
Each family had their own "language policy" of sorts that participants describe as contributing to them becoming bilingual. Cristina's dad moved the family to Mexico, so that Cristina and her sisters would attend school there, ensuring they would know Spanish. She has fond memories of school in Mexico. There was no playground equipment and they did not have many books. The building was concrete and her teacher was strict, but she loved her.

I remember my teacher's name. Her name was Maria. I remember she was really strict and really firm and she would carry a ruler. Not that she would hit us with it, but she would just carry it with her the whole time, and she looked big and strong. I saw her when I went back and she is tiny and small ... She was a really good teacher. She taught me how to read and write in Spanish. She taught me math. I remember knowing how to multiply when I was in first grade . . . That is how good she was. I had her for both kinder and first grade. (CA.I.1)

Cristina also described her mom's influence during their time in Mexico, "She was strict with school, more than my dad. She only did kinder and first, but she is really, really smart. She knows how to read and write, [and do] basic math" (CA.I.6). She also made sure her daughters kept learning during the summers.

[School in Mexico] was fun. I remember, even though we didn't get home until 6:00, I remember having dinner, and then right after that is, was playtime . . . A common myth in second language acquisition is it is easier for children to learn languages (Brown, 2007). Every summer, my mom would buy books for us, workbooks. It wasn't like books, books, but she was really strict on our handwriting. She wanted it . . . to be perfect, even though it is kind of messy now. My mom said, "You have to practice, practice, practice!" (CA.I.6)

She remembers her mom's positive influence on her and her sisters, even though she herself had not had the opportunity to go to school past first grade.

Like Cristina, Cynthia and her sisters were born in the United States, but because their mom was bilingual, and wanted that for her daughters, they also moved to Mexico as small children. She wanted her girls to know Mexico and speak Spanish. She 
remembers her dad enforcing the family language policy when they returned to the United States. She laughed as she recalled:

My dad said that as soon as we walked home, it was Mexico. I was not allowed to speak English at home. He would ignore us, even though he understood what we were saying. He said, "No, you speak Spanish here, or you don't speak." He is an interesting dude, my dad. He used to sit us in front of the TV and say, "If it looks like they are going to score a goal, call me." Then he would go to the other TV and watch the other game. (CM.I.29)

Maintaining Spanish while learning English in school took many forms for all three participants.

Hugo was able to learn English and keep Spanish in a different way than Cristina and Cynthia. He did not have the benefit, and perhaps comfort, of moving with his family. Instead, like many youths today, he went alone to the United States. He described it like this:

When I was 7, my parents sent me to LA to live with my aunt and uncle. I just remember I knew no English. It was a big shock to me ... especially because I didn't have my family. I was here without my parents and my siblings. I was an ESL student in a public school in LA for two years. After that, my sister who lived in Sacramento (she is about 14 years older than me and was a newlywed) came to visit me and saw that I was having a hard time and missed my family. I was kind of miserable. She asked my parents if I could go live with her while I finished school. I was here on a student visa. So, I went with her to Sacramento ... I did the end of fourth grade there. (HJ.I.1-2)

The first few years, he spoke Spanish with his aunt and uncle, while his cousins helped him learn English. Later, he continued to speak Spanish at home with his sister and remembers his mom sending him comics and newspaper clippings in Spanish from Guatemala. In all cases, the participants reported their parents' decisions about moving between countries and their valuing bilingualism as important aspects of them learning English and keeping Spanish. 
Although these participants learned English, kept Spanish, and became bilingual teachers, remembering what it was like for them to enter school in the United States is an important part of their story. In all cases, the participants reported entering school speaking Spanish and not understanding English. That was hard for all of them and they reacted in different ways and they draw upon those experiences now to relate to their bilingual students and families.

Cristina. Cristina was shy and quiet. She did not understand what was going on and felt totally lost as she started second grade in English. She could not understand her teacher or her classmates. There was one other student that spoke Spanish and she was her lifeline to understanding what was going on. However, that student used her power to control Cristina. This is how she described that experience in second grade:

[That student] spoke both languages, and the teacher would tell her to tell me something, so she would translate everything and then she would translate back. It was just back and forth, back and forth. But she was naughty with me sometimes. She was really mean. She said, "If you don't do this, when you are outside, I won't help you. I won't do this for you." I was always depressed. I was always unhappy because I felt she always threatened me. If I didn't do this, if I didn't do that, she wouldn't help me out. How do you tell the teacher that she doesn't want to help you? She is forcing you to do things that you don't want to do . . . How do you not? She was the only one there that could help me. (CA.I.12)

It was a difficult and painful time. Thankfully, the following year they changed the program model and all the Emerging Bilingual students were sent to the same elementary school with teachers that at least understood Spanish. She smiled as she expressed relief as described the new school:

Almost the whole class were ELL's, so I felt I had friends in there. [The teacher] was really sweet ... I remember getting pulled out a lot. I felt safe. I was in a circle with a bunch of people that were like me. I felt safe. I kept being pulled through my elementary school. It felt good. (CA.I.14) 
Cynthia. Like Cristina, Cynthia described her first memories of school in the United States as "harsh.” But unlike Cristina, who was quiet and shy, Cynthia acted out. She did not know what was going on and did not get any help learning English. She felt like she was bullied for not speaking English and in return, became a bully to other students as a defense mechanism. She described it this way:

I had directly come from Mexico . . . in September. At that point, I knew some English, but not much . . . I was thrown into this kindergarten classroom of 40 kids . . . I had no clue what was going on. Behavior-wise, I was awful. I remember, awful, because I didn't even care! [I thought], "Who knows what this lady is saying!" That was really my attitude about it. I didn't care. I didn't want to be there, and just behavior-wise, awful. Some of the kids did speak Spanish, but it wasn't their first language. That was really hard . . . they didn't have ESOL, anything, there. I was just thrown in there, with no support at all . . I cried and I cried that I really didn't want to be there! I hated that school. I think it was that support that I was missing. Also, there was a lot of bullying in that school, because I didn't speak English coming in, and it just followed me. I am also not like a victim kind of person, so I would just push back. There, again, that behavior, I feel like it really came from not understanding what was going on in class. (CM.I.1)

She described that her behavior finally changed in about fourth or fifth grade, when her academic English caught up.

Hugo. Hugo, like Cristina, was also initially pulled out of class for English

support. He felt, like her, that is was a positive experience:

I remember that I got pulled out of class. I think it was good. My affective filter wasn't up. I remember I wasn't dreading that time. I [thought], "Oh, now is the time when I go with this teacher.” It was one-on-one. I don't think they had a lot of ESL students at that school, because I remember it was one-on-one, just me and the teacher, and then I would come back.

That was the only time of the day he understood. The rest of the day, Hugo remembers struggling to understand what the teacher and students were saying. In a sink or swim model, he watched other students intensely, as he tried to pick up what was expected of 
him. He remembers one day, when the teacher was going from student to student, asking students to read two, three, and four digit numbers. As the teacher neared him, he watched as another boy pointed to a 4 of 4,000. He knew the word "four," and heard him say "thousand" next. A lightbulb went on in his head—-he knew 1,000 in Spanish was "mil”! "Mil is a thousand!" As the teacher neared him, he was able to grasp enough from students around him to pass the assessment. He smiled remembering that moment, "Math is where I shined" (HJ.I.21).

In all their accounts, these moments of struggle and triumph still stand out to them today and influence their teaching and learning with bilingual students.

Tracking and Escaping the ESL Ghetto. Students learning English at school and that speak Spanish at home are sometimes tracked into lower-level classes, which Valdés (2001) originally termed the ESL ghetto (referenced in Chapter 2 as the ELL ghetto, an updated term by Darling-Hammond [2010]) . A common experience in the ESL ghetto is for teachers or counselors to tell high school students they are not college material, not ready for AP classes, and have a much lower graduation and rate of participation in college. One participant described a teacher that stood out to her, did not have preconceived ideas of what she was like, thought she was "super-smart." When I asked her why the other teachers would have preconceived ideas of her intelligence her response was simple, “I was Mexican. There weren't many Mexican kids in there.” That reality of a lesser than status and the experience of emerging out of that track forms the basis of this subtheme. During interviews with these participants, it became clear that their transition out of the ESL ghetto was memorable. 
All three participants describe moments when they noticed a shift in their academic setting. Cristina remembered actively working hard to test out of English Language Development (ELD) in sixth grade, which had become a negative environment for her. It was also around sixth grade for Cynthia and Hugo, though for different reasons. Cynthia lobbied hard to get her parents to let her change schools. Once she was in a new setting, it was not long before she was bored in math and consequently moved into all Talented and Gifted (TAG) classes. What Hugo remembered was the shift to advanced classes as well, as he described in the comment below.

I do remember in middle school I was in an advanced English class. Then in high school, I think my English language, English, I don't know, they were a little more advanced in math. Those were the two areas where I was in advanced classes . . . . and that gave me a sense of pride. I don't remember how I got there. I think when I started choosing my classes, my advisor or counselor said these are your choices. That may be another reason why I was successful, that I wasn't tracked down and kept from doing something that I maybe had every potential of doing. (HJ.I.32-34)

This shift to advanced classes gave him a sense of success and he was able to use and be recognized for his talents.

Cynthia also remembered when she shifted to advanced classes and witnessed the tracking that her friends experienced. She described this change below:

When I got into the TAG group it was a world of difference. I got to do all kinds of things, including going to college when I was in 8th grade. Since I was in the TAG group, they gave us this test and I placed in the 97th or 98th percentile for logic, and I was able to attend college. That was fun. I went to a critical thinking class about news and print ... We went to mock trial, just all kinds of stuff that I would have never gotten the opportunity to do. CM.1.29

Some of those opportunities extended themselves to access to important adults like teachers and principals. They were able to engage in their education in creative ways, while enjoying freedom: 
I had a lot of freedom as a TAG student, a lot of freedom. In projects and stuff, they would be, "Oh, you are the TAG kids, you can do whatever you want." My friend and I started a project where we had some kids who were visually impaired, and we would come at lunch and read the textbooks aloud and record them. Then they would take home the tapes. Just all kinds of stuff that we were able to do because of being in the TAG group. They invited me to the aviation group, to learn how to fly a plane, but my mom said girls don't do that, so I didn't do that. [Laughter]. We knew the principal really well, and not because we were in trouble. It was because we were part of the TAG kids. I was able to do band. Most of the kids weren't able to participate, and I played the flute . . .

She went on to list the AP classes she took in high school, which were all the AP classes offered. She commented, "Yeah, I did all the AP classes, because that is just where my friends were" (CM.I.31). She was aware of the tracking that was going on in her school, even though she benefitted greatly from it, she was concerned for her friends. She had a neighbor that she saw at school one day, in the office again, and not to work on projects with the principal. She described the distinct groups in the following comment:

I was in the TAG group and they were in the "hopefully they won't go into prison group." It was very obvious, so I did notice that. I was, "[R], why were you in the office?" ... He was, "Yeah, I got in trouble." To see that in our neighbor was really weird to me ... (CM.I.45)

She knew there were different rights and rules for different groups of people but felt more comfortable floating between groups. After she graduated from high school, she tried out different academic settings and carried with her an academic confidence which would eventually lead her to becoming a teacher.

Unlike Cynthia, Cristina quietly worked every step of the way to achieve academically. She still described herself as "slow" and "behind," but her diligence and persistence are what stood out. At a young age, she was forced to get ahead. Her dad changed the dates on her birth certificate when they moved to Mexico, so she was actually always a year ahead for her grade. She started school a full year early and 
remembered being in the "high ESOL" group in fourth grade. In sixth grade, other students did not like how well she did in class and copied her work. This eventually led her to exit ELD. She remembered being miserable, so high that the other students in ELD made fun of her and stole her work, but not high enough to pass the test to exit out of ELD. After struggling for a year, she finally exited. "I set goals for myself and I kept pushing myself," she recalled. It was not long before she was in Advanced Placement classes in high school where she was surprised when she entered, "I was excited, and when I got there, I see White kids. I was, I can't be here. Am I the only one? I was just terrified."

Each of the participants had interesting twists and turns after high school. Hugo did not know what he wanted to do but went to college because that was what he was supposed to do. He did not know what he wanted to study, got terrible grades, then forgot to drop classes and failed them. That's when he decided to go back to Guatemala, be near his family, and attend college:

Then when I went to Guatemala, that's when I started taking it more seriously. Then it was that thing, going back to that thing where I feel like I am good at something. That propelled me to say, 'I'm really going to try, because I feel like I am good at something!' With my peers, I am toward the top of my class, so I felt like, Yes! I need to lead this group! I want to do this! It motivated me to do better. That is so important — and I think that is important for my kids, to feel successful at something.

He was close to finishing his undergraduate degree when the program fell apart. He taught elementary school for a while in Guatemala but did not earn enough to continue. He remembers thinking, "If I was a millionaire, I would be a teacher, because I love doing that. I love being with kids and I love kids ..." He returned to the United States and through a series of educational assistant positions, he heard about a teacher 
preparation program that had a grant to fund scholarships for bilingual individuals to become teachers. The bilingual teacher preparation (BTP) program was a cohort model, for bilingual teaching assistants, with a social justice focus. He remembers feeling like he had found his home when he began the program:

I felt really good, because I was, "These are my people. I feel good with my people." We can talk about cultural things, and they get me, and it is that thing about not belonging . . . I felt I belonged there. That was the place where I belong. (HJ.I.57)

He concluded with, "I wouldn't be where I'm at right now if it wasn't for [that program]."

Cristina and Cynthia had similarly strong responses. Cristina said when she began the BTP program, for the first time she felt, "It's okay to be ELL." Cynthia described how different it was from all her other college experiences:

Then I went to BTP, and I felt like, "Oh, people like this exist in Portland!" They are bilingual and really cool. That was really awesome. I got [my fellow classmate] here, my [teaching] neighbor. I'm just so grateful that she's here and she gets it, and I just felt like I was at home there, especially with BTP . . For the most part, I felt like we were like-minded and very respectful, and just like family. (CM.I.43)

In their accounts of the events surrounding their elementary and secondary schooling in the United States, each participant experienced tracking and discrimination based on language, race, and/or perceived national origin and reacted in different ways. Those experiences led one to glue a bee to a teacher's chair, one to silently suffer through bullying, and one to disengage and opt out of opportunities. Together these results provide important insights into the ways students have and will react to teachers, programs, and institutions that continue to tell them they are "less than."

Theme 2: Becoming Teachers. The data for this theme comes from observations of the participants teaching in their classrooms, field notes, artifacts from their 
classrooms, and the interviews that followed. The participants, on the whole, demonstrated Culturally Responsive Teaching in many ways; it is evident in their whole class teaching, their small group and one-on-one interactions, and in their preparation and selection of material for teaching.

Culturally Responsive Teaching. A primary concern of beginning teachers is how to manage the classroom in a way that is positive, engaging, and encourages students to learn. Culturally responsive classrooms do this in a way that is particularly attuned to students' linguistic and cultural ways of knowing and encourages all learners. "Positive classroom behavior management" emerged as a popular code for all participants. The other codes that were collapsed under the umbrella of Culturally Responsive Teaching were: establishing routines, democratic classroom, connecting with students, authentic caring, integrating language instruction, biliteracy strategies, creating in Spanish, creating material, differentiating instruction, teaching responsive to students' needs, making learning fun, and growth mindset. What became evident during analysis was that the codes such as, Culturally Responsive Teaching and positive classroom behavior management did not exist on its own, several codes overlapped. The data show the participants held a culturally responsive mindset, which guided their planning, instructing, assessing, and interacting with their students and their families. In this section, I describe briefly each participant's classroom from field notes and recordings taken during observations, and some of the ways they exhibit a culturally responsive mindset and teaching. 


\section{Cristina.}

Cristina's second grade classroom buzzes with activity. It's a warm spring morning and she is beginning to teach an ELD Lesson. Students are sitting crosslegged on the carpet around her and she leans over to be close to their eyes and ears and says, "Click your brain to English! Click!" They all respond with a "click" and a hand motion, like turning a knob on the side of their head. She smiles and says, "Good morning class!"

The class responds, "Good morning!"

She begins her lesson by connecting back to the last lesson and asking them to remember what they were learning about. The whole group responds, "Adjectives!"

She continues, "Yes, and we were talking about your teachers. But some students said, 'Teacher, why don't we do Wildcat?' and so today we are going to write about our school mascot, the Wildcat!"

The students erupted in cheers, "Yay!!!"

"So today we are going to be using the ..."

The class finished her sentence, "Wildcat!"

She whispered to them, "Talk to your partner about what kinds of adjectives do you think we could use with Wildcat?"

Students happily start talking to their partners in hushed voices. She waits for them to have time to talk to each other and motions for their attention. They all stop talking and look at her. She switches to Spanish and quietly asks them, "How many students do we have? How many students need a partner?"

She and everyone respond, “¡Todas!” (Everyone!)

She remembers one student left, and said, "So now we'll have a group of three."

She asks the students, reiterating the question and embedding academic language, "What are adjectives to describe the Wildcat?" On the board, there is a graphic organizer they used previously.

A student responds, "The Wildcat is soft and fury."

Ms. Alvarez repeats the student's words as she writes them on the board in one of the circles of the graphic organizer. Another student says, "Teacher, in the middle you forgot to put Wildcat!" 
"Oh, you're right!" she responds gently and authentically appreciating his help and writes Wildcat in the center. Continuing on with the lesson, she reminds them, "I like how Sebastian is waiting patiently ... We are thinking of adjectives. Using the sentence frames that Maria used, what are some adjectives we can use to describe the Wildcat? Nicolas what's another way to describe the Wildcat."

"Mascot."

She writes on the board the sentence frame, "The wildcat is so ." Then she asks the class, "Let's use the word that Nicolas gave us, mascot. The Wildcat is so mascot. Does that make sense?"

"What's a mascot?"

She explains what a mascot is and gets more examples from students. Together they continue to fill out the graphic organizer with adjectives. She adds more sentence frames with differing levels of complexity and continues to ask for students' input.

"I like how Sofía was turning her head when her partner was talking."

"Can you say it with me? The wildcat is (hmmmm)."

She reads each sentence frame and then the whole class reads it together. Then she models using the graphic organizer to fill out each sentence frame, one at a time she reads them and again has them repeat the complete sentences. She explains the three levels of sentence frames they can choose from in terms of salsa, green is sweet, orange is spicy, and red is super spicy!

She finishes the lesson with exit directions. She signals to the board where the exit directions are posted in English and Spanish.

What are we doing? ELD.

What will we need? Our notebooks and pencils!

What level are we going to be at? Zero!

Where are we doing our work? At our desks or on the carpet!

What do we do when we are done? We have to write until we hear the bell.

Students move quickly and quietly to their desks and start writing. When they are finished, she rings the bell and they all come back to the carpet. She models sharing with a partner and then says, "chips and salsa!" The students find their chips and salsa partners and two lines. The chips are facing the wall and salsas 
facing the whiteboard. She says, "Today we are going to put our teeth together and share like this ... Chips go first, go!" Chips start reading their sentences. Then she says, "Say goodbye to your partner and salsa, move to the next person ... This time we will do it like you're chewing gum ... The salsas will start. Share one of your sentences frames with your new partner." As the students finish reading to each other, they give each other high fives and continue on. The teacher announces it is time for lunch and the class all cheers, "Yay!!"

They quickly and quietly put all their material away and line up at the door in less than a minute. She leads them out the door and they quietly follow her to the cafeteria. (Observation, May 24, 2017)

Cristina models Culturally Responsive Teaching practices constantly. Her positive classroom behavior management is based on routines that give students security: they know where to be, what to do, who to work with, and that they will be able to do the work. She fosters students' leadership and makes sure that all students can meaningfully participate. During another observation, one of the students asked Cristina if he could share a quiz he wrote for the class. She said, "Of course, at the end of the day." When the time came, she handed him her lanyard, which has small colored cards behind her id card. He used the cards, and her routines, to silently call students up to the carpet. He led a whole class activity and then dismissed them back to their tables! She displays lesson objectives in student language and when they read the objectives together they start with, "I can ... !" Then, they all collectively jump in the air. After that they read it again, starting with, "You can . . !"” They jump again. Finally, they repeat it starting with, "We can ... !" and a jump and go to their work area. From observations, it was evident that including movement into instruction was a strategy she used often. This is one of many ways she keeps students engaged, paying attention, and moving.

Culturally Responsive Teaching also means authentically caring for students and finding ways to connect with them. The narrative from the ELD lesson shows how she 
heard students' opinion to write about their school's mascot, the wildcat, and

intentionally planned to use that in the next lesson. When she announced that to the class, they erupted in cheers. She shows them how much she cares about them by using their words and listening to what they are interested in. She also greets each student at the door every morning and knows special things to talk about with them. Some like to talk about their pets and others she asks about new baby brothers and sisters. Another way Cristina authentically cares for her students is through relationships with their families and advocating for their success. She described an after-school program she put together to bring in parents of her emerging readers. She created material in Spanish so she could show them ways to interact with and support their students at home. Some of them came every day and brought babies other siblings. Those students became better readers and she made strong relationships with their family members. She described how she wrote a letter for the mother of one student to help her through the process of becoming a citizen. Another student struggles with learning and memory and she described several conversations with his mom about his successes. She revels in those successes and strives to make sure that every student is successful in her class.

\section{Cynthia.}

There is a lot of movement in Cynthia's classroom. Students are standing around open shoe boxes filled with colorful miniature scenes. They are talking, creating, discussing, and finding more material for their dioramas. Their schedule was changed at the last minute, and they just finished an hour of standardized testing on the computers. The phone rings and a student runs to the phone and says, "Ms. Muñoz's room." Then she calls out, "Cynthia, the office needs to talk to you!" The students make additions and talk about their projects. Students tell me their topics as I walk around: Racism, Pandas, World War II, Space, Volcanos, Uranus. Students appear relaxed and calm and Cynthia seems to have a handle on what 
everyone is doing. She is confident she can get them gently to the next step: writing and presenting speeches to the whole group. (Observation, May 26, 2017)

It was an unusual day in this classroom, but toward the end of the year, that seems to happen fairly often. The creative and engaging classroom fosters an environment where students are learning. This diorama project was a way to engage students in something they really wanted to learn more about. She treats her students with respect and believes in a democratic classroom. They have the opportunity to apply for a job in the classroom, through a Google Form. This teaches them about job applications, responsibility, and leadership. Students hold each other accountable. She laughed as she told me about the jobs:

Let's see; I try to do it every year in Spanish. Ingeniero de sacapuntas (Pencil Sharpening Engineer) because I hate kids getting up and sharpening their pencil all the time. We had one person designated to be the Ingeniero de sacapuntas. Ingeniero de electricidad (Electrical Engineer), which is the person that turns on and off the light. Facilitador de tareas (Homework Facilitator), Facilitador de lentes (Glasses Facilitator), which is the - I have a lot of kids who wear glasses that didn't want to wear them, so I started giving points for bringing them in, and then at the end of the day, for actually wearing them all day. The kids were, I don't have glasses. Yeah, you don't have that responsibility, so there you go. What else? Reciclador (Recycler) - because we have to take out our own recycling. Ingeniero de tecnología (Technology Engineer), basically make sure all the computers are plugged in, make them nice and orderly. Distribuidor de papeles (Paper Distributor) (laughter), Bibliotecario (Librarian), I think that is it. I always had two or three people per job, except for Ingeniero de sacapuntas (Pencil Sharpening Engineer), only one person got that. Oh, Recepcionista, they pick up the phone. There is a script, "Maestra Muñoz's class, ¿la necesita?" (Teacher Muñoz's class. Do you need her?) Or "She is teaching right now." (CM.II.29)

Students thrive in this environment where they feel important. The respect she shows for her students extends to their families as well. Her door is always open. Biliteracy and integrating language instruction into daily lessons comes naturally for her. She picks up on words or phrases that her students may not know or may not know how to use 
correctly, and creates fun activities to practice vocabulary, syntax, and discourse in a variety of ways. One example she shared was a website called FLOWcabulary.

Every week they have the Week in Rap. Everything is a rap song. Everything is a rap song, and the kids are really into rap right now ... They loved watching it. I don't think that they ever got to talk about 9-11 before, or current events at all, because it is a scary thing to talk about with kids. But they do a really great job with current events .... I would do this game where I would put the vocabulary word, with a picture, which sometimes can get complicated ... and then we would watch our video, so they knew what the vocabulary is. Their job was to tell me what they thought was interesting from the current events. Then we would watch it again, once we talked about the interesting. Usually it is, "The dog on the skateboard at the end." "That wasn't a story-although I did like the dog on the skateboard, it was cool, but what were some of the stories? What did they talk about?" At the end they get really good at saying, "I really like how they talked about the woman and this and that." Or just snippets - they would say, "I didn't really understand, but they talk about something about iPhones." We would take the vocabulary words and make a rap out of them. They have a tool there where you can make your own rap, and it even has beats. We would choose a beat, and we have some good rappers who have no clue. The wiggliest boys you can think of - great rappers. I couldn't believe it! ... There were people great at rhyming or thinking of ideas. (CM.II.30)

This is just one of many ways she gets her students to engage in language, critical

thinking, and interacting in fun and engaging ways. She specifically described the opportunities and choices she gave one student that she said was constantly in trouble before being in her class. In her mind, he needed options, boundaries, and someone that believed in him. She described it like this:

[Giving him options] was new and different. At first he [would ask], "Why am I in trouble?" I said, "No, no, you are not in trouble. You have to think; do I need to sit in my chair? Or can I sit with everybody else and talk and miss the lesson? It is only going to be 10 to 15 minutes."

"Hmmm, I'll sit with everybody else."

“¿Ya ves por que te digo? ¿Qué ese so?” (See why I tell you-what is this?) But it was just the ADHD out of control. By at the end of the year he would say, "I'm going to sit at my desk." He [didn't want to be in trouble] and he wasn't. [I would 
say,] "No te estoy regañando, estoy preguntando. (I'm not scolding you; I'm asking you.) Look at my face. Do I look angry? No.” (CM.II.56)

She remembers what it was like to be misunderstood, that kid, and makes sure that her students have every opportunity possible to be successful, grow, and make positive choices for themselves.

Hugo.

It's a warm September afternoon in a crowded room of fourth graders. The desks are arranged in table groups of four or five individual desks. There are books in English and Spanish on the desks. One wall is all windows, looking out at a side street. The opposite wall has windows looking into the hallway but they are covered in butcher paper charts from lessons. One is a large green paper, with a table with lists of positive classroom behaviors on top and ways it reduces negative behaviors on the bottom:

"Hey class?” asked Hugo.

"Hey yes!" responded the students and he begins to introduce an ELD lesson. It is September, Hispanic Heritage month. He selected an article off the website newsela.com that discusses the terms Latino/a and Hispanic. His fourth grade students follow along, interested. He begins in front of the class and asks students to read the title of the article with him, "What is the difference between Latino/a and Hispanic?"

He continues, explaining, "In our article we're going to be looking for information that answers that question. The second step, and with the help of our rubric we're going to highlight any information we can find about what is a Latino/a, and what is a Hispanic? Step number two, José, so you tell us what is step number two for those that were not paying attention to me."

José responds, "What is the difference between Latino/a and Hispanic?"

"Exactly! Because that's the question that we're going to answer. It helps us to highlight it in the article. Then we're going to answer that question on Google classroom ... Notice that I ask you the question, you can read it, it says, what is the difference Latino/a and Hispanic? It says, 'Use information from the text to explain the difference between those two words."

"I give you some sentence frames that you can use. I'm going to read them for you. Once you get into your device, you're going to have the sentence frames right in front of you. You only need to pick one ... You can start with an easier 
one, do the first one. If you want more of a challenge, you can maybe do the second one. If you want, if you think you're a Jedi Master, you can try to do the third one. Let me read them all to you, okay?"

He continues to read aloud the sentence frames for the whole class and then checks in with them again to make sure they understand the instructions. Then he wraps up the instructions, "When you are done, if you want to go and read other people's answers, you can make a comment and say, 'Hey, I agree with you,' or 'Oh, tell me more about that.' You can go to see other people's answers . . Any questions before we get started?" He fields a few questions and then students begin reading at their desks. He calls a small group back to a kidney-shaped table in the back corner of the room.

"My reading group, raise your hand if you're in my reading group. Arturo, Diego, Ale, Nicolás, you guys can come to that table and I will be your group. I will read with you and we will work through this together. We'll highlight together; we'll do that together, okay?..."

The chimes of Class Dojo sound as he gives points to students who are starting to read. "Evelia, thanks for getting started, I see that you're already reading. Thank you. Susana. Thank you very much ..." as he walks to the back table. The students he asked to meet him at the back table slowly start making their way back there. Once they are all there, he reviews the instructions again and very intentionally states, "I'm going to read the article. I want you to follow along. When you come across information that says what is a Latino or what is a Hispanic, stop me. Say, 'Stop,' okay? Stop me, and then we're going look at it together, okay? Finger on the title .... We want to highlight the definition, what it means. Follow with me, let's see who's the first one to catch it and stop me. What are we looking for?"

"You're looking for information."

"Information of what is a Hispanic or information on what is a . .?"

"Latino."

"So, follow along and listen to my voice, okay? Listen to what I'm saying and stop me when we come across it." He begins to read, "Hispanic students have mixed feelings about Hispanic Heritage month. Hispanic Heritage Month starts on September 15. Spanish students gather to talk about it. They go to school in East San Jose, California."

“Stop!" says Diego.

"Stop. What did you hear?" 
"They go to the school."

"They go to a specific school. Do we know what it is yet? Have they told us what is a Hispanic or what is a Latino?"

"Yeah. No, no."

"Not yet, right. Let's go to the second paragraph. 'Do you know what Hispanic Heritage Month is,' the students were asked. 'No,' they said. Okay, stop. Did we figure out what is a Hispanic?"

"No."

"Or what is a Latino?"

"No."

"Not yet. Okay, let's keep going. Number three. Hispanic Heritage Month is meant to celebrate Hispanic-Americans."

"Stop."

He continues on with this group, each time they stop him, he responds in the same way, asking if that has the information they need, waiting for them to decide, and then continuing on if it does not. He's interrupted several times, and always gives his full attention to the question and then goes right back to his reading group. A student comes up to him and asks him a question. He asks the student to have Leslie and Evelia come over to him.

They come right over, and he says, "Hi, ladies. You guys are my technology bosses and I apologize if I'm going to interrupt your work, but when people come and need a device, I'm going to send them to you because you guys are the experts on that. Can you make sure you come, you unplug it properly and give them the devices they need? And then go back to work. Thank you, appreciate it."

He looks back at his group, and continues, "Okay, I think you're on the right track there, Arturo. I don't think the sentence explains it yet. Let's keep going, maybe that'll explain it. Arturo, you're on the right track. Everybody should be on paragraph three. We're starting the second sentence where it says September. Finger on September, good. Thank you, Ale." They stop him several more times, finally identifying the information to explain the difference between the terms Latino/a and Hispanic. (Observation, June 5, 2017)

With each interaction, Hugo models respectful and authentic caring relationships.

Throughout this research study, Hugo seemed to highlight love, stability, and long-term 
connections, which guided his teaching practice. He begins each day with a community circle, where he can get a pulse on how things are going in his students' lives. The information he gathers from students during that time guides him the rest of the day. $\mathrm{He}$ uses positive comments, directing attention to students who are on task, to manage offtask behavior and also differentiates, like Cristina and Cynthia do- they all make sure that everyone stayed engaged in learning. The emergent readers are invited to the back table to read with him which not only gives them an opportunity for more connections with him, but allows them to do the same work as the rest of the class, helping maintain a positive classroom.

The learning tasks and material are carefully chosen or created to connect with students and be culturally relevant in Hugo's classroom. The lesson in the narrative above is an example of this - he found an article on the terms Latino/a and Hispanic to read for an ELD lesson, for his students that are almost all Latina/o or Hispanic. He frequently rewrites the paragraphs for the dictation exercises in the district curriculum to include students' names, inside jokes, and situations that would be relevant to his students. The mentor texts he chooses for writing in English and Spanish are Latina/o authors and he has started a collection of books in English and Spanish that are culturally relevant for novel groups as well.

The dialogue in the narrative above is just an excerpt of that conversation and is an example of the patient and tireless way Hugo interacts with students. He fosters students' critical thinking and leadership skills. They talk about high school and college 
graduation; he promises a gift if they invite him. To their shock, he tells them he loves them.

I tell my kids .... "I love you guys." As soon as I do [they started groaning] . . . They weren't used to hearing that from a guy. I talk to them about their future and tell them, 'Invite me to graduation and I will come. I will bring a present when you graduate college! I just love you guys and I want you guys to make good choices.' When I have those conversations with the boys, last year they were very [not so sure] about that. But this year, they say, "Oh, we love you, too."

(HJ.III.10)

His attention to culture, language, and students' families and lives is apparent in every subject and interaction.

All three participants highlight their students' strengths, bring out their liderazgo (leadership), and build on their cultural, linguistic, and familial ways of knowing. They are exemplary culturally responsive teachers, that show how and why having bilingual, bicultural teachers can make such a difference in students' lives and academic futures.

Developing Into Teachers. This subtheme, Developing Into Teachers, came from the first and second interviews with the participants. As I listened to their educational experiences and also their teaching experiences, it seemed important to highlight the ways these participants describe the educational road to becoming a teacher and also how they are continuing to develop. They each shared ideas related to the notion that they were "becoming"- a humble way to expressed that their development as teachers is an ongoing process.

The educational aspirations of K-12 students are often connected to what they eventually attempt, so as educators, we teach students to think of their futures. We hope this encourages aspirations of a successful future, however how "success" is defined within cultural frameworks for individuals. As educators, admittedly, that usually 
includes a strong push for students to graduate high school and go to college. Educators quote research that tells us: school absences are connected to future dropouts, incarceration is related to dropout rates, career opportunities grow with more education, future salaries are related to educational attainment, and happiness is a high salary. In reality it is much more complicated than that. Race, language, and economics open and close doors more often than most people believe (Tatum, 2017). As I listened to the participants describe how they navigated their way through college, graduate school, and experienced becoming teachers I heard stories that are not part of the mainstream narrative and I believe they need to be. In this section, the participants describe how they are developing into bilingual teachers and the ways they are still learning.

Cristina. From a review of the interview transcripts, Cristina described that she worked hard to graduate high school because she wanted to go to college. She explained that classes were hard and she spent a lot of time studying, crying, worrying that she would not make it into college. Her older sisters had done this before her, attending private 4-year colleges in the same state, and this influenced her desire to follow. However, she decided to attend a public university about an hour from home. By the time she started school there, she already wanted to become a teacher. In high school, she took classes that resulted in an internship in a first-grade classroom. She admired the teacher who demonstrated an authentic caring relationship with her students and the participant, as the excerpt below demonstrates.

I fell in love with a first-grade class. The teacher was always involving me with the kids. I remember testing them for their sight words. Every time they would pass a level, they would get a prize from me, so they loved coming to me . . . Then after the whole year, they made me a book. The teacher bought me a shirt, 
and I thought, I want to be a teacher now! During that time, we were going through a lot of difficulty, money-wise. My dad lost his job and everything, and I never told her anything, but I felt like she always kind of knew. She would ask, “QQué tienes m’ija? ¿Todo está bien?” (What’s wrong child? Everything okay?) But I would say, "Todo está bien." (Everything is fine.) Maybe that is the reason I struggled, too, with school. It was hard . . . it was hard. (CA.I.38)

Her desire to become a teacher pushed her to continue. She took several standardized tests and struggled every time. Many people quit after failing these tests, believing it is an indication of their ability to become a teacher. Cristina did not quit, like other times in life, when confronted with difficulties, she persevered and found ways to overcome the barriers.

I wanted to become a teacher when I was at Western, but I couldn't pass the CBEST. It was the writing . . . It took me years. I kept taking it, taking it, and I kept thinking, 'Oh, I'll pass it one of these days.' Then I got a tutor . . . She was super-nice. She said, 'You really want to pass this?'

I said, "Yes!"

She said, "Okay, you are going to write to me. Every Wednesday you are going to write two essays. You are going to write them and I am going to correct them. You are going to send them by email, and I am going to print them, I am going to correct them, and you are going to come. I am going to revise it with you, and then you have another two days to revise them, give them to me again. The following week, two more to do."

We did that for four weeks! I was going to school and I was still doing the writing. She made me a better writer. She just helped me so much, and when I went and took the test, I passed! . . . I was just so happy-I passed! (CA.I.47)

It appears that Cristina exhibited diligence and strength through many more struggles in college and then on to graduate school as she finished her master's degree to become a teacher. As a teacher, she employs this same tenacity and never quits with students with. She has taken advantage of opportunities to improve and in the first 2 years of teaching has continued learning through professional development opportunities. She signed up 
for an instructional coach, inviting constructive criticism and improving her practice. She is also learning from her peers and has learned they will support her and she can ask for help. One of the biggest hurdles to overcome her first year was planning - there were not enough hours in the day. Now she feels that planning is a must, but perfection is not. One thing that has helped with that is figuring out that students can be in charge sometimes! When students exhibit a desire or ability to lead, she takes advantage of the opportunity and lets them shine. Her struggles and persistence have shaped her into becoming a culturally responsive teacher that passes on that growth mindset and resolve to her students.

Cynthia. Although Cynthia started taking college courses in eighth grade, she was not supposed to go to college after high school. Her mom had enough of college when her older daughter went to the University of California at Berkeley and had a child. Her mom took her out to breakfast instead of taking her to school and she missed half her senior year. Shortly after graduating high school, she fell in love and decided to get married. Her parents did not approve of the person, which started a series of moves for Cynthia. The creative, curious, independent characteristics she exhibited as a young student were also present during this tumultuous time after high school. She attended a technical college that ended up not offering a certificate. Then she attended a series of community colleges in California and Oregon. Finally, she graduated from a large, public, urban university with a bachelor's degree. She started working in an elementary school as a bilingual secretary and later her sister found her a position teaching Spanish for all grades at an elementary school. It was then that she decided to be a teacher and 
began the BTP program mentioned previously. She could not afford to work as an assistant while she was in the program, so she looked all over for school to sponsor her with a transitional license while she was in school. She was hired to teach fourth grade in the largest elementary school in the state, during the second year of her 2-year teaching program. Although she finished her coursework, she was in the process of completing an educational portfolio as part of her licensure requirements.

The route to teaching for Cynthia was unique. Since middle school she excelled at school and she seems to continue being academically confident. Before she became a bilingual elementary teacher, she spent time in schools first as a bilingual secretary. In that role she gained a range of educational experience from dealing with a student making weapons from disposed CDs, to babysitting and running a parent computer class. Then she was hired to teach Spanish at an elementary school in a neighboring district. As she transitioned into the role of a bilingual classroom teacher in multilingual, multicultural elementary school, she was a natural advocate for parents and colleagues, but as a new teacher she felt her voice did not count. Her creative, out-of-the-box thinking was not welcome with lockstep team planning and grade level rubrics that did not fit her students. She kept bumping up against racism and intense segregation. When she reported the racist incidents, it was turned around on her. She was investigated, twice, "It was all on us, and we were just angry brown people. It is awful" (CM.II.2). Contending with segregation in her school and the rigid schedules were difficult aspects of becoming a teacher for Cynthia. She has learned to get to know parents and not trust what other people have said about them. 
She described taking advantage of professional development that is offered. She reported that finding creative ways to meet her students' needs keeps her going. She applied for and received a technology grant to purchase a class set of Chromebooks. She described using them in a variety of ways to make learning fun and meet students' needs. There are things she is still figuring out. She gives points to motivate students in an app called Class Dojo, but has to keep a spreadsheet for who has cashed in their points. She uses the Chromebooks to differentiate math for all her students and she figured out how to use an app to record herself, which freed her up in class to meet with students in small groups or individually, but she spent most of her Saturdays doing it. She cannot stand her students not getting their needs met but is still figuring out how to differentiate for everyone. She described the different ways students reacted and learned during a hand-on science unit she created in the following vignette:

We do a whole little unit that I made out of circuits. We talked about circuits and what you need for a circuit. Then I brought in - I read somewhere, that with tape, you can make a circuit — copper tape, a coin battery, and an LED lighteverything super-cheap ... The kids got to make their own circuits in a really nonthreatening way. It was really hard for them! . . No one had ever told them that, they had to figure it out on their own.

Some kid would be over there, "What, mine is turning on!!"

I would say, "Go ask so and so, see what they did! What happened? Look at their circuit!" That was fun. Then there were a lot of kids that just gave up . . "Why are you giving up? Why?"

"It is just too hard. I don't want it."

"That's too sad, my friend, you are so smart. You could figure this out." I had four boys, boys especially, giving up.

They were just, "Nah, I can't do it." 
[I learned a lot about them as learners] like Antonio, "You are hands on! I didn't know that about you!" [He was very hands on] and [can] draw. He is very visual. Since the circuit is very visual, he was able to do it right away, and so it turned out in the visual department, he was almost more than average. Everything else, no. Working memory, no. I thought, "Oh, no wonder you could do that circuit!" ... Next year I need to scaffold some more, I think. Kids that I would never have thought-figured it out right away. (CM.II.32)

Cynthia is learning to find ways to meet the needs of her students, as we see in the example above. In addition, she confessed that at times she is learning how to negotiate and give in with her colleagues (when it is okay for her students), and gently nudge others in positive directions when she can. From the data, we see that Cynthia is constantly trying new things and embracing becoming.

Hugo. For Hugo, becoming a teacher took many steps, as discussed Tracking and Escaping the ESL Ghetto. He went to community college in the states but did not finish. He was re-inspired and decided to go to college in Guatemala and be around his family again.

I was little less than a year away from finishing, but then ... they were changing the whole curriculum! . . . Other classes that were added to what I had to do. I thought, "That's not fair!" So, I just left it. Life, I just needed to focus on living, because I was on my own. Then after that, a long time without any schooling, and then I moved up here in 2010. I started looking for jobs and I got hired by the school district as a bilingual assistant and special education assistant. Then I worked as a bilingual secretary and as the librarian, and as the ERC secretary as well. ERC is like special ed. I had many office and support jobs around school. (HJ.I.6)

It appeared that his bilingualism opened doors for him to work in a variety of settings. It was when Hugo was working as a bilingual assistant in these different roles that he found out about the scholarship available for the BTP program. He continued to work as an educational assistant as he completed his teaching program. 
Even though he had that experience and taught in Guatemala before that, the firstyear teaching was a big learning curve. The K-6 elementary school where he teaches is small, and he is the only fourth grade teacher. He looks back on the support he had his first year:

My first year I did go and observe some teachers in other schools, and I was able to go and sit with them and plan. It was one day-it wasn't really a unit, but one day they kind of broke down a unit for me and they explained to me what they are doing. Then I took that. I probably could have been more proactive in saying, "Hey, I want to have a date to go plan with this teacher." But again, going back to my first year, I didn't really know what I needed. People would ask me, "What do you need?"-I don't know. Then I realized, "It would be kind of nice to talk to this teacher and see what they are doing ...” Now I know . . . before, I had no idea. (HJ.II.9)

Even though he felt like he did not know what to ask, he learned a lot and continues to learn. Like the other participants, he takes advantage of professional development opportunities and integrates new ways of teaching as he learns, as much as he can:

I have to finagle things to make it work, and hit the standards, and comply with Lit Squared things that I am supposed to be doing in the class. GLAD (Guided Language Acquisition Design) is great, I love GLAD. I did a really quick half-day GLAD thing, like a training, but it wasn't the official GLAD training . . . but I did an energy GLAD unit last year, and it was really good. I didn't do the whole thing. I kind of took bits and pieces of it, but I liked it. I liked it a lot. (HJ.II.11)

He also felt like a lot of the professional development was too brief and he was stretched thin. As a bilingual teacher, the curriculum available is usually in English and he has to look for culturally relevant books and create examples in order for it to make sense in Spanish. Even though it is a lot of work, he continues to try new things and humbly reflects on his missteps.

I think it is helpful. I just feel, like any other teacher, there is so much on my plate that I wish there was less so I could actually focus and go deeper into these few things, instead of trying to do all these things, and then not being able to go deep into any of them. I'm just on the surface in a lot of them. I wish I could just dive 
in deep on a couple of them and have that time to become proficient or an expert at this. (HJ.II.18)

Throughout the interviews and observations in his classroom, Hugo was constantly analyzing his practice, being reflective and continuing to learn. As a new teacher, Hugo set his focus on his students and his commitment to them was obvious in his words and actions.

These three participants are developing into teachers: their positions in school have shifted and they are constantly learning. Their path to teaching was not easy or quick. They had stumbles and yet the all continued on.

Theme 3: "It's complicated." This section explores how these bilingual teachers describe their thoughts on teaching bilingual students, being a bilingual teacher, and how their experiences as former emerging bilingual students influence their teaching. The overarching theme, "It's complicated," describes their position, on one side is "I love being a bilingual!" and the other is, "Te desinfla, te saca el aire" (it deflates you, it takes the air from you). The participants hold these ideas at the same time: Their passion and love for being bilingual is strong, while their sadness and frustration for the trauma, hardships, and unfair situations they and their students and families are in is at times overwhelming. In addition to these diametrically opposed feelings of frustration and love, in the midst of it all, are the ways these participants are passing on their knowledge and experiences with their students and students' families. The subtheme Pass it on! shares examples and stories of this. The stories that emerged in this section remind me of Freire's (1998) description of education as political, as all social change is political. Because for these participants, teaching and learning in their home language is a political 
decision with consequences. However, their commitment to bilingualism and bilingual education is strong. "It's complicated" begins with "Te desinfla, te saca el aire," turns to Pass it on! and finishes with stories of hope and love they are bringing to their students in "I love being a bilingual!"

"Te desinfla, te saca el aire." When I asked Hugo about his thoughts on bilingual learners and bilingual education, he took a deep breath and started explaining all the assessments his students were required to do at the time, the double work, the lack of culturally responsiveness in standardized tests, and the factors that come into play and influence his students' learning. He used the phrase, "Te desinfla, te saca el aire," which stood out to me. In Spanish literally means "it deflates you, it takes the air out of you," but figuratively it means "to lose heart," or "to be crushed." This was the feeling that he was expressing - that he did not want to have. This feeling came up over and over, for the heartlessness of racist comments, the mischaracterizing of bilingual parents' intentions, or the lack of understanding what bilingual learners needed. Hugo explained more about these intersecting factors below.

I think people, at heart, they have the best intentions. Just the way things are progressing, it makes it really hard. It makes it really hard for us as educators and, in turn, it makes it hard for the kids to be successful. There are just so many more layers put on us and on the kids. Of course, it's going to be hard for you to score higher on the state assessment because you have all these layers. I don't know. I think bilingual education cannot be seen the same as monolingual education. Even the expectations the district has of teachers at bilingual schools, I think they need to be different than the expectations they have of other teachers. Just talking about my DRAs (Developmental Reading Assessments) and EDLs (Evaluación del desarrollo de la lectura), that's twice the work. (HJ.III.9)

These reading assessments are done one-on-one with the student and the teacher and can take from 20-45 minutes to complete. All three participants expressed this sentiment, that 
bilingual education was treated like monolingual education, and they were expected to create the Spanish part.

Cynthia. Cynthia's school is unique. Not only is it over twice the size of the schools of the other participants, it also is home to three language strands. Students are in one of the following: English Plus, Bilingual Spanish/English, or Bilingual Russian/ English. In fourth grade, all students have almost an hour of language instruction every morning. They change classrooms depending on need or interest. Students in the English Plus strand have the option of learning Spanish or Russian as a Foreign Language. Students in the bilingual strands, both Spanish and Russian, if needed, will have ELD during this time. If they have exited from ELD, they can take the Spanish or Russian class.

Cynthia teaches in the strand Spanish/English Bilingual and her students primarily speak Spanish at home. She teaches the Spanish Plus class, which she explained means most of her students leave for ELD while English and Russian speakers come to her class to learn Spanish. She has a range of English- and Russian-speaking students that are learning Spanish as a Foreign Language at many levels and students that speak Spanish at home and have exited ELD. She does her best to meet the needs of all her language learners. From our interviews, Cynthia described how she creates her own Spanish curriculum. Although she finds ways to engage all her Spanish language learners, she lamented the time she is missing with her own students. She wishes she could keep her students that need English Language support. According to Cynthia, everyone in her school teaches a language, but it is the bilingual teachers that are taxed with creating their 
own curriculum, finding language materials, and teaching to a wide range of learners. The monolingual English teachers teach leveled ELD, with smaller groups and district provided curriculum and materials in the language of instructions (English).

Cristina. Cristina teaches content in Spanish (math, reading, writing, social studies) and ELD. She explained that she is the only one in her grade level teaching in Spanish. When she plans with her grade level team, she does her best to translate the instructional materials and plans into Spanish. She shared that she is thankful because her team is supportive and asks her if the questions and instructions they plan will work in Spanish. Sometimes the book that should go with the curriculum either she does not have in Spanish or the concept that is supposed to be taught just does not make sense in Spanish. She explained how that impacted her first year:

There was a lot of complaining because of the [curriculum] ... There was a lot of complaining because the books weren't there yet, the materials weren't there, they weren't being translated. Some of the translations were incorrect, so there was a lot of complaining instead of talking. When I went into those meetings as a firstyear teacher, I felt really overwhelmed, because everybody kept complaining ... [I thought], "This is going to be a horrible year ..." (CA.II.31)

She found that teaching the lessons straight from the curriculum guides for reading and ELD confusing. She admits now, she rarely teaches the lessons the way they are provided, because they just would not make sense for her students.

I never ... [teach straight] from the book. I look up the graphic organizer, the sentence frame, and what I want them to do afterwards to share out their sentences ... . I come up with a new [topic]. What I'm saying, it's not from the book. I don't want to be reading from the book because it's not going to be meaningful to them. (CA.III.37)

For all three participants, the time it takes to plan, translate, and/or create instructional material in Spanish is significant. Also, academic testing feels particularly heavy in 
bilingual classrooms. Bilingual classrooms have double the requirements of English Only classrooms. This means bilingual students spend more time being assessed and less time being instructed and practicing their skills. Additionally, the testing rarely matches the ways of knowing and economic and culturally backgrounds of the students which was expressed by Hugo.

Hugo. It was June, and Hugo's fourth grade class had just finished taking several rounds of standardized testing. It was over 90 degrees in the classroom and the lights were off. The students just left and he looks over the empty classroom and sighs.

It's a little ... I don't know what the word is . . I don't want to say frustrating or disheartening, but . . . to be there testing, and seeing your kids ... You know the student knows it; and they're on the right track, but then maybe some misunderstanding about the way the question was formulated or something, and you watch them go down a wrong path. You can't say anything, but . . . then you get the results, and then it's like, "Oh ..." (downcast) ... In Spanish, we would say "te desinfla, te saca el aire," because it's like, "Oh, man. I'm not doing my job as a teacher." (HJ.III.4)

In our interviews, Hugo wondered how his students would do on the exam if reading comprehension questions were about quinceañeras or if the math problems challenged students to figure out proportions for making tamales. He is frustrated that bilingual education, which is important to many people, is misunderstood and much more complicated than people understand. Hugo touched on the sociocultural, political, and economic conditions that influence education. He shared the issues outside of school that many of his students face:

Sexual abuse, rape, domestic violence at home, not eating. If a student didn't have dinner last night and didn't eat breakfast this morning, of course, their mind is going to be on "I'm hungry" instead of the math problem in front of them. Luckily, at this school everybody gets free breakfast; everybody gets free lunch. At least that part is covered. I know that they get breakfast and lunch. I just don't know if they get dinner: I don't know if, on the weekends, they're eating properly. 
Students who don't have clothes. In the winter months, they're cold. I don't know if at home they have heat, if they have proper clothes to sleep and be warm. I have students who don't ... (He pauses to consider his words.) There's a little bit of neglect. They don't bathe for a long time or their clothes are not washed. Then that also creates some social problems with the other students. At this age, they start noticing ... Students have older siblings who might not be a good role model. There are gang things that they might be observing or have contact with ... Sometimes no adult supervision. At home, they get into things that they shouldn't. Their mind is more advanced than it should be at this age. I have boys that are thinking about things, drawing things, speaking things that . . . very sexually explicit things that I worry about ... Domestic violence, sexual abuse, neglect. (HJ.III.11)

From our interview, it was evident that these factors weighed on Hugo. He knows his students are dealing with these issues and more. For example, he talked about a girl in his class who had crossed the border by herself and was picked up by an agency and claimed by a family. She now lives "like a Cinderella kind of story where the kids of the family get everything and she, since she isn't part of the family, she does all the chores, she gets kind of abused and not given things" (HJ.III.12). As a mandatory reporter of abuse, he reports what he hears, but then is let down when week after week, then months pass, and his student seems to be in the same situation.

I've done everything that I can do. I can't physically remove her from that situation. It's hard sometimes. There's times when I think about specific students and it kind of breaks me, but I try to keep it strong for everybody-my kid and my co-workers-because I have co-workers that are going through similar or worse situations with students that they have and it's hard. It's hard dealing with all of the trauma on top of just academic things. (HJ.III.13)

It's not new that the secondary-trauma effects on teachers takes its toll, however, Hugo actively combats it. Although he feels selfish doing it, he tries to concentrate on his family when he gets home. He feels that if he did not try to separate himself from his students once he got home, it would be too much and he would burn out. He feels like 
that cycle, of teachers coming and going, creates great instability in schools for students and he is determined not to do that.

I try to stay sane so that I can continue to be here. I continue to be a source of stability for them. That's why I don't have plans of going anywhere, even if things get really bad. I want to stay year after year and keep giving them that stability of knowing that these teachers ... "Oh, yeah! I know him like, when I was in kindergarten," and looking forward to being in my class year after year and then I get to know all the kids in the school, even if they're not my students. (HJ.III.14)

In order to do this, he needs more time and support. Teaching in two languages brings him joy and he wants to pass it on, but planning, finding resources, and supporting his learners takes more time. He appreciates the support he does get, for example his principal will get a half day substitute so that he can do one-on-one reading assessments. Each assessment can take up to an hour, and with 20-30 students, and two languages, a half-day substitute just is not enough.

Cynthia echoed this sentiment. She loves being bilingual and being able to connect with parents, and, like Hugo, she is the only one. She feels like if she does not help the students or families navigate the educational system, no one else will. It is that kind of pressure that is continually on Bilingual Teachers. She explained,

Absolutely [being bilingual] does help, and there are things that I would love to start where I'm at right now. But, at the same time I feel like why am I putting more stuff on my plate? I always do that, and then I don't have any free time for my family because there I am for other people ... So, it's always like a, "Should I, should I not?" Like, that basic computer's class, parents loved it, because first of all I started with "How do you turn on a computer?" .. ."This is a mouse ..." (CM.III.42)

While these Bilingual Teachers are constantly making changes to meet the needs of their students and their students' families, being a bilingual teacher is complicated. From their 
perspectives, it feels like it required more time, more energy, and different demands on the skills sets as bilingual teachers.

Pass it on! Throughout the interviews, but especially during the third interview protocol, Cynthia, Hugo, and Cristina reflect on what they learned from their experiences as emerging bilingual and Latinx students in K-12 schools and how they are passing that on to their students and their families. In this section, Cynthia relates how her experiences with racism and being silenced have led her to engage her students to demystify racism. Both Hugo and Cynthia explicitly work against sexism in their classes and make college plans with their students. All three participants demonstrate strong student leadership in their classrooms and mentor other future teachers.

Cynthia. Cynthia connected her own schooling and life experiences with her teaching is a prime example of Pass it on! She remembered being bullied at school for her race as a child; she would talk about it with her sisters and mom. Now, her partner is White, and they have frequent conversations about race and racism. She explained how she connects these experiences to the classroom:

I feel like I've heard many different perspectives on race that I feel comfortable being uncomfortable ... [I can say], "This is a difficult conversation, but this is what I think, and maybe what's going on ..." Right now, it's a relevant thing, and kids are scared. And people don't want to talk about it, so we've had many conversations about Trump.

According to Cynthia, when she was a child, racism at school was silenced. She could go home and talk about it, but at school, she had to act like it never happened. She said it was "too uncomfortable." Yet, she countered, "People were suffering, and it's not right. When we talk about race, and racism, it just doesn't affect people of color, but it affects everybody. That's something that we don't realize." From my observations and 
conversations with Cynthia, it appears that she takes her childhood experiences, her adult understandings, and weaves them into her classroom. Her favorite conversation in her classroom last year was about race. She recalled explaining to her students that, "a lot of White people don't see racism, and think it doesn't happen." They were aghast. How could that be? She went on to give them personal examples of people she knows who are White and grew up around mostly White people. She questions, “Are other White people going to be racist to him? Never! Because they're the same!" Her students were dumbfounded. She went on to explain how she watched their expressions as they processed this information - growing up White, you might never experience racism, or even encounter it. She decided to use that moment - the moment they realized a new perspective, to dig deeper and teach writing. "So, we are going to write an essay, I'm going to pick the topic of racism ..." Starting with a recent incident at school, she began to tell a story about a parent recoiling from her in the hallway. The parent grabbed her daughter and told Cynthia not to touch her. She continued, "She wanted me fired because I was a bad example." She did not leave it at that.

Just so that they could see that, yeah-it happens. And it's okay, and sometimes you need to tell, and sometimes you just need to be like, 'Oh, that person's in a different place in their life.' And that, that's okay too. But, to be able to protect yourself when you think that you're in a situation where you could get hurt.

Cynthia described how she empathized with the little girl, wondering how hard it must be for her to grow up around overt racist acts. She explained that sometimes you have to be an advocate and speak out, and sometimes, you just have to see where a person is in their life and realize they need to grow. Cynthia admits it is hard work - and worth it, "It's really hard. But, kids were super-amazing, and talking about it, and feeling okay with it, 
and having really interesting conversations with me." This attitude of facing hard issues head on was evident in both fourth grade classrooms. Cynthia and Hugo, both actively push back against sexism in their classes.

Cynthia described the many ways sexism affected the expectations her family had for her and the educations and life opportunities she had. In high school, she was invited to be part of the aviation club, but "girls don't fly." She missed half her senior year of high school, because her mom did not want her to go to college, "so what was the point?" She was not allowed to leave the house until she was married. When she fell in love and chose to marry someone, her parents forbid the marriage, threatened her fiancé to the point his family hid him, and she ran away from home. Soon after, she married "a very traditional Mexican man" and they had a child. He had traditional gender roles; he did not want her to work and wanted her to have more children. After he became violent, she decided that she could not let her son see that. Instead, chose to be a single mom. She found a job at her son's school and finished her undergraduate degree in Liberal Studies. She remembers that at school, she was good at taking tests, "Because I was supposed to do good, even though I wasn't going to college ... At the same time our Russian population is doing the same thing. So, although I feel like I don't get it, I understand."

The following is an example of how Cynthia bridged her own experiences and understood them to be similar to the Russian community in her school district. She took those experiences with cultural norms and expectations, and actively works against them. In her class, she leads an inquiry lesson into discovering the sexism students are steeped in. They do Google searches of different careers. She asked her students, 
"What do you notice? Well, let's look at the woman doctor that came up .... Oh, interesting!" We did nurse, doctor, teacher — construction worker was my favorite!

They were like, "Why would women work in construction?"

"Plenty of women work in construction! But you see what you're doing there? It's because do you see them? Oh, you don't!" It was really interesting how the boys then became advocates ... (CM.III.91)

She explained how she led them to construct their own conclusion, based on their own Google searches. Later, she described how several students chose feminism as their topic for an essay. They described what it was like to be girls, the unequal and unfair treatment they experienced, and described how important it was that we become aware of the socialized norms that hold girls back. Cynthia identifies with the cultural norms her Latinx and Russian students may have to navigate and works with them to understand their cultural roots and explore others at the same time.

Hugo. As the only boy in his family with four sisters, Hugo takes empowering the girls in his class seriously. Although he was not limited personally by sexism, he saw the ways it impacted those around him. Like Cynthia, who also teaches fourth grade, Hugo pushed back on sexism.

I think this isn't consistent with the culture that I come from, but with the girls, I try to raise them up and say, "You can do anything you want," and I don't know if my culture necessarily does that, but understanding that my culture doesn't do that, is why I do it. Because I know that at home, it's like, "Oh, your brother this, your brother that," but you're the girl, so different expectations. I don't want to raise these kids differently than what their parents would do. I don't want to interfere with that at all, but I also want them to see this other side of "You can do anything you want to do in life and you can be a scientist, you can be a mathematician, just like Einstein. Be proud, do this and have respect for yourself and make people respect you ..." I can have all of these little conversations-I have four older sisters, that's why I might be a little more into that - to try to get them to be strong, independent women because in my culture, I don't think that's what parents want their girl. I don't want them to rebel against their parents. I just 
want them to know that they're capable. They're totally capable and they're just as good as any boy. I see it all the time- - how the standards are different; the expectations are different for boys and girls in my culture. (HJ.III.28)

He intentionally walks this line, between teaching and modeling that girls should have respect and agency and respecting the culture of his students' families. The way he addresses the girls in his class shows this attention to empowering them too, like in the vignette in Culturally Responsive Teaching, where he called over his "technology bosses" to manage the computers. The following comes from field notes and recording from a classroom observation:

Another day, during a math lesson, students worked in pairs to figure out all the factor pairs of a certain number or numbers. For example, two students had the number 56 , and they had to find all the ways you make $56(1 \times 56,2 \times 28,4 \times 14$, $7 x 8)$. They cut up grid paper into rectangles to represent the numbers and glued them to a large piece of colored construction paper. Then each pair presented their findings to the whole class. A pair of particularly quiet girls came to the front of the class and Hugo handed one student the microphone. They quietly looked at each other, not quite sure how to start. Hugo says, "It's okay. What you have. Whatever you have! We want to see what you have. Remember Anita, to wait for everyone to listen to you, because you deserve that respect." She has a hard time starting. Hugo moves behind their $11 \times 17$ piece of construction paper to hold it up so they can be more in the front. She hesitantly says, "Four times four ..." and stops.

He responds, "Okay, four times four, and what else?" encouraging her to continue.

"Ummm. Two times 8 is $16 . "$

Continuing to encourage, he points out their success and wonders about their other number, 31. Again, they look at him shyly. Hugo looks at Anita's partner and probes her, "Griselda, I see that you have one way for 31, what did you find for 31 ?"

After a few attempts, she finally gets the whole equations out, "Thirty-one times one is 31." 
Restating her words Hugo says, "Thirty-one times one ... . Guess what? That's the only way! You found the only way!" Then reiterating to include the academic vocabulary they are practicing, he asks, "How many factor pairs does 31 have?"

“One ... . ?" she hesitantly answers.

"One! that is how many you found! How many factor pairs does 16 have?" Going back to the previous number. He waits for the class to be quiet so the girls can answer, and they go on to respond using the new academic vocabulary. (Observation, September 27, 2017)

Hugo's attention to disrupting the common behavior of boys talking over girls, naming it, and teaching them to demand "the respect they deserve" stood out in Hugo's classroom during the observations I conducted.

Cristina. In the same way that Hugo demonstrated Pass it on! in how he works against sexism to empower the girls in his classroom, Cristina does the same for students that are shy or seem to struggle academically in her classroom. She described a nonverbal management technique she learned recently, and how she made changes to it to address certain students. She remembers learning to finish instructions and ask if students have questions. If they do not have questions, she is supposed to dismiss them and "send them on their way." Meanwhile, she stands quietly and holds her hand up to stop them if they stop and want to ask her a question. While it seems like a valid technique, she brings her experience to the situation and responded:

I disliked teachers who do that. When I have a question, it was important. Maybe I didn't have a question right on the spot, but you know, later on I did. I'd go up to the teacher and they'd be like, "No, go. Don't bother me right now." I go ask the other students, nobody else knows the question ... Now, [as a teacher] I have to do it-and when I do it-I send them on their way and then I'm like, 'I need to go take care of that because he has something important!' I used to be the kid that had something important, you know? And I remember the teacher never coming back to me. So, I try to go back to them because - that's important! So even if I forget, I say, "I'm so sorry. What was that? Two minutes ago, you asked me something ..." (CA.III.40-41) 
Cristina draws on her experience and uses it to inform her teaching. This happens over and over; she gets to know students and sees their strengths and ensures that they can be successful in her classroom. More than once she described students that were struggling and at times, their parents were told they likely had learning disabilities or disorders. Cristina saw their strengths and worked with them and their families and saw them successful in her classroom. For example, last year, a new student arrived around December.

... I guess her teacher from last year thought she had some sort of, like, on the spectrum, that she had a disorder. I told mom, "No, she's really impatient sometimes, yeah. But, she cares for others. She's not always moving around. She works hard. She finishes her tasks that I give her. It's just like, she needs that extra attention sometimes. But, if you tell her, 'Ahorita no. Alma, ahorita no.' (Not now. Alma, not right now.) [In a caring, soft, firm tone.] Y ya. No trata de decirlo otra vez (and that is it. She doesn't try to do it again.) At the beginning I was like, "Come on, come on, come on."

“Teacher, no. ¿Por qué no? ¿Por qué no?” (Why not? Why not?)

[I thought] wait a minute, ya te dije que no (I already told you no). "You can't do that, that's not okay." [Smiling and chuckling at the memory.] (CA.III.26)

She went on to describe how much that girl has changed and become a part of their learning community. She also described communicating with the mom of the student, and how the mom said the student was so happy now and talked about her often at home.

Partnering with the family and forming meaningful relationships is another powerful way Cristina passes on her experiences and ways of knowing.

One thing is, if you have a shy student like myself, don't underestimate them! Sometimes we are seen as weak or, think of that person like, "Oh she hardly talks in class." We know a lot, but we're really shy to talk about it, or we don't know how to use our words to express what we're feeling or thinking. It's really hard to express that sometimes. But, when you're teaching it with kids you're a whole different person. I become a whole different person when I'm with them. I can't explain it but it's like, I love my job. (CA.III.51) 
She went on to explain that she can go home and realize she had a bad day. But, she reflects and says, "I can't wait to go back the next day and teach them something differently." She continues to pass it on.

Hugo and his four sisters led him to empower girls; Cynthia and her troubled early years leads her to understand and be curious about student behavior; and Cristina's shy character and experiences struggling in school guide her in forming close relationships with her most struggling students and their families. The approach to teaching all three participants had was: culturally responsive, fundamentally studentcentered, and demonstrates authentic caring.

“I love being a bilingual!” Although the participants have extra work and sometimes impossible expectations, they are passing on what they have learned. Ultimately, their love for being bilingual and their desire for their students to become bilingual too, supersedes all else. In this last section of findings, instead of presenting each participant separately, their voices are woven together as a collective last voice on being bilingual. Their passion for bilingualism is united as they echo and build on each other's stories. Cristina opens, remembering how different it felt to enter a bilingual school:

As soon as you come in, you feel it. You hear other kids speaking Spanish, your teachers, adults, are talking to you in Spanish, you know, you get it. Even in the office, people, they spoke Spanish. As soon as I came in, it was like, "Oh!!!” If I needed anything, I could always go back to them. It felt different ... (CA.III.11)

That comfort and joy that comes from being able to communicate in Spanish is evident in her teaching and connections with students' families. Even though she does not feel like she excelled in school in either English or Spanish, she feels that reinforcing Spanish 
with her students that are struggling gives them the best opportunity for academic success.

I was never really good in both of them, I just did what I could in both languages to sort of survive. It was like I never really got the opportunity to say, "Oh, I got this." I feel like with some of my kids who are higher readers in Spanish, because they're high in Spanish, they're high in English. Then my low ones who are low in my Spanish, they're low in English . . . If you can't have them improve in . . . Spanish, in their native language, there's no way they're going to learn the second language! (CA.III.11)

She explained how one of these students that struggled academically, made huge improvements over the year. She was in constant communication with his mom. After school his mom often asked Cristina how he was doing and Cristina would recount the positive moments in class. Cristina invited her to an after-school reading club for families of students needing support with reading.

He just needed more practice I guess, and more . . . and, I think anything I give him, he takes home to his mom, and his mom is there with him. The more he gets, the more she helps. But, if I wasn't to provide any of the work that I give him, then Mom wouldn't know how to work with him. But, because of the work that I give her she knows, "Oh, this is what he needs to work on." Because sometimes I catch her outside and she'll ask me, “Cómo va mi [hijo]?” (How is my son doing?) and I'm like, "Oh señora, hizo esto, esto, y esto . .." [Explaining to the mom all the things her child did in class.] O mando una notita como con un OWL (Or I send a little note with an OWL_a school-wide reward) . . . Su mamá me dice, "Tenía como tres en su mochila que se le había olvidado darme" (laughter). (His mom tells me, "He had like three in his backpack and he'd forgotten to give them to me!") And that's how he is! He forgets things! And, I'm like, “¡Llévalo por un nieve — o algo! Prémialo, iporque se lo merece!" (Take him for an ice cream or something! Reward him, he deserves it!) (CA.III.21)

Cristina attributed his success in class to the extra practice he gets at home - and the extra practice he gets at home is because she kept calling and sending notes - in Spanish. Her struggles in school inspire her to intentionally bridge the two environments for her students that have a hard time in school. She explained, 
I think just me struggling, or not having any support in school, inspired me as a teacher . . . I remember being this age, and I remember being lost. I remember looking at my teacher and going, 'I don't know who she is or what she's teaching me.' I couldn't relate to her. School and home were two different places. There was no connection at all. And, when I'm talking to them [students], I always try to make connections from home, because I need to make sure that they know that school and home is a connection, and parents and teachers are correlated, and we talk to each-other. And, whether you're doing good or bad, they're going to know about it. That's one of the impacts that I wanted to make ... It's all about family. Somos una familia. (We are a family.) (CA.III.24-25)

"We are family," she said. It sounds simple, yet it comes from the heart and it's telling that it was sufficient to express it just in English. Being able to communicate in students' home languages plays an integral part in these connections.

The importance of speaking with students in their language, was echoed by all three participants in different ways. Cynthia described it this way,

Talking to someone in their language is super-powerful, because, all of a sudden you're their in-crowd ... They feel like there's a connection to you. Even just saying people's names correctly-even if it takes you the whole nine months, just try it! Be like, "No, wait, correct me again. No wait, how do you say it again?" Because, sometimes it's like that because you've never heard that name and that's fine. But, that's key I think. And the kids love that we say Fernando [in Spanish] and not Fernando [in English]. (CM.III.12)

Being part of their "in-crowd" is also being able to joke and have fun. Hugo brought this up too, "It helps being bilingual ... There's these little, subtle jokes and things that we have fun with, that are based on bilingualism or culture, that I think they appreciate and so, we create a tighter community because of these things" (HJ.III.27). He smiled as he told a story about creating a dictation in Spanish.

Last year, I was doing a dictado (dictation). I always say, whenever I come across a cognado - a cognate - I'm like, "Oh, that's a cognate," and I wait for them to say it in the other language and they always say it. Now, it's like a contest when they say it. When I come across a word that I think they might have difficulty with, I say, "Do you know how to say that in English or in Spanish?" and then they shout out things and then I tell them what it is. I remember it was like, "la 
noche tenebrosa" (a dark and scary night), I'm like, "tenebrosa ..." and a lot of times, the word is very similar. You just add an "l" or an "a"- that's the joke and I was like, "la noche tenebrosa. Do you guys know? ¿Saben que es tenebroso? Ah, es cuando ... ¿Cómo se dice en inglés? (Um, it's like ... How do you say it in English?) Then, one student who is Latino and a Spanish speaker [exclaimed], "Tenebrose!" Then, I just started laughing. From then on, that was the thing! On the next dictado or a couple of dictados later, I wrote the dictado and I was like, "Lily came up to her friend. All of a sudden, there was a little strange animal and his name was Tenebrose!" Those little connections ... And now, when I meet kids in the hallway, I might ask them, "How's Tenebrose doing?" They'd be like, "Oh my God!" (laughter). Things like that, those connections! (HJ.III.28)

Laughing and making linguistic and cultural connections with students was a highlight for all three participants. On a more serious note, they also had stories of ways they used their linguistic and cultural ways of knowing to bring students' families into the academic in-crowd.

Cynthia explained how it is also important to understand how to communicate in a culturally respectful way. As previously mentioned, she has an open-door policy for students' families. During conferences, she teaches them how to access and use a classroom application they can download onto their phone, which she uses for quick communication (similar to texting) and showcasing student work. She explained how conferences are not sufficient for family time. She tells families,

"If you need help, let me know." Because, I only have 15 minutes of conference. Which is ridiculous, but that's another story. Especially, for us Latinos ... because getting to the point is rude ... This is ridiculous. 15 minutes? That's super-rude ... Y You can't just get to it. You have to say, 'How are you? My name's so-and-so, oh it's great to see you. I love your kid ... You have to think about something authentic to say, at first, then ... culturally you go around the thing, you go around the thing, you go around the thing, and before they leave you make sure you say the thing you actually came to say, and then they leave. (CM.III.5758)

When teachers have this ability to connect with students culturally and linguistically, they deepen relationships with students. 
Likewise, not having cultural competence can get in the way of communicating clearly with families. Cynthia reported several parents asking her if their kids would actually learn that year. She laughed and said to them, "It's just cultural. You and I understand each other." She gave the example of calling a parent about a behavior problem:

If I'm going to call and dar una queja (complain), I start with, "Ay, estoy molestando. Ay, no más le llamo con quejas. Va a decir, calla esta Maestra, ¡como!" (Oh, I'm bugging you! I only call you with complaints ... You're going to say, "Wont this teacher stop complaining!")

“No Maestra!” (No Ma'am!)

So, the approach is different as well. (CM.III.59)

This willingness to try all different ways to communicate, understand parents from multiple perspectives, to make sure that families were welcomed, informed, and in partnership with schools was expressed by all three participants. Several times the participants told stories of being warned of a supposed "crazy parent," that turned out to be a concerned or scared mom trying to get help for their child. Cynthia explained how she approached the news:

I got the, "Oh, you got so-and-so's parent, she's crazy."

I'm like, "She is?"

"Well, she just shows up in the classroom."

"I know, and I tell the kids I'm talking to a parent. They just need to be respectful and wait. That's okay." (CM.III.61)

When the participants were able to communicate with these crazy parents in a culturally responsive way in Spanish, the participants formed respectful relationships with the parents and the parents became strong advocates for their children. 
In all cases, the participants specifically reported the impact of bilingual and culturally responsive communication with students that were being considered for Special Education and/or diagnosed with learning differences. Hugo recalled interpreting for a meeting in which a student was being considered for Special Education.

The teachers were saying, "We see these things. We think your student qualifies." I remember, many times, parents would be like, 'Oh my God!' They would get really apprehensive like, "Oh my God! My child is a special needs child . . like, handicapped? What's going on?" I could understand where they are coming from because in my country, it's a very different story with students that have disabilities - very different. They are not part of the mainstream classroom. I could understand the concerns, so I could quickly ... say, "Look, this isn't anything that is bad. Your student isn't leaving, going anywhere. They're going to stay with the kids. They're just receiving help and support that's going to help them do this and that." That's an example. There's many little things like that that I can maybe, from their perspectives, see it . . . I think that's . . helped me to make those connections with the parents. (HJ.III.27)

The participants expressed ways in which they create inclusive environments, for students and families, through bilingual and bicultural relationships. They believe their experiences growing up as ELs in K-12 schools influences the ways they teach and learn with emerging bilingual and bilingual students. Hugo explained it this way,

It makes me a better teacher, absolutely . . . I was them. I was exactly them! I came to this country in third grade, knowing no English, and I had to learn English. I was in ESL. Having to go through that process of learning, I remember what it was like not to understand my friends and having them not understand me - not academically, just socially. I remember what that was like . . . I lived it! ... I connect the two languages in my mind and share that with them-that metacognitive awareness and then [explain], "Oh, yeah, that is a cognate! That is spelled a little bit different." All of those little connections, I think it helps me teach them because I realize it in my brain-how I think and the little tricks I use to remember how to spell this or the rule for that. I share that with them ... I think that helps me be a better teacher to them, a little more understanding of what they would be going through ... With the families, I think I can have a better rapport ... If I ever need to talk to a parent, it's like talking to somebody from back home. We have those connections. Culturally, there's certain things that people might value more than others, and I can understand that. (HJ.III.25-26) 
Being bilingual for these teachers encompasses much more than knowing two languages. "I love that I am a bilingual!" demonstrates how these bilingual teachers create and sustain close and caring relationships with their students and their families. As they translanguage, they laugh, discover new things about each other, and share difficulties and triumphs with their students and their students' families.

\section{Limitations of Study}

The findings of this research study confirm much of the established research on bilingual teachers and bilingual students, and also brings up interesting areas for further research. The major limitation of this study is the number of participants. The small sample size does not allow for generalizability. Also, the participants are all Spanishspeaking and in bilingual schools or are in a bilingual program within a school. Although the similar nature of these participants can be seen as a strength of the study, because it makes cross-participant comparison less complicated, it can also be a limitation.

Bilingual teachers in other situations, like English-only schools with smaller numbers of bilingual learners, in majority monolingual schools, or with majority monolingual colleagues, may have very different experiences than these bilingual teachers. Another limitation is that the data in this study is all self-reported and through observations. Quantitative analysis of student learning overtime would strengthen the assertion that these bilingual teachers, and their Culturally Responsive Teaching practices, have a positive impact on student learning.

\section{Conclusion}

The bilingual and bicultural teachers in this study experienced what it was like to learn English in PK-12 schools in the United States. The results from this study suggest becoming bilingual in the United States is influenced by the desire of students' families 
for their children to have a positive view of their home language and culture. Becoming bilingual as a child in U.S. schools can also be hard, and bilingual teachers and teachers that show a genuine interest and care about their students can help alleviate the hardships. The findings also point to the heavy load new bilingual teachers face, but their perseverance and strong reflective skills allowed them to take advantage of professional development when available. Overall, these results indicate what other studies have shown about teaching and learning with bilingual students, when teachers have similar experiences and understand the language and culture of a student, they are more likely to see the assets of bilingual students and teach in a culturally responsive way. The next chapter, therefore, moves on to discuss the synthesis of the findings and their implications. 


\section{Chapter 5 Discussion}

The purpose of this research study was to explore the experiences of current bilingual and bicultural teachers, formerly classified as ELs, to better understand teaching and learning with bilingual learners. Three bilingual teachers volunteered to participate in the study to explore these research questions:

1. How do the bilingual teachers in this case study describe their schooling experiences (up to and including their teacher education program)?

2. How do these bilingual teachers describe their current daily teaching and learning experiences with bilingual learners?

3. How do these bilingual teachers make sense of their experiences as ELs and as bilingual teachers?

They discussed these questions in three, in-depth interviews, and also allowed me to spend time in their classes, observing them teaching and learning in community with their bilingual learners. This chapter revisits the theoretical frameworks of Sociocultural theory and LatCrit, to illuminate their usage, synthesize the findings from the interviews and observations, as well as situate the findings in a larger context with implications shared for various stakeholders. This chapter then concludes with recommendations for educators, educational leaders, and policymakers.

\section{Theoretical Frameworks}

The theoretical frameworks used in this study were Sociocultural theory and LatCrit. Sociocultural theory provides a way to understand the context, how these bilingual teachers formed their identities as students and teachers, the communities they are a part of, their experiences as students and teachers, and their descriptions of agency. 
These five intersecting aspects of Sociocultural theory help us see these bilingual teachers more holistically (see Figure 5.1).

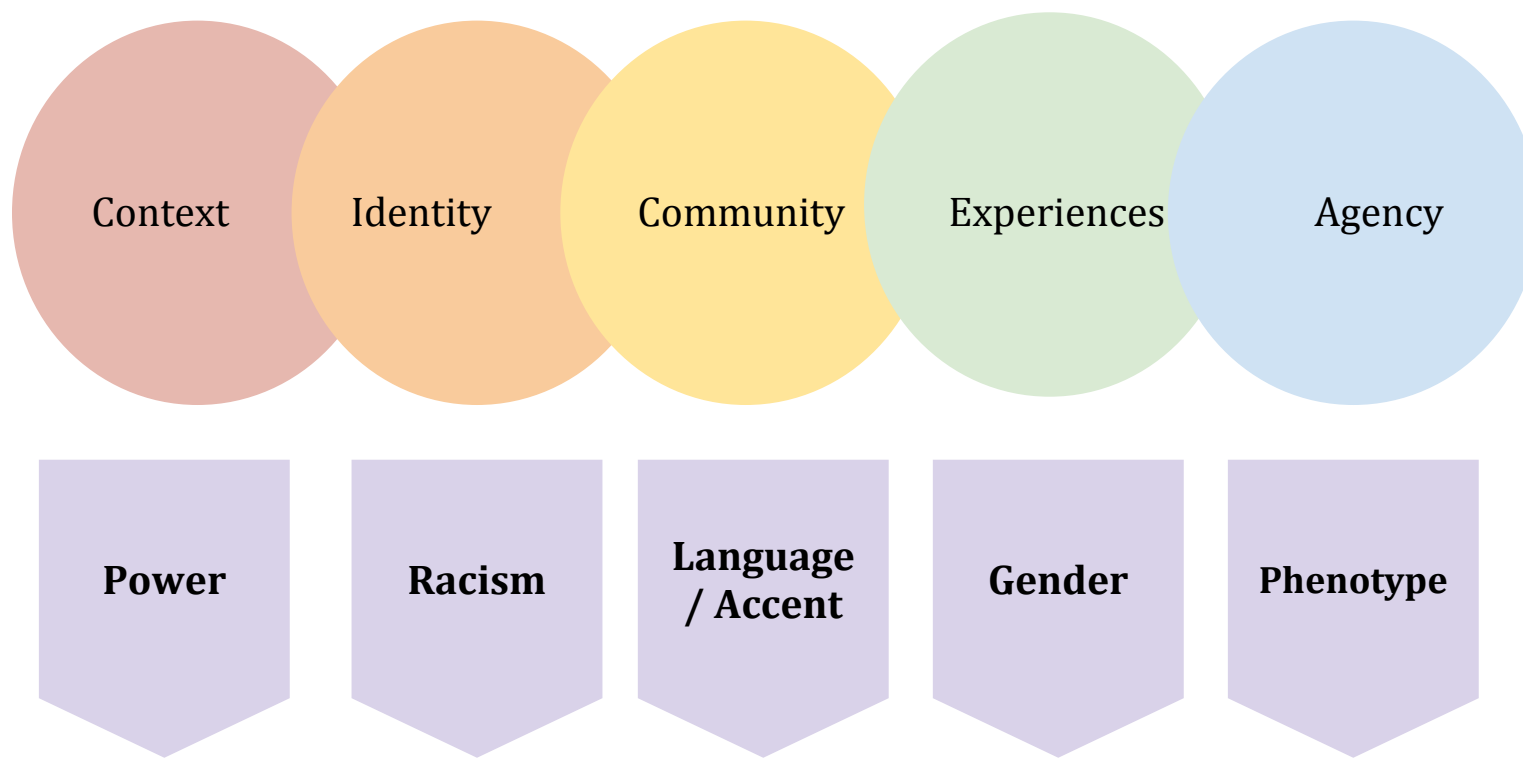

Figure 5.1. The components of Sociocultural theory and LatCrit work together to inform the synthesis of the findings.

In addition to Sociocultural theory, LatCrit adds a particular lens because of who the participants are, Latinx and bilingual. LatCrit provides a way to honor the stories and lived experiences unique to them as Latinx, taking into consideration the racism, linguicism, sexism, and classism that are part of their stories. It also helps us to understand the positionality and lack of agency they faced as young children and as students learning English. It brings into focus the power structure they were educated in and are educating in now, and the hierarchical and individualistic nature of education in the United States. LatCrit posits that the cultural and linguistic ways of knowing in the Latinx community differ from the mainstream, Euro-centric ways in U.S. schools (Yosso, 
2005). For example, community-orientation is a part of these bilingual teachers' ways of being, which is in conflict with the meritocratic and individualistic nature of U.S. schools (Kohli \& Pizarro, 2016). LatCrit offers an emphasis on experiential knowledge and a challenge to dominant ideologies, as Delgado Bernal (2002) explained,

For too long, the experiential knowledge of students of color has been viewed as a deficit in formal learning environments. Critical raced-gendered epistemologies allow this experiential knowledge to be viewed as a strength and acknowledge that the life experiences of students of color are "uniquely individual while at the same time both collective and connected" (Dillard, 2000, p. 676). (p. 109)

These life experiences and ways of knowing and relating must be a part of teaching and learning with bilingual students.

\section{Synthesis of Findings}

Becoming Bilingual. The findings discussed in Chapter 4 center around this study's three research questions. The first question asked participants to discuss their schooling experiences as bilingual learners. During those conversations, two broad themes emerged from the analysis: (a) Keeping Spanish and Learning English and (b) Tracking and Escaping the ESL Ghetto.

Keeping Spanish and Learning English. In the first theme, the data revealed that familial support recurred throughout. All three participants remember their parents valuing bilingualism, retaining their Mexican or Guatemalan culture, and having a positive cultural identity (Valenzuela, 1999). While it may have looked different among the participants, it was evident in their narratives that having someone in their family that valued and cultivated their home language and culture was an important factor in their eventual bilingualism. This finding affirms the literature; a strong foundation in native language literacy and strong command of the native language contributes to ELs' 
academic success in English (Cummins, 2008; Lightbown \& Spada, 2000; Wong-

Fillmore, 1991). It contributes to the growing body of literature, which connects academic success with a positive cultural identity (Prieto, 2014). Keeping Spanish was a critical part of their identity development as bilingual individuals.

The idea of "keeping Spanish" is not just a matter of linguistics, but a key component of guarding the cultural and familial roots of their emerging identities. This is an additive process to a foundational truth; that being immersed in the home language and culture, where English is not the dominant language, affirms bilingual and bicultural identity. Thomas and Collier (2002) explained what happens in the absence of strong bilingual/bicultural identity.

Power and identity issues come to the fore in institutions such as school, where the process of integration and assimilation creates a slow destruction of ethnolinguistic identity. Marginalized groups often experience ambivalence and insecurity in relation to their bilingual/bicultural identity, resulting in low achievement in school and underemployment in the workplace. (p. 41)

The implications of this finding lie with educators advocating for immigrant and multilingual families to keep their language and cultural roots. While family engagement activities at school can be well meaning, care must be given to provide culturally responsive activities that promote a family's funds of knowledge, instead of implying that the families are deficient and need to be 'educated' (Delgado Bernal \& Alemán, 2017). Baquedano-Lopez, Alexander, and Hernandez (2013) explained it this way,

Typical parental involvement practices often marginalize lower income and racial minority parents while creating pathways of access for White and middle-class parents. The important forms of education, socialization, and advocacy that nondominant parents do engage in are often not only disregarded but sometimes met with hostility by school leaders who interpret them as threatening or too critical. Families' lives are deeply shaped by racial, class, and migrant inequality 
but schools often fail to acknowledge or understand this, and thus participate in these inequalities, embracing deficit perspectives instead. (p. 172)

The stories of these bilingual teachers provided examples of how families in their schools were disregarded or treated with hostility, reflecting what Sociocultural and LatCrit literature report on the relationship between linguistically and culturally diverse families and schools. What this study adds are the ways these three bilingual teachers are actively working against these negative forces and embrace their students' families as partners in their students' education.

Tracking and Escaping the ESL Ghetto. The second theme that emerged included the transitional moment of leaving ESL settings and entering into mainstream educational settings, where the support for ELD was no longer provided. These participants were transitioned out of ESL and into advanced courses during their middle school years, which in turn prepared them for AP courses in High School. All the participants appeared to have salient memories of this transition. Confirming the literature on tracking, they recalled being the only or one of a few Latinx students in their advanced classes. As Cristina noted “... it was all White." This recollection is supported by the research about the prevalence of "tracking" ELLs into courses that do not "count" toward graduation as well as the underrepresentation of Latinx students in advanced or AP courses (Dabach, 2014; Umansky et al., 2016). Another interesting aspect of this finding is that none of the participants knew how they got out of their ESL track. This points toward implications for educators to help emergent bilingual students understand what the goals are of their ELD and/or sheltered classes, providing specific feedback, which is a key component for academic success (Hattie, 2009). 
As bilingual educators today, the participants could look back and understand the implications of what could have happened to them had they stayed on the "lower track." Both Cynthia and Cristina noticed their former peers in Elementary School did not have the same educational experiences and opportunities that they themselves were experienced in a "higher track" (Ochoa, 2013). Because of their experiences, their practice as bilingual teachers was impacted. They intentionally teach in an inclusive manner and give more time to those learners that need it, as demonstrated in Pass it on!.

These findings raise intriguing questions regarding the nature and extent of tracking for ELs. Studies indicate simply placing everyone in higher tracked classes or AP courses results in mass failure (Domina, McEachin, Penner, \& Penner, 2015) and continuing the current tracking practice is also disastrous (Callahan, 2005; Mosqueda, 2010). The findings from this study, combined with the current literature on tracking and Bilingual students indicates a need for further in-depth study on this topic.

Becoming Teachers. The findings from the second research question, regarding participants current teaching and learning experiences with bilingual students, came from in-depth interviews and multiple classroom observations. The main theme, Becoming Teachers, has two strong findings: First, Developing Into Teachers explores the paths to they took to becoming bilingual teachers and the lessons they have learned in the early years of teaching. Second, Culturally Responsive Teaching examines how the bilingual teachers in this study embody Culturally Responsive Teaching.

Developing Into Teachers. The development of these bilingual teachers took many paths. The findings suggest the transition between high school and college, or 
community college and a bachelor's degree are critical and the barriers they faced took many forms: high stakes standardized testing, colleges without certificates, and a lack of role models. Sociocultural theory and LatCrit both insist on understanding the historical context in order to make changes. Villalpando (2004) explained,

... it is important to understand how their history, which involves educational tracking and substandard schools, has affected Latinos' entry into higher education. Rather than accept the prevailing myths that Latinos and other students of color come from families that do not value higher education, this CRT and LatCrit tenet insists that we recognize how they have traditionally been tracked by ineffective schools into non-college-bound majors, which has resulted in their disproportionate attendance at community colleges that frequently decreases aspirations rather than sustains or builds them ... (p. 47)

Through internships or classified jobs in school, they found their way back to elementary schools, and eventually into a BTP program. Understanding these participants' stories and the historical context of Latinx students in the United States can inform educators, educational leaders, and policymakers to make changes to bridge key transitions and strengthen pathways for future bilingual educators.

Once the participants became teachers at bilingual schools, the topic of professional development also came up repeatedly, as helpful and a frustrating waste of time. This points to an implication that reaches out to districts and administrators of bilingual schools. There is a need to ensure that beginning teachers have time to plan, collaborate, and develop their classroom management with meaningful support. New bilingual teachers do not need a new method every week, but time for extended and indepth practice with important biliteracy strategies. In one instance, an instructional coach was offered and came monthly for help with management, which was reported to be very helpful. 
The research shows that in comparison to White teachers, teachers of Color are $24 \%$ more likely to leave the profession each year, for a variety of reason such as: teaching in higher poverty schools with less resources and more turnover, racism, and low teacher salaries (Gándara, 2010; Ingersoll \& May, 2011). Kohli and Pizarro (2016) described the tension that exists between Eurocentric school structures and the teachers of Color that are what they term as "community-oriented":

Community-oriented teachers of Color are often sought after because of their strong relationships with students and insider knowledge of the community. Ironically, an individualistic cultural paradigm of schools alienates these same teachers of Color from building on their insights and strengths. They are often pressured to dismiss the ways of being that they share with students and have developed as members of communities of Color. Schools that recruit communityoriented teachers of Color must recognize this ontological conflict. (p. 82)

The participants' stories highlight this ontological conflict; a concentrated mentoring program with other bilingual/bicultural teachers could benefit them during their critical beginning years (Bustos Flores, Riojas Clark, Claeys, \& Villareal, 2007). Retaining teachers, especially bilingual teachers, should be a priority that is examined with a historical lens and includes bilingual/bicultural ways of knowing and communityorientations.

Culturally Responsive Teaching. The bilingual teachers in this study consistently and constantly use strategies and ways of interacting which are considered Culturally Responsive Teaching, as noted by Gay (2010) in Chapter 2. Through observational data, it was noted that all three classrooms were democratically organized, in which students had choice, agency, and leadership roles. Participants described incidents in which they mentored parents and students to speak up about critical issues such as racism and bullying. Classroom lessons and conversations turned emancipatory as anti-tracking, anti- 
racism, and anti-sexism become the heart of many lessons modeled through literacy, mathematics, and daily interactions (Aronson \& Laughter, 2016; Ladson-Billings, 1994; Yosso, 2006). Curriculum, examples, and interactions were rooted in students' home language and cultural ways of knowing (Delpit, 2006; González et al., 2005). These findings also echo the results of prior studies, which have noted the importance of bridging language and culture for bilingual students (Escamilla et al., 2013; O. García et al., 2017).

More research like this may help us to understand how bilingual and bicultural teachers impact bilingual students learning and academic progress in elementary school. They understand their students from a unique vantage point, looking out at their students and their families, as they look within and draw on their own multidimensional experiences as students in U.S. schools, including being ELs, being Latinx, and as immigrants or from immigrant families. The tenets of Culturally Responsive Teaching are at the heart of working with bilingual students in today's diverse world. However, the teachers in this study go beyond being "responsive." They are teaching with this unique positionality, they are building bilingual and bicultural teaching and learning communities that affirm their students bilingual and bicultural identities.

The bilingual teachers in this study provided strong examples of how Culturally Responsive Teaching can be used as a model for teachers of bilingual and bicultural students. It is not outside the realm of new teacher pedagogical skills. This has implications for teacher educational programs to position Culturally and Linguistically Responsive Teaching as a model. For most teacher education programs, the amount of 
material covered within coursework can seem overwhelming with lesson planning, classroom management, methods courses and all the various requirements for content knowledge states mandate for teaching licensing. However, one of the specialized areas that gets left off the list of teacher education is how to connect and work with parents, families, and communities. This study points to the importance of this key knowledge, skill, and disposition in beginning teachers. In the increasingly diverse world and classrooms, learning how to be culturally responsive or congruent is essential for all teachers.

"It's complicated." A number of issues were identified in the data regarding bilingual teachers' professional experiences and expectations. The participants in this study spoke about how they were required to assess their students twice much, sometimes more, than their monolingual teacher counterparts. A recurrent theme in the interviews was a sense amongst participants that they often plan in isolation, translate and create their own material in Spanish, and bridge the curriculum and standards to match their students' language, culture, and learning levels; none of which is required of Englishonly teachers. The data also indicated these bilingual teachers teach in racially/ethnically segregated schools or are racially/ethnically and linguistically segregated within their schools, teach almost entirely emergent bilingual students, and almost all their students live in poverty. These results seem to be consistent with other research which found that Latinx students are the most segregated K-12 student population, by race/ethnicity, poverty, and language (Gándara \& Aldana, 2014) and have inequitable access to appropriate assessments, materials, and resources (E. García et al., 2010). 
"Me desinfla, me saca el aire." The findings in this theme address exhausting nature of being a bilingual teacher. The In Vivo code, “Te desinfla, te saca el aire," conveys the image of being deflated, the pressures and expectations that are unfairly placed on bilingual teachers and students is at times overwhelming. These bilingual teachers recognize that teaching and learning with bilingual students requires so much more than Spanish, like the Latina teachers in Weisman's (2001) study, they have to be, conscious of the ways in which schooling can exert pressure to suppress the cultural and linguistic identities of their Latino students ... It requires a more critical understanding of the role of language in the construction of identity and an awareness of how linguistic ideology can serve to either contribute to or contest divisions of power that work to the detriment of subordinate groups. (p. 222)

Indeed, these bilingual and bicultural teachers persist against a myriad of obstacles. LatCrit urges educators to understand the intersectionality of these issues and work for change. Yosso, Smith, Ceja, and Solórzano (2009) found Latino/a college students leaving their communities engage in three stages: "rejection, community building, and critical navigation between multiple worlds [and] rarely enjoy the same guarantee of ecological fit as do their White classmates" (p. 674).

The data suggest the bilingual teachers in this study also exist in these stages but exist concurrently. They are dismayed by and reject educational meritocracy and color blind ideology, build communities "that represent and reflect the cultural wealth of their home communities ... [and] foster skills of critical navigation between multiple worlds of home and school, academia, and community" (Yosso et al., 2009, p. 680). These findings indicate a need for further investigation on the aggregate effects of being a/the bilingual/bicultural teacher, teaching and learning with bilingual students, especially in 
majority minority schools. The findings also reflect a need for stronger supports for bilingual/bicultural teachers at school, district, and policy levels.

Pass it on! The findings show the bilingual teachers in this study draw upon their experiences growing up in the United States as Latinx emerging bilingual students in K12 schools, to pass on what they have learned. Knowing the institutional barriers, they tutor other future bilingual teachers to be able to pass the teacher exams. They also teach topics that most teachers are hesitant to discuss, much less plan lessons about, such as: racism, sexism, and classism. They also teach their students' families about Special Education; they served as a culture brokers to explain when students may need services and also as gatekeepers to explain to parents and colleagues when students do not. Reflecting on their own experiences, they modified, supported, and scaffolded, giving emerging bilingual students the ability to be successful in their classes. As mentioned in the literature review, emerging bilingual students are overrepresented in Special Education, and underrepresented in advanced courses. The present study raises the possibility that bilingual teachers, especially those who learned English in schools in the United States, may be better equipped to detect the nuances that assist in when determine when students may need Special Education services.

“I love being a bilingual.” The final subtheme came from an In Vivo code, "I love being a bilingual!" The love for bilingualism and biculturalism was pervasive message woven throughout the data. There was a sense of pride amongst all the participants in their bilingualism and biculturalism, which extended to their relationships with students, students' families, and colleagues. Cristina experienced a bilingual 
elementary school as a student. Her experiences exemplify how her affective and academic experiences in school were dramatically better in a bilingual setting in comparison to an English-only setting. There is a wide range of research demonstrating the positive benefits of valuing and using students' home language in the classroom, such as: increased literacy achievement in English (Cheung \& Slavin, 2012; Krashen \& McField, 2005; Slavin \& Cheung, 2005), a positive influence on academic and social self-esteem (Lee, 2008), and the development of a positive ethnic identity which is linked with academic success (Pizarro, 2005). The data suggest that language and culture act as a bonding agent in classrooms, creating a tightly knit community or family. The participants revel in the ways that language and culture bring closeness and mutual understanding in their classrooms. The relationships these bilingual teachers have with their students extends to their families. This creates connections between home and school, empowering parents to be an integral part of their student's education, which is quite different from typical bilingual students families' experiences (Baquedano-Lopez et al., 2013). Furthermore, sociocultural research suggests Latinx students from a community and family centered culture may benefit from educational settings that foster interdependence and collaboration (Annamma, Boelé, Moore, \& Klingner, 2013; Valenzuela, 1999; Weisman, Flores, \& Valenciana, 2007). Tatum (2017) explained that many students from Latinx homes view family as a "centripetal force" vs. mainstream White culture which views family as a "centrifugal force" from which to be liberated (p. 244). These results indicate the cultural congruence between Latinx bilingual teachers and bilingual students and their families may have a positive impact on the academic 
achievement of bilingual students in their classes (Au \& Kawakami, 1994; Delpit, 2006;

Gándara \& Hopkins, 2010; Ladson-Billings, 2014; Yosso \& Solórzano, 2006).

In conclusion, this section has synthesized the findings of this qualitative research study in regards to the research questions and the relevant literature. The next section discusses the recommendations, based on these findings.

\section{Recommendations}

The synthesis of results in this chapter indicates that bilingual/bicultural teachers offer a unique vantage to understanding teaching and learning with bilingual students, particularly those teachers that experienced learning English in school in the United States. The current data highlight the importance of sharing these experiences in order to create better learning environments and outcomes for bilingual students. The data show a variety of ways these bilingual teachers engage their bilingual students, through Culturally Responsive Teaching, relationships, and mindsets. This combination of findings provides support for the conceptual premise that supporting bilingualism and biculturalism in school strengthens the development of a positive bilingual identity (Riojas Clark, Jackson, \& Prieto, 2011), fosters familial cohesion (August, Goldenberg, \& Rueda, 2010), and increases academic success leading to attending college (Santibañez \& Zárate, 2014).

The need for more bilingual/bicultural educators, educational leaders, and policymakers is clear. This is not new - the nation is experiencing a shortage of ESOL/bilingual teachers — but with the population of emerging bilingual students growing so rapidly, the need for bilingual teachers is becoming a crisis. The bilingual 
teachers in this study showed a keen awareness of the intersection of language and literacy learning and their mutual influence, indicating the possibility that bilingual teachers may have an advantage to identifying areas that hold students back from advancing in literacy and foster ways to find success. This study is limited in scope but offers promise for future research. The evidence from this study suggests that bilingual teachers are strong advocates for their students, students' families, and their colleagues. These findings strongly support the need to recruit and retain more bilingual and bicultural teachers, which have important implications for supporting strong pathways for bilingual individuals to gain access to teacher preparation programs. In order to do this, teacher educator programs must provide a space for cultural and linguistic ways of knowing, experiences to be valued, and critical mentoring (Figueroa \& Rodriguez, 2015). From the participants, it was clear that a bilingual program provided a community for them while navigating a university setting to pursue their goals of becoming teachers.

In order to create equitable opportunities for bilingual learners, there needs to be bilingual educators, educational leaders, and policymakers at every decision-making table. Careful consideration must be had at every part of the teaching and learning process, from preschool to higher education. This change must begin from the moment bilingual students and their families walk in the door. Families of bilingual students need to be valued partners. School administrators, office staff, teachers, and instructional assistants need the training and practice to ensure families are involved in their students learning in a culturally respectful manner and treated with dignity. This includes time and format considerations for parent-teacher conferences, parent technology classes, and 
flexible scheduling to bring family members in after school. This needs to be part of a district/school organizational plan; connecting with families should not rest solely on the shoulders and hearts of bilingual teachers.

One way to begin to shift the culture of schools is to begin at the policy level, requiring minimally, that all teachers in the United States become ESOL endorsed or have courses that enable them to understand the process of second language acquisition and the powerful role of language and culture plays in the education process. Teacher Educator programs need to integrate these concepts/constructs into their program instead of adding one "course" to check off a requirement. It's not about adding a course to the transcript — but to changing the mindset and understanding of preservice teachers — so that they can be better prepared to work with diverse students and families. Ideally, all educators would also have experience living outside their own culture and learn a language in addition to English. Almost all teachers have emergent bilingual students in their classrooms. When teachers have experiences with the cultures and languages of their students, they are more likely to see their students' assets and feel more competent teaching them.

In addition to requiring that all teachers have linguistic and cultural competencies, policymakers and institutions of higher education should have de-tracking and desegregating at the top of the list as a way to move toward equity and social justice. Unfortunately, tracking and segregation work to give opportunities to the privileged and oppress the marginalized students. In order to make systemic and long-term changes, educators, educational leaders, and policy makers need to be educated on the insidious 
effects of tracking and segregation. They also need to know and act against the seemingly small decisions that are made by educators and policymakers, that add up to tracking and segregation and how to dismantle current systems. Policy makers, educators, and educational leaders must make this a priority, using an equity lens with multilingual/multicultural stakeholders making decisions.

This research study has brought up many questions in need of further investigation. There is a lack of research about the nature of being a bilingual teacher. We do know that, if bilingual teachers are working with bilingual students, they more likely to work in racially and linguistically segregated schools, with more students living in poverty, less academic resources, and as indicated by this study, with a significantly larger workload than their monolingual English speaking colleagues. They are often the only link between students' families and the schools. Although the current study is based on a small sample of participants, the findings demonstrate that these bilingual teachers are an invaluable resource in their elementary schools for students, families, and colleagues.

Further research needs to be done to investigate the experiences of a broader scope of bilingual teachers who are currently teaching bilingual students to determine if these results are generalizable. Taken as they are, these results indicate a need to adjust the amount of time bilingual teachers have to plan and collaborate with other bilingual teachers, the allocation of resources, take into consideration the important role they play with bilingual families and the advocacy work that comes with a being bilingual teacher (perhaps by eliminating other duties or including time for this in their schedules). These 
results also indicate a need to carefully plan mentoring and professional development, especially in the first three years. This has important implications for administrators and policy makers, as they consider the economic and educational value of bilingual educators in improving educational outcomes of bilingual students.

In summary, the purpose of this qualitative research study was to amplify the voices and experiences of bilingual teachers with the goal of improving schools for our growing population of bilingual students, by contributing to bilingual/bicultural educational literature and informing teacher preparation for future bilingual teachers and teachers of bilingual students. My hope is that by sharing the experiences of these three bilingual teachers, I have met the goal of this study. I am humbled beyond belief by each of them and it has truly been amazing to be a witness to their teaching and their stories. Spending time listening to and observing these bilingual teachers and their students was an honor and a privilege. In my role as a teacher educator working with bilingual preservice teachers today, I can honestly state that my teaching practice has been impacted; I draw upon the participants of this study in my daily work and often reference their teaching strategies, organization, interaction styles, stories, and the artifacts from their classrooms. Cristina, Hugo, and Cynthia are role models for all of us, as we strive to create community-oriented communities of learning for bilingual students. 


\section{References}

The American Heritage dictionary. (2015). Boston, MA: Houghton Mifflin Harcourt.

Amos, Y. T. (2013). Becoming a teacher of color: Mexican bilingual paraprofessionals' journey to teach. Teacher Education Quarterly, 40(3), 51-73.

Anderson, J. D. (2015). A long shadow: The American pursuit of political justice and education equality. Educational Researcher, 44(6), 319-335. Retrieved from https://doi.org/10.3102/0013189X15601427

Annamma, S., Boelé, A., Moore, B., \& Klingner, J. (2013). Challenging the ideology of normal in schools. International Journal of Inclusive Education, 17(12), 12781294. Retrieved from https://doi.org/10.1080/13603116.2013.802379

Aronson, B., \& Laughter, J. (2016). The theory and practice of culturally relevant education: A synthesis of research across content areas. Review of Educational Research, 86(1), 163-206. Retrieved from https://doi.org/10.3102/ 0034654315582066

Au, K., \& Kawakami, A. (1994). Cultural congruence in instruction. In E. R. Hollins, J. E. King, \& W. C. Hayman (Eds.), Teaching diverse populations: Formulating a knowledge base (pp. 5-24). New York, NY: State University of New York.

Aud, S., Fox, M. A., \& KewalRamani, A. (2010). Status and trends in the education of racial and ethnic groups (NCES 2010-015). Washington, DC: U. S. Department of Education, National Center for Education Statistics, Institute of Education Sciences.

August, D., Goldenberg, C., \& Rueda, R. (2010). Restrictive state language policies: Are they scientifically based? In P. Gándara \& M. Hopkin (Eds.), Forbidden language: English learners and restrictive language policy (pp. 139-158). New York, NY: Teachers College Press.

Ayón, C., \& Philbin, S. P. (2017). “Tú no eres de aquí”: Latino children's experiences of institutional and interpersonal discrimination and microaggressions. Social Work Research, 41(1), 19-30. Retrieved from https://doi.org/10.1093/swr/svw028

Ballón, E. G. (2015). Mexican Americans and education: El saber es poder. Tucson, AZ: The University of Arizona Press.

Baquedano-Lopez, P., Alexander, R. A., \& Hernandez, S. J. (2013). Equity issues in parental and community involvement in schools: What teacher educators need to know. Review of Research in Education, 37(1), 149-182. Retrieved from https://doi.org/10.3102/0091732X12459718 
Bilingual Education Act, Pub. L. No. (90-247), 88 Stat. 503 (1968).

Bilingual Education Act, Pub. L. No. (93-380), 92 Stat. 2268 (1974).

Boyd, D. J., Grossman, P. L., Lankford, H., Loeb, S., \& Wyckoff, J. (2009). Teacher preparation and student achievement. Educational Evaluation and Policy Analysis, 31(4), 416-440.

Brown v. Board of Educ., 347 U.S. 483 (1954).

Brown, D. H. (2007). Principles of language learning and teaching (5th ed.). White Plains, NY: Pearson Education.

Bunch, G. C. (2013). Pedagogical language knowledge: Preparing mainstream teachers for English learners in the new standards era. Review of Research in Education, 37(1), 298-341. Retrieved from https://doi.org/10.3102/0091732X12461772

Burciaga, R., \& Erbstein, N. (2012). Latina/o dropouts: Generating community cultural wealth. Association of Mexican American, 6(2), 24-33.

Bustos Flores, B., Riojas Clark, E., Claeys, L., \& Villareal, A. (2007). Academy for teacher excellence: Recruiting, preparing, and retaining Latino teachers through learning communities. Teacher Education Quarterly, 34(4), 53-69.

Calderón, M., Slavin, R., \& Sánchez, M. (2011). Effective instruction for English learners. The Future of Children, 21(1), 103-127. Retrieved from https://doi.org/10.1353/foc.2011.0007

Callahan, R. (2005). Tracking and high school English learners: Limiting opportunity to learn. American Educational Research Journal, 42(2), 305-328.

Casteñeda v. Pickard, 648 F.2d 989 (5th Cir. 1981).

Chávz, A. F., \& Guido-DiBrito, F. (1999). Racial and ethnic identity and development. New Directions for Adult and Continuing Education, Winter(84), 39-48.

Cheung, A. C. K., \& Slavin, R. (2012). Effective reading programs for Spanish-dominant English Language Learners (ELLs) in the elementary grades: A synthesis of research. Review of Educational Research, 82(4), 351-395. Retrieved from https://doi.org/10.3102/0034654312465472

Christian, D. (2006). Introduction. In F. Genesee, K. Lindholm-Leary, W. M. Saunders, \& D. Christian (Eds.), Educating English language learners: A synthesis of research evidence (pp. 1-13). New York, NY: Cambridge University Press. 
Coles, R. (1989). The call of stories: Teaching and the moral imagination. Boston, MA: Houghton Mifflin Company.

Cooperative Children's Book Center. (2015). Publishing statistics on children's books about people of color and First/Native Nations and by people of color and First/Native Nations authors and illustrators. Retrieved July 1, 2017, from https://ccbc.education.wisc.edu/books/pcstats.asp

Cosentino de Cohen, C. C., \& Clewell, B. C. (2007). Putting English language learners on the educational map: The No Child Left Behind Act implemented. Washington, DC: The Urban Institute.

Covarrubias, A. (2011). Quantitative intersectionality: A critical race analysis of the Chicana/o educational pipeline. Journal of Latinos and Education, 10(2), 86-105.

Creswell, J. W. (2007). Qualitative inquiry and research design (2nd ed.). Thousand Oaks, CA: Sage.

Creswell, J. W. (2009). Research design: Qualitative, quantitative, and mixed methods approaches (3rd ed.). Los Angeles, CA: Sage.

Cross, C. T., \& Manna, P. F. (2014). Political education: Setting the course for state and federal policy (2nd ed.). New York, NY: Teachers College Press.

Cummins, J. (2008). BICS and CALP: Empirical and theoretical status of the distinction. In B. Street \& N. H. Hornberger (Eds.), Encyclopedia of language and education (2nd ed., Vol. 2, pp. 71-83). New York, NY: Springer Science + Business Media.

Cummins, J., Bismilla, V., Chow, P., Cohen, S., Giampapa, F., Leoni, L., . . Sastri, P. (2005). ELL students speak for themselves: Identity texts and literacy engagement in multilingual classrooms. Curriculum, 1-15.

Dabach, D. B. (2014). "I am not a shelter!": Stigma and social boundaries in teachers' accounts of students' experience in separate "sheltered" English learner classrooms. Journal of Education for Students Placed at Risk, 19(2), 98-124.

Daniels, H. (2001). Vygotsky and pedagogy. New York, NY: Routledge.

Darling-Hammond, L. (2010). The flat world and education: How America's commitment to equity will determine our future. New York, NY: Teachers College Press.

de Jong, E. J. (2014). Preparing mainstream teachers for multilingual classrooms. Association of Mexican American Educators Journal, 7(2), 40-49.

Dee, T. S. (2004). Teachers, race, and student achievement in a randomized experiment. Review of Economics and Statistics, 86(1), 195-210. 
Delgado et al. v. Bastrop Independent School District et al., Civil No. 388 (W.D. Tex, 1948)

Delgado Bernal, D. (2002). Critical race theory, Latino critical theory, and critical racegendered epistemologies: Recognizing students of color as holders and creators of knowledge. Qualitative Inquiry, 8(1), 105-127.

Delgado Bernal, D., \& Alemán, E. (2017). Transforming educational pathways for Chicanalo students: A critical race feminista praxis. New York, NY: Teachers College Press.

Delpit, L. (1988). The silenced dialogue: Power and pedagogy in educating other people's children. Harvard Educational Review, 58(3), 280-299. Retrieved from https://doi.org/10.17763/haer.58.3.c43481778r528qw4

Delpit, L. (2006). Other people's children: Cultural conflict in the classroom (2nd ed.). New York, NY: The New Press.

Domina, T., McEachin, A., Penner, A., \& Penner, E. (2015). Aiming high and falling short: California's eighth-grade algebra-for-all effort. Educational Evaluation and Policy Analysis, 37(3), 275-295.

Dyson, A. H., \& Genishi, C. (1994). Introduction: The need for story. In A. H. Dyson \& C. Genishi (Eds.), The need for story: Cultural diversity in classroom and community (pp. 1-7). Urbana, IL: National Council of Teachers of English.

Echevarria, J., Vogt, M., \& Short, D. (2002). Making content comprehensible for English learners: The SIOP model. TESL Reporter (4th ed.). Boston, MA: Pearson. Retrieved from https://journals.lib.byu.edu/spc/index.php/TESL/article/ viewFile/3802/3548

Escamilla, K. (2006). Semilingualism applied to the literacy behaviors of Spanishspeaking emerging bilinguals: Bi-illiteracy or emerging biliteracy? Teachers College Record, 108(11), 2329-2353. Retrieved from https://doi.org/10.1111/ j.1467-9620.2006.00784.x

Escamilla, K., Hopewell, S., Butvilofsky, S., Sparrow, W., Soltero-González, L., RuizFigueroa, O., \& Escamilla, M. (2013). Biliteracy from the start: Literacy squared in action. Philadelphia, PA: Caslon Publishing.

Faltis, C. (2013). Language, language development and teaching English to emergent bilingual users: Challenging the common knowledge theory in teacher education \& K-12 school settings. Journal of the Association of Mexican American Educators, 7(2), 18-29. Retrieved from http://search.ebscohost.com/login.aspx? direct=true $\& \mathrm{db}=$ eric $\& A N=E J 1017072 \&$ site=ehost-live $\% 5 \mathrm{Cnhttp}: / /$ amaejournal. asu.edu/index.php/amae/article/view/123 
Faltis, C., Arias, M. B., \& Ramírez-Marín, F. (2010). Identifying relevant competencies for secondary teachers of English learners. Bilingual Research Journal, 33(3), 307-328. Retrieved from https://doi.org/10.1080/15235882.2010.529350

Feistritzer, C. E. (2011). Profile of teachers in the U.S. 2011. Washington, DC: National Center for Education Information. Retrieved from http://www.edweek.org/ media/pot2011final-blog.pdf

Figueroa, J. L., \& Rodriguez, G. M. (2015). Critical mentoring practices to support diverse students in higher education: Chicana/Latina faculty perspectives. In I. Wiley Periodicals (Ed.), New Directions for Higher Education (pp. 23-32). Retrieved from https://doi.org/10.1002/he

Fitts, S., \& Weisman, E. M. (2010). Exploring questions of social justice in bilingual/ bicultural teacher education: Towards a parity of participation. Urban Review, 42(5), 373-393. Retrieved from https://doi.org/10.1007/s11256-009-0139-9

Flores, B. B., Sheets, R. H., \& Clark, E. R. (2011). Teacher preparation for bilingual student populations: Educar para transformar. New York, NY: Routledge Taylor $\&$ Francis.

Flores, N. (2016). A tale of two visions: Hegemonic Whiteness and bilingual education. Educational Policy, 30(1), 13-38. Retrieved from https://doi.org/10.1177/ 0895904815616482

Flores, N., \& Rosa, J. (2015). Undoing appropriateness: Raciolinguistic ideologies and language diversity in education. Harvard Educational Review, 85(2), 149-172.

Freire, P. (1998). Pedagogy of the heart. New York, NY: Bloomsbury.

Gamoran, A. (2010). Tracking and inequality: New directions for research and practice (WCER Working Paper No . 2009-6). Madison, WI: University of WisconsinMadison, Wisconsin Center for Education Research.

Gamoran, A. (2017). Engaging English Learners with rigorous academic content: Insights from research on tracking. New York, NY: William T. Grant Foundation.

Gándara, P. (2010). Overcoming triple segregation. Educational Leadership, 68(3), 60-64.

Gándara, P., \& Aldana, U. (2014). Who’s segregated now? Latinos, language, and the future of integrated schools. Educational Administration Quarterly, 50, 735-748. Retrieved from https://doi.org/10.1177/0013161X14549957 
Gándara, P., \& Contreras, F. (2009). The Latino education crisis: The consequences of failed social policies. Cambridge, MA: Harvard University Press.

Gándara, P., \& Hopkins, M. (2010). Forbidden language: English learners and restrictive language policies. New York, NY: Teachers College Press.

Gándara, P., \& Orfield, G. (2010). A return to the "Mexican Room": The segregation of Arizona's English learners. Retrieved from http://escholarship.org/uc/item/ 7m67q3b9

Gándara, P., Rumberger, R., Maxwell-Jolly, J., \& Callahan, R. (2003). English learners in California schools: Unequal resources, unequal outcomes. Education Policy Analysis Archives, 11(36), 1-54.

García, E., Arias, M. B., Harris Murri, N. J., \& Serna, C. (2010). Developing responsive teachers: A challenge for a demographic reality. Journal of Teacher Education, 61(1-2), 132-142. Retrieved from https://doi.org/10.1177/0022487109347878

García, E., Lawton, K., \& Diniz de Figueiredo, E. H. (2011). The civil rights project/ Proyecto derechos civiles. The Civil Rights Project, 1-35.

García, O., Ibarra Johnson, S., \& Seltzer, K. (2017). The translanguaging classroom: Leveraging student bilingualism for learning. Philadelphia, PA: Caslon.

García, O., \& Wei, L. (2014). Translanguaging: Language, bilingualism and education. Translanguaging: Language, bilingualism and education. New York, NY: Palgrave Macmillan. Retrieved from https://doi.org/10.1057/9781137385765

García, O., Woodley, H. H., Flores, N., \& Chu, H. (2012). Latino emergent bilingual youth in high schools: Transcaring strategies for academic success. Urban Education, 48, 798-827. Retrieved from https://doi.org/10.1177/ 0042085912462708

Gardner, D. P., Larsen, Y. W., Baker, W., Campbell, A., \& Crosby, E. A. (1983). A nation at risk: The imperative for educational reform. Washington, DC: United States Department of Education. Retrieved from https://doi.org/10.2307/3323945

Gay, G. (2010). Culturally responsive teaching: Theory, research, and practice (2nd ed.). New York, NY: Teachers College Press.

Gay, G. (2015). Teachers' beliefs about cultural diversity: Problems and possibilities. In H. Fives \& M. Gregoire Gill (Eds.), International handbook of research on teachers' beliefs (pp. 436-452). New York, NY: Routledge. 
Genesee, F., Lindholm-Leary, K., Saunders, W., \& Christian, D. (Eds.). (2006). Educating English language learners: A synthesis of research evidence. New York, NY: Cambridge University Press. Retrieved from https://books.google. com/books?id=pZyyoMk1lpMC

Glesne, C. (2016). Becoming qualitative researchers: An introduction (5th ed.). Boston, MA: Pearson.

Gonzales v. Sheely, 96 F. Supp.1004 (D.C. Ariz. 1951).

González, N., Moll, L. C., \& Amanti, C. (2005). Funds of knowledge: Theorizing practices in households, communities, and classrooms. New York, NY: Routledge Taylor \& Francis.

Goodman, A. (2008). Exposing race as an obsolete biological concept. In M. Pollock (Ed.), Everyday antiracism: Getting real about race in school (Kindle ed.; pp. 4-8). New York, NY: The New Press.

Hakuta, K. (2011). Educating language minority students and affirming their equal rights: Research and practical perspectives. Educational Researcher, 40(4), 163-174. Retrieved from https://doi.org/10.3102/0013189X11404943

Haneda, M. (2008). Contexts for Learning: English Language Learners in a U.S. Middle School. International Journal of Bilingual Education and Bilingualism, 11(1), 57-74. Retrieved from https://doi.org/10.2167/beb425.0

Hattie, J. (2009). Visible learning: A synthesis of over 800 meta-analyses relating to achievement. New York, NY: Routledge Taylor \& Francis Group.

Hopkins, M., Thompson, K. D., Linquanti, R., Hakuta, K., \& August, D. (2013). Fully accounting for English learner performance: A key issue in ESEA reauthorization. Educational Researcher, 42, 101-108. Retrieved from https://doi.org/10.3102/0013189X12471426

Hornberger, N. H. (2007). Biliteracy, transnationalism, multimodality, and identity: Trajectories across time and space. Linguistics and Education, 18, 325-334.

Ingersoll, R., \& May, H. (2011). Recruitment, retention and the minority teacher shortage (Consortium for Policy Research in Education [CPRE] Research Report \#RR-69). Retrieved from https://doi.org/10.1037/e546592012-001

Irizarry, J. (2011). En la lucha: The struggles and triumphs of Latino/a preservice teachers. Teachers College Record, 113(12), 2804-2835. 
Kamhi-Stein, L. D., Aagard, A., Ching, A., Paik, M.-S. A., \& Sasser, L. (2004). Teaching in kindergarten through grade 12 programs: Perceptions of native and nonnative English-speaking practitioners. In L. D. Kamhi-Stein (Ed.), Learning and teaching from experience: Perspectives on nonnative English-speaking professionals (pp. 81-99). Ann Arbor, MI: The University of Michigan Press.

Kohli, R., \& Pizarro, M. (2016). Fighting to educate our own: Teachers of color, relational accountability, and the struggle for racial justice. Equity and Excellence in Education, 49(1), 72-84. Retrieved from https://doi.org/10.1080/ 10665684.2015.1121457

Kozol, J. (2005). The shame of the nation: The restoration of apartheid schooling in America. New York, NY: Crown Publishers.

Kozol, J., Tatum, B. D., Eaton, S., \& Gándara, P. (2010). Resegregation: What's the answer? Educational Leadership, 68(3), 28-31. Retrieved from http://www.ncbi. nlm.nih.gov/pmc/articles/PMC1593767/\%5Cnhttp://scholar.google.com/scholar?h $\mathrm{l}=$ en\&btnG=Search\&q=intitle:Resegregation:+What's+the+Answer?\#1

Krashen, S. (1982). Principles and practice in second language acquisition. Oxford, England: Pergamon Press.

Krashen, S., \& McField, G. (2005). What works? Reviewing the latest evidence on bilingual education. Language Learner, 1, 7-10, 34.

Krathwohl, D. R. (2009). The methods of educational and social science research: The logic of methods (3rd ed.). Long Grove, IL: Waveland Press, Inc.

Ladson-Billings, G. (1994). The dreamkeepers: Successful teachers of African American children. San Francisco, CA: Jossey-Bass.

Ladson-Billings, G. (2006). From the achievement gap to the education debt: Understanding achievement in U.S. schools. Educational Researcher, 35(7), 3-12. Retrieved from https://doi.org/10.3102/0013189X035007003

Ladson-Billings, G. (2009). Just what is critical race theory and what's it doing in a nice field like education? In E. Taylor, D. Gillborn, \& G. Ladson-Billings (Eds.), Foundations of Critical Race Theory in education (pp. 17-35). New York, NY: Routledge.

Ladson-Billings, G. (2014). Culturally relevant pedagogy 2.0: A.k.a. the Remix. Harvard Educational Review, 84(1). Retrieved from https://doi.org/10.17763/haer.84.1. p2rj131485484751

Lau v. Nichols, 414 U.S. 56 (1974). 
Lave, J. (1996). Teaching, as learning, in practice. Mind, Culture, and Activity, 3(3), 149164. Retrieved from https://doi.org/10.1207/s15327884mca0303_2

Lee, J. W. S. (2008). The effect of ethnic identity and bilingual confidence on Chinese youth's self-esteem. Alberta Journal of Educational Research, 54(1), 83-96.

Leonardo, Z. (2015). Contracting race: Writing, racism, and education. Critical Studies in Education, 56(1), 86-98. Retrieved from https://doi.org/10.1080/ 17508487.2015.981197

Lewis, C., Enciso, P., \& Moje, E. B. (2007). Introduction: Reframing sociocultural research on literacy. Reframing Sociocultural Research on Literacy: Identity, Agency, and Power, 12(3), 1-11.

Lhamon, C., \& Gupta, V. (2015). Dear colleague letter: English learner students and limited English proficient parents. Retrieved from https://www2.ed.gov/ about/offices/list/ocr/letters/colleague-el-201501.pdf

Lightbown, P. M., \& Spada, N. (2000). How languages are learned (2nd ed.). Oxford, England: Oxford University Press.

Loeb, S., Soland, J., \& Fox, L. (2014). Is a good teacher a good teacher for all? Comparing value-added of teachers with their English learners and non-English learners. Educational Evaluation and Policy Analysis, 36(4), 457-475. Retrieved from https://doi.org/10.3102/0162373714527788

López, G., Harvey, L., \& Chesnut, C. (2013). Latino English language learners in a changing demographic landscape. In L. Tillman \& J. J. Scheurich (Eds.), Handbook of research on educational leadership for equity and diversity (pp. 257-286). New York, NY: Routledge.

Lucas, T. (Ed.). (2011). Teacher preparation for linguistically diverse classrooms: A resource for teacher educators. New York, NY: Routledge. Retrieved from https://doi.org/10.4324/9780203843239

Lucas, T., \& Grinberg, J. (2008). Responding to the linguistic reality of mainstream classrooms: Preparing all teachers to teach English language learners. In M. Cochran-Smith, S. Feinman-Nemser, \& D. J. McIntyre (Eds.), Handbook of research on teacher education: Enduring questions in changing contexts (3rd ed., pp. 606-636). New York, NY: Routledge.

Lucas, T., Villegas, A. M., \& Freedson-Gonzalez, M. (2008). Linguistically responsive teacher education: Preparing classroom teachers to teach English language learners. Journal of Teacher Education, 59(4), 361-373. Retrieved from https://doi.org/10.1177/0022487108322110 
Lucas, T., Villegas, A. M., \& Martin, A. D. (2015). Teachers' beliefs about English language learners. In H. Fives \& M. Gregoire Gill (Eds.), International handbook of research on teachers and teaching (pp. 453-475). New York, NY: Routledge.

Macedo, D., \& Bartolomé, L. I. (2014). Multiculturalism permitted in English only. International Multilingual Research Journal, 8(1), 24-37. Retrieved from https://doi.org/10.1080/19313152.2014.852426

Master, B., Loeb, S., Whitney, C., \& Wyckoff, J. (2016). Different skills? Identifying differentially effective teachers of English language learners. The Elementary School Journal, 117(2), 261-284.

Maxwell, J. A. (2013). Qualitative research design: An interactive approach (3rd ed.). Thousand Oaks, CA: Sage.

McField, G. (Ed.). (2014). The Miseducation of English learners: A tale of three states and lessons to be learned. Charlotte, NC: Information Age Publishing. Retrieved from https://books.google.com/books?hl=en\&lr=\&id=1gQoDwAAQBAJ\&oi= fnd\&pg=PP1\&dq=mcfield $+2014+$ english+only\&ots $=$ H53QDA7vKZ\&sig=tCask BM8_5rmaaNOq6eH76toR64\#v=onepage\&q=mcfield 2014 english only\&f=false

McLaren, P. (2015). Life in schools: An introduction to critical pedagogy in the foundations of education (6th ed.). New York, NY: Taylor \& Francis.

Mendez et al. v. Westminster School District of Orange County, 64 F. Supp. 544 (S.D. Cal. 1946), aff'd, 161 F.2d 774 (9th Cir. 1947) (1947).

Menken, K., \& Solorza, C. (2015). Principals as linchpins in bilingual education: The need for prepared school leaders. International Journal of Bilingual Education and Bilingualism, 18(6), 676-697. Retrieved from https://doi.org/10.1080/ 13670050.2014.937390

Merriam, S. B. (1998). Case studies as qualitative research. Qualitative research and case study applications in education: Revised and expanded from case study research in education (2nd ed.). San Francisco, CA: Jossey-Bass.

Merriam, S. B., \& Tisdell, E. J. (2016). Qualitative research: A guide to design and implementation (4th ed.). San Francisco, CA: Jossey-Bass.

Milner, H. R., IV. (2010). Start where you are, but don't stay there: Understanding diversity, opportunity gaps, and teaching in today's classrooms. Cambridge, MA: Harvard Education Press.

Mitchell, C. (2018). The national shortage of ELL teachers has caught the eye of congress. Retrieved March 26, 2018, from http://blogs.edweek.org/edweek/ learning-the-language/2018/01/solve_ell_teacher_shortage.html 
Molle, D. (2013). The pitfalls of focusing on instructional strategies in professional development for teachers of English learners. Teacher Education Quarterly, 40(1), 101-124. Retrieved from http://proxy.mul.missouri.edu/login?url= http://search.ebscohost.com/login.aspx?direct=true \&db=eric\&AN=EJ1014349\&si te=ehost-live\%5Cnhttp://www.teqjournal.org/

Mondale, S. (Director). (2001). School: The story of as American as public education 1900-1950. American Public Education Series[Video file]. United States: Public Broadcasting Service. Retrieved June 6, 2018, from http://stats.lib.pdx.edu/ proxy.php?url=http://fod.infobase.com/PortalPlaylists.aspx?seriesID=1538\&wID $=102733$

Moore, S. C. K., Fee, M., Ee, J., Wiley, T. G., \& Arias, M. B. (2014). Exploring bilingualism, literacy, employability and income levels among Latinos in the United States. In R. Callahan \& P. Gándara (Eds.), The bilingual advantage: Language, literacy and the U.S. labor market (pp. 45-71). Toronto, Canada: Multilingual Matters.

Morillo-Campbell, M., \& Arias, M. B. (2008). Promoting ELL parental involvement: Challenges in contested times. Retrieved from http://epsl.asu.edu/epru/ documents/EPSL-0801-250-EPRU.pdf

Mosqueda, E. (2010). Compounding inequalities: English proficiency and tracking and their relation to mathematics performance among Latina/o secondary school youth. Journal of Urban Mathematics Education, 3(1), 57-81.

Motha, S. (2014). Race, empire, and English language teaching: Creating responsible and ethical anti-racist practice. New York, NY: Teachers College Press.

Musanti, S. I. (2014). "Porque sé los dos idiomas": Biliteracy beliefs and bilingual preservice teacher identity. In Y. Freeman \& D. Freeman (Eds.), Research on preparing preservice teachers to work effectively with emergent bilinguals (Advances in research on teaching (Vol. 21; pp. 59-87). Retrieved from https://doi.org/10.1108/S1479-368720140000021002

National Center for Education Statistics. (2016a). The condition of education 2016. Retrieved from https://nces.ed.gov/ pubs2016/2016144.pdf

National Center for Education Statistics. (2016b). English language learners in public schools, 2016. Retrieved from https://nces.ed.gov/programs/raceindicators/ indicator_rbc.asp\%0D

National Center for Educational Statistics. (2017). The condition of education 2017 (NCES 2017-144). Washington, DC: U.S. Government Printing Office. 
National Dropout Prevention Center. (2018). Economic impoacts of dropouts. Retrieved from http://dropoutprevention.org/resources/statistics/quick-facts/economic-impactsof-dropouts/

Nieto, S. (2000). Placing equity front and center: Some thoughts on transforming teacher education for a new century. Journal of Teacher Education, 51(3), 180-187. Retrieved from https://doi.org/10.1177/0022487100051003004

Nieto, S. (2002). Language, culture, and teaching: Critical perspectives for a new century. Mahwah, NJ: Lawrence Erlbaum Associates.

Nieto, S. (2010). The light in their eyes: Creating multicultural learning communities (10th anniv). New York, NY: Teachers College Press.

Nieto, S., \& Bode, P. (2012). Affirming diversity: The sociopolitical context of multicultural education (6th ed.). Boston, MA: Pearson.

No Child Left Behind Act of 2001, Pub. L. No. 107-110, § 115, Stat. 1425 (2002).

Noddings, N. (2012). The language of care. Knowledge Quest, 40(4), 52-56. Retrieved from https://doi.org/10.1177/1745691612459060.

Noguera, P. A. (2003). The trouble with Black boys: The role and influence of environmental and cultural factors on the academic performance of African American males. Urban Education, 38(4), 431-459. Retrieved from https://doi.org/10.1177/0042085903254969

Noguera, P. A. (2008). The trouble with Black boys: And other reflections on race, equity, and the future of public education. San Francisco: Jossey-Bass.

Ocasio, K. M. (2014). Nuestro camino: A review of literature surrounding the Latino teacher pipeline. Journal of Latinos and Education, 13(4), 244-261. Retrieved from https://doi.org/10.1080/15348431.2014.887467

Ochoa, G. L. (2007). Learning from Latino teachers. San Francisco, CA: Jossey-Bass.

Ochoa, G. L. (2013). Academic profiling: Latinos, Asian Americans, and the achievement gap. Minneapolis, MN: University of Minnesota Press.

Oregon Education Investment Board. (2013). English learners in Oregon's education system. (2013). Salem, OR: Author.

Orfield, G., \& Frankenberg, E. (2014). Increasingly segregated and unequal schools as courts reverse policy. Educational Administration Quarterly, 50(5), 718-734. Retrieved from https://doi.org/10.1177/0013161X14548942 
Orfield, G., Kucsera, J., \& Siegel-Hawley, G. (2012). E Pluribus . . separation: Deepening double segregation for more students. Retrieved from https://escholarship.org/uc/item/8g58m2v9

Orosco, M. J., \& O’Connor, R. (2014). Culturally responsive instruction for English language learners with learning disabilities. Journal of Learning Disabilities, 47(6), 515-531. Retrieved from https://doi.org/10.1177/0022219413476553

Palmer, D., \& Martínez, R. A. (2013). Teacher agency in bilingual spaces: A fresh look at preparing teachers to educate Latina/o bilingual children. Review of Research in Education, 37, 269-297. Retrieved from https://doi.org/ 10.3102/0091732X12463556

Pappamihiel, E. (2007). Helping preservice content-area teachers relate to English language learners: An investigation of attitudes and beliefs. Retrieved January 19, 2015, from http://www.teslcanadajournal.ca/index.php/tesl/article/viewFile/ $138 / 138$

Perry, K. H. (2012). What is literacy? A critical overview of sociocultural perspectives. Journal of Language and Literacy Education [Online], 8(1), 50-71. Retrieved from http://jolle.coe.uga.edu/wp-content/uploads/2012/06/What-isLiteracy_KPerry.pdf

Pimentel, C. (2011). The color of language: The racialized educational trajectory of an emerging bilingual student. Journal of Latinos and Education, 10(4), 335-353. Retrieved from https://doi.org/10.1080/15348431.2011.605686

Pizarro, M. (2005). Chicanas and Chicanos in school: Racial profiling, identity battles, and empowerment. Austin, TX: University of Texas Press.

Polat, N., Zarecky-Hodge, A., \& Schreiber, J. B. (2016). Academic growth trajectories of ELLs in NAEP data: The case of fourth- and eighth-grade ELLs and non-ELLs on mathematics and reading tests. Retrieved from https://doi.org/10.1080/00220671. 2014.993461

Prieto, L. (2014). Conciencia con compromiso: Aspirantes as bridges for Latin@ bilingual learners. Association of Mexican-American Educators, 8(1), 10-19.

Quiroz, P. (2001). The silencing of Latino student "voice": Puerto Rican and Mexican narratives in eighth grade and high school. Anthropology \& Education Quarterly, 32(3), 326-349. Retrieved from https://doi.org/10.1525/aeq.2001.32.3.326

Riojas Clark, E., Jackson, L. G., \& Prieto, L. (2011). Identity: A central facet of culturally efficacious bilingual education teachers. In Teacher preparation for linguistically diverse classrooms: A resource for teacher educators (pp. 27-39). New York, NY: Routledge. 
Roda, A., \& Wells, A. S. (2013). School choice policies and racial segregation: Where White parents' good intentions, anxiety, and privilege collide. American Journal of Education, 119(2). Retrieved from https://doi.org/10.1086/668753

Romo, V. (2013). English-language learners: Public school's forgotten kids. Retrieved January 1, 2015, from http://www.takepart.com/article/2013/06/25/englishlanguage-learners-struggle-public-schools

Rubin, H. J., \& Rubin, I. S. (2012). Qualitative interviewing: The art of hearing data (3rd ed.). Los Angeles, CA: Sage.

Ryan, C. (2013). Language use in the United States: 2011. Retrieved from https://doi.org/ACS-22

Saldaña, J. (2013). The coding manual for qualitative researchers. Thousand Oaks, CA: Sage.

Salinas, C., \& Castro, A. J. (2010). Disrupting the official curriculum: Cultural biography and the curriculum decision making of Latino preservice teachers. Theory and Research in Social Education, 38(3), 428-463. Retrieved from https://doi.org/10.1080/00933104.2010.10473433

Sánchez, P., \& Machado-Casas, M. (2016). At the intersection of transnationalism, Latina/o immigrants, and education. The High School Journal, 92(4), 3-15.

Santibañez, L., \& Zárate, M. E. (2014). Bilinguals in the U.S. and college enrollment. In R. Callahan \& P. Gándara (Eds.), The bilingual advantage: Language, literacy and the U.S. labor market (pp. 211-233). Toronto, Canada: Multilingual Matters.

Scanlan, M., \& Lopez, F. (2012). ¡Vamos! How school leaders promote equity and excellence for bilingual students. Educational Administration Quarterly, 48(4), 583-625. Retrieved from https://doi.org/10.1177/0013161X11436270

Scott, S., \& Palincsar, A. (2013). Sociocultural theory. Retrieved November 20, 2016, from http://dr-hatfield.com/theorists/resources/sociocultural_theory.pdf

Seidman, I. (2013). Interviewing as qualitative research: A guide for researchers in education and the social sciences (4th ed.). New York, NY: Teachers College Press.

Sensoy, O., \& DiAngelo, R. (2017). Is everyone really equal?: An introduction to key concepts in social justice education (2nd ed.). New York, NY: Teachers College Press.

Singleton, G. E. (2013). More courageous conversations about race. Thousand Oaks, CA: Corwin. 
Slavin, R. E., \& Cheung, A. (2005). A synthesis of research on language of reading instruction for English language learners. Review of Educational Research Review of Educational Research, 75(2), 247-284. Retrieved from https://doi.org/10.3102/ 00346543075002247

Steele, C. M. (2009). A threat in the air: How stereotypes shape intellectual identity and performance. In E. Taylor, D. Gillborn, \& G. Ladson-Billings (Eds.), Foundations of Critical Race Theory in education (pp. 163-189). New York, NY: Routledge Taylor \& Francis.

Steele, C. M. (2010). Whistling Vivaldi: How stereotypes affect us and what we can do. New York, NY: W. W. Norton \& Company. Retrieved from https://doi.org/ 10.1126/science.1194619

Steele, D. M., \& Cohn-Vargas, B. (2013). Identity safe classrooms: Places to belong and learn. New York, NY: Corwin.

Tatum, B. D. (2017). Why are all the Black kids sitting together in the cafeteria?: And other conversations about race (20th Anniv). New York, NY: Basic Books.

Téllez, K., \& Mosqueda, E. (2015). Developing teachers' knowledge and skills at the intersection of English language learners and language assessment. Review of Research in Education, 39, 87-121. Retrieved from https://doi.org/ $10.3102 / 0091732 \times 14554552$

Thomas, W. P., \& Collier, V. P. (2002). A national study of school effectiveness for language minority students' long-term academic achievement. Santa Cruz, CA: University of California Santa Cruz, Center for Research on Education, Diversity and Excellence.

Title VI Civil Rights Act, $69 \S 7$ (1964).

Umansky, I. M., Valentino, R. A., \& Reardon, S. F. (2016). Promise of two-language education. Educational Leadership, 73(5), 10-17.

United State Census Bureau. (2016). FFF: Back to school: 2016-2017 (Release No. CB16-FF.15). Retrieved Retrieved from https://www.census.gov/newsroom/factsfor-features/2016/cb16-ff15.html

United States Department of Education. (2015). Race. Retrieved October 4, 2015, from https://www.census.gov/topics/population/race/about.html

United States Department of Education. (2016). National- and state-level high school, 2016. Retrieved from https://www2.ed.gov/admins/lead/account/ consolidated/index.html 
Urrieta, L. (2006). Community identity discourse and the heritage academy: Colorblind educational policy and White supremacy. International Journal of Qualitative Studies in Education, 19(4), 455-476. Retrieved from https://doi.org/10.1080/ 09518390600773197

Valdés, G. (2001). Learning and not learning English: Latino students in American schools. New York, NY: Teachers College Press.

Valdés, G., Menken, K., \& Castro, M. (Eds.). (2015). Common core bilingual and English language learners: A resource for educators. Philadelphia, PA: Caslon.

Valencia, R. R. (2002). The plight of Chicano students: An overview of schooling conditions and outcomes. In R. R. Valencia (Ed.), Chicano school failure and success: Past, present, and future (2nd ed., pp. 3-51). New York, NY: RoutledgeFalmer.

Valenzuela, A. (1999). Subtractive schooling: U.S.-Mexican youth and the politics of caring. Albany, NY: State University of New York Press.

Varghese, M., \& Stritikus, T. (2005). "Nadie me dijo (nobody told me)": Language policy negotiation and implications for teacher education. Journal of Teacher Education, 56(1), 73-87. Retrieved from https://doi.org/10.1177/ 0022487104272709

Villalpando, O. (2004). Practical considerations of critical race theory and Latino critical theory for Latino college students. New Directions for Student Services, 2004(105), 41-50. Retrieved from https://doi.org/10.1002/ss.115

Villegas, A. M., \& Lucas, T. (2011). Preparing classroom teachers for English language learners: The policy context. In T. Lucas (Ed.), Teacher preparation for linguistically diverse classrooms: A resource for teacher educators (pp. 35-52). New York, NY: Routledge Taylor \& Francis.

Vogt, W. P., Gardner, D. C., \& Haeffele, L. M. (2012). When to use what research design. New York, NY: The Guilford Press.

Waxman, H., Téllez, K., \& Walberg, H. J. (2004). Improving teacher quality for English language learners: Reports and next-step recommendations from a national invitational conference. The Laboratory for Student Success Review, 3(1), 1-3.

Weisman, E. M. (2001). Bicultural identity and language attitudes: Perspectives of four Latina teachers. Urban Education, 36(3), 203-225. 
Weisman, E. M., Flores, S. Y., \& Valenciana, C. (2007). Building bilingual-bicultural learning communities: Experiences of Latino teacher candidates. Journal of Hispanic Higher Education, 6(3), 191-208. Retrieved from https://doi.org/ $10.1177 / 1538192707302284$

Wertsch, J. V., Del Río, P., \& Alvarez, A. (Eds.). (1995). Sociocultural studies of mind. New York, NY: Cambridge University Press. Retrieved from https://books. google.com/books?hl=en\&lr=\&id=r5-VtL7zl8IC\&oi=fnd\&pg=PR7\&dq= Sociocultural+studies+of+mind\&ots=uRshwqptWN\&sig=r6A5iYvk1PvV0dmo_ $\mathrm{kZUdo} 9 \mathrm{fbCM} \# \mathrm{v}=$ onepage $\& \mathrm{q} \& \mathrm{f}=$ false

Wiemelt, J., \& Welton, A. (2015). Challenging the dominant narrative: Critical bilingual leadership (liderazgo) for emergent bilingual Latin@ students. International Journal of Multicultural Education, 17(1), 82-101.

Wiley, T. G., \& Lukes, M. (2014). English-only and standard English ideologies in the U.S. TESOL Quarterly, 30(3), 511-535. Retrieved from https://doi.org/ $10.2307 / 3587696$

Wong-Fillmore, L. (1991). When learning a second language means losing the first. Early Childhood Research Quarterly, 63, 323-346. Retrieved from https://doi.org/10.1016/S0885-2006(05)80059-6

Wong-Fillmore, L., \& Snow, C. E. (2000). What teachers need to know about language. Washington, DC. Retrieved from https://doi.org/http://dx.doi.org/10.1016/ j.system.2004.02.006

Yosso, T. J. (2005). Whose culture has capital? A critical race theory discussion of community cultural wealth. Race Ethnicity and Education, 8(1), 69-91. Retrieved from https://doi.org/10.1080/1361332052000341006

Yosso, T. J. (2006). Critical race counterstories along the Chicana/Chicano educational pipeline. New York, NY: Routledge Taylor \& Francis.

Yosso, T. J., Smith, W., Ceja, M., \& Solórzano, D. (2009). Critical racetheory, racial microaggressions, and campus racial climate for Latina/o undergraduates. Harvard Educational Review, 79(4), 659-691. Retrieved from https://doi.org/ 10.17763/haer.79.4.m6867014157m7071

Yosso, T. J., \& Solórzano, D. G. (2006). Leaks in the Chicana and Chicano educational pipeline (Latino Policy \& Issues Brief No. 13). Retrieved from http://www.chicano.ucla.edu/files/LPIB_13March2006.pdf Google Scholar 
Yturriago, J. K., \& Gil-Garcia, A. (2010, May 2). Preparing bilingual teacher candidates: A linguistic conundrum in a changing political landscape. Paper presented at the annual meeting of the American Educational Research Association, Denver, Colorado.

Zirkel, S. (2002). Is there a place for me? Role models and academic identity among White students and students of color. Teachers College Record, 104(2), 357-376. Retrieved from https://doi.org/10.1111/1467-9620.00166 
Appendix A: Informed Consent 


\section{Informed Consent}

You are invited to participate in a research study conducted by a research team from the Graduate School of Education (GSE) at Portland State University (PSU). The goal of the study is to learn about the perceptions and development of bilingual teachers when they were considered English Learners in p-12 public schools, how they describe being a bilingual teacher of bilingual students, and how they make sense of those experiences. The secondary goal of the study is to share with the educational community in the hopes of creating more opportunities for bilingual students and teachers. You were selected as a possible participant in this study because you are a graduate of the BTP program, are currently teaching bilingual students, and were considered an "English Learner" when you were in school.

Should you decide to participate you will be asked to participate in three interviews, one potential classroom observations, and share school assignments or lesson plans if you choose. The interviews will be 60-90 minutes long. Participants can expect to devote a total of 4-6 hours in this study. With your permission, artifacts from your classes may also be used (such as pictures of projects, lesson plans, videos, and written assignments). The interviews will be audio-taped and/or video recorded with your permission, and only members of the PSU research team will have access to the recordings. The interviews can be conducted at your school site, at Portland State University, or another location at your suggestion. There are a few potential risks of participating in this study. You may feel uncomfortable when asked about your personal beliefs or perceptions about equity and social justice in education. Please note, however, 
you may refuse to answer any questions or stop participating in the interview at any

time. Another potential risk is breach of confidentiality. It is possible that despite the safeguards built into maintaining confidentiality, a breach of confidentiality is a potential risk for all subjects. To reduce this risk, we will use the following procedures: identify participants only by a coded identifier, maintains records in a locked file cabinet at the Graduate School of Education which is a secured facility as well as a stored on a securePSU Research server, and require that all research team members pledge to respect subjects' confidentiality. Risk of breach of confidentiality is minimal.

You may not receive any direct benefit from taking part in this study, but the study may help to increase knowledge which may help others in the future by learning from your experiences and perspective about your schooling, as well as your teacher education program. The PSU research team hopes to gain an enhanced understanding on how pre-service and in-service teachers develop an understanding and subsequently enact teaching for social justice, teaching ESOL, and how their identity develops in relation to these topics. The findings from this study could help the Bilingual Teacher Pathway Program faculty to enhance the educational experiences of and find best practices in preparing bilingual teachers for today's classrooms.

We will use many safeguards to protect your confidentiality. The research team members have been trained in protecting your confidentiality. Additionally, the researchers are mandatory reporters of child/elder abuse. If information is revealed to suspect abuse, the researcher must report it and the participant's confidentiality will not be preserved. 
ID numbers will be assigned to each person and the ID numbers will be used for each interview you complete. Your name will not appear on any interview forms. The data we keep in our computers will be password-protected and will also only identify you by a unique ID number. To ensure confidentiality, all information will be kept in a locked file, and will be available only to the research staff. Neither your name nor your identity will be used for publication or publicity purposes.

Your participation is completely voluntary. If you choose to participate and decide at some point that you do not feel comfortable with the interviews, focus groups, observations or the use of your artifacts, you may withdraw from the study at any time without affecting your status at Portland State University, your status in the Bilingual Teacher Pathway Program, your course grade (if you are a current BTP teacher candidate), or your relationship with the faculty researchers.

If you have concerns about your rights as a research subject, please contact the PSU Office of Research Integrity, 1600 SW 4th Ave., Market Center Building, St. 620, Portland, OR 97201, (503) 725-2227 or 1 (877) 480-4400. If you have questions about the study itself or your participation in this study, contact any one of the PSU research team members listed below:
Dr. Esperanza De La Vega
503-725-9902 delavega@pdx.edu
Carrie Larson, Graduate Assistant 503-725-9901 csl3@pdx.edu 
Your signature indicates that you have read and understand the above information and agree to take part in this study. Please understand that you may withdraw your consent at any time without penalty, and that, by signing, you are not waiving any legal claims, rights or remedies. The researcher will provide you with a copy of this form for your own records.

Signature

Date 
Appendix B: Recruitment Materials 


\section{Recruitment Materials}

\section{Email Recruitment Script for Bilingual Teacher Pathway Graduates}

This document will be emailed to graduates from the Bilingual Teacher Pathway program who are currently teaching in Oregon or the greater Pacific Northwest in the field of Bilingual/ESOL/Dual-Language education.

Hello ----,

You are getting this email because you are a former Bilingual Teacher Pathway student and current bilingual teacher of bilingual students. I am writing to ask if you would be willing to be a participant in a research study about bilingual and multilingual education. It is the researchers' hope that your experience thus far has given you the opportunity to reflect on bilingual and multilingual education, as both a teacher and a learner, and may have some insights that could inform future educators.

The goals of the study are to capture the perceptions and narratives of bilingual/multilingual teachers about their teaching and learning experiences as bilingual/multilingual students and bilingual/multilingual teachers. In addition, the researchers would like to understand what it means to teach for equity and social justice while enrolled in the Bilingual Teacher Pathway program, upon completion and graduation, and during the first few years of teaching in schools.

If you are interested in participating in this research study, you will be asked to take part in three 90-minute interviews about a week apart, to talk about your experiences in schools as teachers and learners. The researchers would also like to corroborate the 
experiences that may unfold in interviews with artifacts from your current teaching and learning setting as well as previous coursework and program surveys. If interested, we may also visit your classroom.

Please note that as a participant, you can withdraw from the study at any time and do not need to provide a reason. Participation is completely voluntary and there are no repercussions to withdrawing from the study or not volunteering to be a participant.

We would be most grateful if you would consider this request and let us know if you would be willing to be a participant. Please sign and return the attached consent form at your convenience (scanned, in person, or in the mail). If you have any questions, please contact Dr. De La Vega, Carrie Larson, or the PSU Office of Research Integrity. Sincerely,
Dr. De La Vega
delavega@pdx.edu
503-725-9902
Carrie Larson
carrie.larson@pdx.edu
$971-241-8274$

PSU Institutional Review Board

Office of Research Integrity

1600 SW 4th Ave., Market Center Building, Ste. 620

Portland, OR 97201

(503) $725-2227$ or 1 (877) 480-4400 
Appendix C: Demographic Survey 


\section{Demographic Survey}

Name:

What languages do you speak?

Please briefly describe the schools you attended (change/add as needed):

For how long?
Current teaching position:

\begin{tabular}{|l|l|l|l|l|}
\hline $\begin{array}{c}\text { Name of School: } \\
\text { (ex. Aztec } \\
\text { Elementary } \\
\text { School) }\end{array}$ & $\begin{array}{c}\text { Location } \\
\text { (ex. El Cajon, CA) }\end{array}$ & $\begin{array}{c}\text { Grades } \\
\text { (ex. K-4) }\end{array}$ & $\begin{array}{c}\text { Language of Instruction } \\
\text { (ex. English Only) }\end{array}$ & $\begin{array}{c}\text { Memorable } \\
\text { People of } \\
\text { Experiences } \\
\text { (ex. Ms. } \\
\text { Robby-math! } \\
\text { rows } \downarrow \text { ) }\end{array}$ \\
\hline School 1 & & & & \\
\hline School 2 & & & & \\
\hline School 3 & & & & \\
\hline School 4 & & & & \\
\hline School 5 & & & & \\
\hline School 6 & & & & \\
\hline
\end{tabular}

Please describe your family: (please add/change anything you need to make it fit your family)

\begin{tabular}{|l|l|l|l|}
\hline Name & Relationship & Education & Languages \\
\hline & & & \\
\hline & & & \\
\hline & & & \\
\hline & & & \\
\hline & & & \\
\hline
\end{tabular}

Note any strong memories from when you were a "English Language Learner":

Note any moments or accomplishments you remember feeling proud of: 
Appendix D: Semi-Structured Interview 1 


\section{Semi-Structured Interview 1}

\section{Focused Life History}

This first interview seeks to explore the salient experiences of bilingual teachers as students, particularly their experiences as former "English Language Learners."

Script for the beginning of the interview:

Thank you so much for volunteering to be a participant in this research study! As you know, I'm interested in bilingual students and bilingual teachers' experiences and perspectives. I would love to learn as much today about your experiences in schools growing up. Next week we will talk about your current experience as a bilingual teacher. Then the week after that I will ask about how you make sense of all of it! The questions are flexible, and really I want you to feel comfortable to talk about the things that are most meaningful to you. Each interview will be 90 minutes. I want to respect your time and also give you enough time to give me a meaningful description of your experiences. When we are done, you can always email me or call me if you remember something you want to add. I will record the interviews so I can read them later. Later on, when I'm writing up the stories, I will check in with you to make sure I've got it right. You can end at any time — or withdraw for any reason and there will be no consequence for you. Do you have any questions for me before we start?

1. Tell me about your schools growing up.

a. Locations? Populations?

2. How would you describe your schooling experience? (elementary, middle, high school) 


\section{a. Language?}

3. Tell me about your experience as an "English Language Learner"?

a. What do you remember feeling about that?

4. Research talks a lot about the barriers in school systems that hold bilingual learners back. Do you feel like you were affected by things like racism or segregation? (nativism, English dominance, teachers that didn't know about teaching ESOL)

5. Take me back to (from demographic survey). What would I see, hear, etc.?

6. Tell me about any teachers (good or bad) that stand out to you.

- Tell me more...

- Explain....

- Clarify...

- Is there anything else you'd like to add?

Script for the ending of the interview:

Here's the ground we covered today . Is there anything else you would like to add?

Next week we will talk about your current life as a bilingual teacher. I'm excited to see you teaching in your classroom and hear all about your current practice! Please email or call me if you remember something you would like me to add to today's transcript. Thank you so much for your time! 
Appendix E: Semi-Structured Interview 2 


\section{Semi-Structured Interview 2}

\section{Focus on Concrete Participant Experience}

This second interview asks participants to describe, in detail, their current experiences as bilingual teachers of bilingual students.

Script for the beginning of the interview:

It is so good to see you again! Today we are going to talk about your life as a bilingual teacher of bilingual students. I would love to know all the details!

1. Tell me about a typical day at school, from start to finish.

2. Tell me about a great moment at school

3. Tell me about a bad day.

a. You probably had a lot on your mind, what were you considering?

4. What are some things that have surprised you about teaching bilingual learners?

5. If you could have a direct line to the top of the decision makers, what would you tell them? Change? Advice on how to make education amazing for bilingual students? How to get more bilingual teachers? (maybe one or two of these)

Script for the ending of the interview:

I'm pleased to learn and Is there anything else you would like to add?

Next week we will talk about how you make sense of your experiences as a student and as a teacher. It was a pleasure to see you teaching in your classroom today! Please email or call me if you remember something you would like me to add to today's transcript. Thank you so much for your time 
Appendix F: Semi-Structured Interview 3 


\section{Semi-Structured Interview 3}

\section{Reflection on the Meaning}

The third interview asks participants to make meaning of their experiences, in reference to the first and second interviews. Script for the beginning of the interview:

It is so good to see you again! Today we are going to tie together your experiences as a bilingual student and your current life as a bilingual teacher of bilingual students. I'm really interested in how you make sense of it all.

1. Regarding your experience $X$,

2. How do you perceive the impact of ? (from first / second interviews)

a. What is your attitude toward that impact?

3. How does your experience as a second language learner influence your desire to teach and/or your goals for teaching?

a. people who impacted your decision

b. funds of knowledge that you bring

c. critical incidents or events in your life that led you to teaching

4. What barriers did you overcome to become a teacher? What bridges did you find or build in order to pursue teaching?

5. What were the challenges for you as a new Bilingual/ESOL teacher?

6. How does your experience as a second language learner influence your desire to teach and/or your goals for teaching?

a. people who impacted your decision

b. funds of knowledge that you bring 
c. critical incidents or events in your life that led you to teaching

7. What has been the greatest influence to your understanding of teaching for social justice? How do you think teaching for social justice actually happens in the school setting?

8. How are students' culture and/or language seen as assets or deficits in your school setting? How does this reflect back and align (or not) with your experiences as a student in K-12?

9. Tell me about the best part/about a success story for one student in your beginning year(s) of teaching?

10. What advice would you give to a new bilingual teacher?

11. Is there anything I missed that you would like to tell me about?

Script for the ending of the interview:

I feel so privileged to have spent the last few weeks talking with you about your experiences as student and now as a professional. Is there anything else you would like to add?

Please email or call me if you remember something you would like me to add to today's transcript. I will be in communication with you as I read through the transcripts and consider the themes and ways to think about your experiences to make sure that I represent them in the way that you intended. Is email or by phone better? (or text) I have a small token of appreciation for you, it doesn't represent what your time is worth, but I hope it at least shows my appreciation.

Thank you so much for your time! 